\title{
Contribución al conocimiento florístico del Chaco Oriental, SUdESTE dE LA PROVINCIA DE Formosa, Argentina
}

\author{
SILVINA A. CONTRERAS ${ }^{1,2}$, FELIX I. CONTRERAS ${ }^{1}$, ALICIA I. LUTZ ${ }^{1,2}$ y \\ ALEJANDRO F. ZUCOL ${ }^{3}$
}

\begin{abstract}
Resumen: El sureste de la provincia de Formosa integra parte de la Región del Chaco Oriental, caracterizada por una gran heterogeneidad ambiental, donde se mezclan componentes leñosos y pastizales. Esta característica compleja está vinculada con las formas del paisaje, la cual, es el resultado de la dinámica aluvional durante el Pleistoceno-Holoceno y de la migración de los cinturones fluviales de los principales ríos. En esta contribución se analiza la composición florística de las comunidades dentro del Departamento de Laishi (Formosa), con la finalidad de establecer la composición y variabilidad de sus elementos. A través datos de campo, de herbario y bibliográficos se encontraron 625 especies, donde predominan las familias de Asteraceae, Poaceae y Fabaceae. Se establecieron las siguientes unidades de vegetación: selvas, bosques, palmares, arbustales, pastizales mesófilos, pastizales hidrófilos y esteros/lagunas, donde predominaron las selvas y pastizales hidrófilos. Sobre la información obtenida de imágenes satelitales, se analizó la distribución espacial de la vegetación según la altura topográfica de preferencia, resaltando la presencia de las comunidades arbóreas. Las especies chaqueñas fueron encontradas conviviendo en muchos casos con componentes selváticos amazónicos (Yungas y Paranaense).
\end{abstract}

Palabras clave: Análisis florístico, unidades de vegetación, Región Chaqueña, Villa Escolar.

Summary: Contribution to the floristic knowledge of the Eastern Chaco, Formosa province, Argentina. The southeastern of Formosa province integrates part of the Oriental Chaco, characterized by a great environmental heterogeneity, where woody components and grassland are mixed. This complex characteristic is linked to the forms of the landscape, which it is the result of alluvial dynamics during the Pleistocene-Holocene and of the migration of fluvial belts of principal rivers. In this contribution, the floristic composition of different communities of Laishi (Formosa) is analyzed, in order to establish the composition and variability of its elements. For this, species collected near the town, herbarium and bibliography data showed the presence of 625 species, where Asteraceae, Poaceae and Fabaceae families were predominated. There are different vegetation units: forests, palms, shrubs, mesophyte and hydrophyte grasslands, and marshes, where forests and hydrophyte grasslands are dominated. Spatial distribution of the vegetation was analyzed according to the topographic height preference, especially the distribution of tree communities. This information was obtained from satellite images. In addition, Amazon forest components (Yungas and Paranaense) among Chaquenian species were found.

Key words: Floristic analysis, vegetation units, Chaco Region, Villa Escolar.

1 Centro de Ecología Aplicada del Litoral- Consejo Nacional de Investigaciones Científicas y Técnicas- Universidad Nacional del Nordeste (CECOAL-CONICET-UNNE), Ruta 5, km 2.5. W3400. Corrientes, Argentina; sailcontreras11@ gmail.com (autor corresponsal).

2 Cátedra de Paleontología - Facultad de Ciencias Exactas, Naturales y Agrimensura (FaCENA)-Universidad Nacional del Nordeste (UNNE). C.C. 128, 3400, Corrientes, Argentina.

3 Centro de Investigaciones Científicas y Transferencia de Tecnología a la Producción - Consejo Nacional de Investigaciones Científicas y Técnicas (CICyTTP-CONICET), Dr. Materi y España SN, E3105BWA Diamante, Entre Ríos, Argentina. 


\section{INTRODUCCIÓN}

El Chaco Oriental es una extensa región que, en Argentina, ocupa aproximadamente la mitad este de las provincias de Chaco y Formosa, parte del norte de Santa Fe (Ginzburg \& Adámoli, 2006) y el noroeste de Corrientes (Tortorelli, 2009). Desde un punto de vista geomorfológico, esta región se caracteriza por ser un bloque hundido, constituido por las regiones distales de los abanicos aluviales de los grandes ríos (Pilcomayo, Bermejo y Juramento) que la atraviesan (Iriondo, 1992), y rellenado con sus sedimentos (Ginzburg \& Adámoli, 2006). Además, presenta áreas pantanosas atravesadas por las antiguas fajas fluviales de dichos ríos (Iriondo, 1992). La baja pendiente y la torrencialidad estacional de los ríos favorecen los procesos fluviomorfológicos, generando una topografía local irregular, con albardones elevados con respecto a los alrededores anegables (Ginzburg \& Adámoli, 2006).

Como consecuencia de la gran heterogeneidad ambiental, la vegetación del Chaco Oriental es compleja (Biani et al., 2006). La estrecha vinculación entre las distintas formas del paisaje y la vegetación que se desarrolla en ellas (Ginzburg \& Adámoli, 2006), ha sido interpretada como la respuesta de la vegetación a las precipitaciones, la escasa energía de drenaje, el hidromorfismo de los suelos, los déficits hídricos variables (Biani et al., 2006), así como al tipo y la altura relativa del sustrato (Iriondo, 1992). Se han reconocido 24 unidades de vegetación presentes en esta región, que varían desde distintas comunidades arbóreas (Monte Fuerte, Algarrobales, Bosque de albardón o Selvas en Galería, Bosque Transicional Austro-Brasileño, Bosques Riparios de Inundación y palmares), comunidades herbáceo-arbustivas (Arbustales, Pastizales Altos, Pajonales/Bañados/ Cañadas, Esteros y vegetación de lagunas); como así también comunidades mixtas como las sabanas (Morello \& Adamoli, 1967, 1974; Prado, 1993; Maturo et al., 2005, Ginzburg \& Adámoli, 2006, Peña Chocarro et al., 2006; Molina \& Rúgolo, 2006). En función de su composición florística, el Chaco Oriental ha sido caracterizado como transicional entre el Dominio Chaqueño y el Amazónico (Cabrera, 1971; Prado, 1993). Se ha sugerido que el patrón de la vegetación Chaqueña, en particular la vegetación del Chaco Central-
Oriental donde se mezclan los componentes leñosos con las comunidades de gramíneas (Serra, 2002), sería el resultado de la dinámica aluvional durante el Pleistoceno-Holoceno de la llanura, y de la migración intensiva de los cinturones fluviales de los ríos principales (Iriondo, 1995; Morelo \& Matteucci, 1999). Sin embargo, la información paleobotánica disponible acerca de la vegetación de la región que pudo haber acompañado este proceso es aún escasa.

En este sentido, el sudeste de la Provincia de Formosa constituye una interesante región para estudiar la evolución de la vegetación, ya que, en recientes campañas de exploración en sedimentos cuaternarios de la provincia, se hallaron impresiones de plantas (hojas, frutos, tallos y microrestos), sobre las márgenes del río Bermejo en la localidad de Villa Escolar. A partir del hallazgo de impresiones de Equisetites afines a la especie actual E. giganteum L., así como de algunas gramíneas megatérmicas, se sugirió que las condiciones paleoambientales y climáticas en el pasado reciente, habrían sido similares a las condiciones actuales en el Chaco Húmedo (Contreras, 2010; Contreras et al., 2014).

El análisis comparativo de fósiles en secuencias sedimentarias con la vegetación actual ha contribuido a interpretar los cambios evolutivos en la vegetación (Salas \& Cendrero, 1988; Ruiz Zapata et al., 1996). Este enfoque podría ser de utilidad en el estudio de la evolución de la vegetación del Chaco Oriental. Al respecto, la única información disponible sobre la vegetación del sudeste de Formosa es un estudio realizado en la Reserva El Bagual (Di Giácomo 2005; Maturo et al. 2005). Sin embargo, dado que la composición florística y las comunidades vegetales presentes en el Chaco Oriental pueden variar en un espacio de pocos metros (Maturo et al., 2005), es preciso contar con información acerca de las especies y de las unidades de vegetación presentes en el área donde se hallaron las impresiones cuaternarias.

En este marco, el objetivo de este trabajo es realizar un análisis de la composición florística y distinguir las unidades de vegetación presentes al sudeste de la provincia de Formosa; en un área dentro del Departamento de Laishi. Esto permitirá a futuro establecer un marco de comparación entre la vegetación actual con los restos cuaternarios hallados en la localidad de Villa Escolar y alrededores. 


\section{Materiales y Métodos}

\section{Área de estudio}

El estudio se llevó a cabo relevando un área de $50 \mathrm{~km}^{2}$ alrededor de la Localidad de Villa Escolar $\left(26^{\circ}\right.$ $36^{\prime}$ 'S y $58^{\circ} 40^{\prime}$ O), correspondientes al Departamento de Laishi, Formosa (Fig. 1). Este Departamento está incluido en el la ecoregión del Chaco Húmedo (Morrone, 2014), también conocida como Chaco de esteros, cañadas y selvas de ribera propuesta por Morello \& Adamoli (1974).

Una de las principales características de la región Chaqueña es su homogeneidad geológica (Placci \& Holz, 2004). Esta región es considerada una vasta cuenca sedimentaria cubierta en su mayoría por sedimentos de edad cuaternaria, terminando hacia el este en la región de las efusiones basálticas de la Mesopotamia (Morello \& Adamoli, 1974). Los materiales parentales del suelo corresponden a limos, arcillas y arenas (Molina \& Rúgolo, 2006), de origen eólico debido a cambios climáticos ocurridos desde el Pleistoceno (Gorleri, 2005), fluvial y lacustre de granulometría variada, con predominio de las fracciones finas (Molina \& Rúgolo, 2006), o incluso sedimentos de ingresiones marinas devónicas (Prado, 1993). Estos sedimentos, son del mismo tipo que los que afloran en la llanura Pampeana, fundamentalmente loess y limos loessoides. (Morello \& Adamoli, 1974). Esta región, como otras del país, tiene un tiempo de formación breve, con un crecimiento derivado de la continua depositación superficial de nuevos aportes de materiales transportados en su mayoría por el viento, con modificaciones fluviales (Molina \& Rúgolo, 2006).

El clima es tropical húmedo y está caracterizado por un intercambio permanente de masas de aire tropical y austral(Iriondo, 1992). Las precipitaciones oscilan los $1200 \mathrm{~mm}$ anuales (Bucher, 1980), y son del tipo frontal y convectivas, propias de la latitud y de la abundancia de fuentes evaporantes (Serra, 2002). La distribución estacional de las precipitaciones presenta un régimen unimodal con lluvias durante la estación cálida, con una tendencia a una doble presencia de máximas: una próxima a finalizar la primavera y otra al finalizar el verano e inicio del otoño, con un mínimo durante la estación invernal (Gorleri, 2005). El 80\% de la lluvia está concentrada en verano, lo que refleja una estación seca marcada, que dura aproximadamente dos meses (Bucher, 1980).

\section{Análisis florístico}

La información acerca de las especies presentes dentro del Departamento de Laishi, se obtuvo de la Base Documentae Florae Australis (http://www. darwin.edu.ar/iris), de la bibliografía (Di Giácomo, 2005; Maturo et al., 2005; Molina \& Rúgolo, 2006; Zuloaga et al., 2012) y de colecciones botánicas.

Las colecciones se realizaron en siete sitios cercanos a la localidad de Villa Escolar, sobre la Ruta Provincial $N^{\circ} 9$ y caminos aledaños, entre El Colorado y Mansilla próximos a las localidades fosilíferas (Fig.1, 2). Fueron seleccionados, a partir del análisis de imágenes satelitales y de la observación a campo en trabajos previos. El material herborizado se encuentra depositado en el herbario del Instituto de Botánica del Nordeste (CTES).

Se analizó la composición florística estimando el número de familias, géneros y especies presentes en el Departamento de Laishi. Posteriormente, las especies fueron clasificadas de acuerdo con su hábito de crecimiento (árbol, arbusto, árbol/arbusto, subarbusto, herbácea, herbácea/ subarbusto, enredadera, palmera, epífita, parásita, palustre y acuática) y a las unidades de vegetación donde fueron encontradas: Bosque (Monte fuerte, Bosques bajos), Selvas (Bosques de albardón, Bosques Transicionales y Bosques riparios de inundación), Palmares, Arbustales, Pastizales mesófilos (campos altos), Pastizales hidrófilos (pajonales, Bañados, cañadas), Esteros/ambientes acuáticos (esteros, lagunas). A su vez, se detalla las unidades de vegetación presentes en el límite sur del Departamento, teniendo en cuenta las especies recolectadas en el campo. Dicha área es atravesada por los ríos Desaguadero Bonett y Desaguadero Bellaco, así como por los canales Mansilla y Sáenz y por el arroyo El Alazán, los que son tributarios del río Bermejo.

\section{Imágenes satelitales}

Mediante el uso del software QGIS 2.8.2 se realizó una Composición de Bandas RGB 4-5-3 de las imágenes del satélite LANDSAT 5 TM Path/Row 226/078 y 226/079 respectivamente, ambas con fecha 16/01/2011. Posteriormente sobre ellas, se hizo un Análisis de Componentes Principales para discriminar la distribución de las comunidades arbóreas sobre el Departamento Laishi. 


\section{Análisis fitogeográfico}

A través de la información bibliográfica, se reconocieron las especies que son de linaje chaqueño o amazónico (i.e. que son típicas y/o abundantes en las Provincias Fitogeográficas del Bosque Paranaense y Provincia de las Yungas, sensu Morrone, 2001, 2014) y de amplia distribución continental. A partir de esta información, se calculó la cantidad de especies de linaje no chaqueño que actualmente habitan en la región.

\section{Resultados}

\section{Composición florística}

Se encontró un total de 625 especies (ver Apéndice en sitio web de la revista), distribuidas en 5 familias de Pteridophyta (2\%) y 89 de Angiospermae, incluyendo 18 familias de
Monocotyledoneae (23\%) y 71 de Dicotyledoneae (75\%). La mayoría de los especímenes pertenecen a las familias Asteraceae (83), Poaceae (81), Fabaceae (56), Solanaceae (33), Malvaceae (23) y Cyperaceae (20), las cuales concentran el $47 \%$ del total de las especies halladas. El 53\% restante de las familias posee menos de 20 especies, de las cuales, el $22 \%$ está representado por una sola especie, como ser Achatocarpaceae, Annonaceae, Aristolochiaceae, Asparagaceae, Begoniaceae, Combretaceae, Dioscoreaceae, Hydrocharitaceae, Lentibulariaceae, Loasaceae, Melastomataceae, Myrsinaceae, Nymphaeaceae, Opiliaceae, Plantaginaceae, Rhamnaceae, Salviniaceae, Selaginellaceae, Simaroubaceae, Ulmaceae y Violaceae.

Se registró un total de 361 géneros, de los cuales, 273 son dicotiledóneas, 79 monocotiledóneas y los restantes, helechos. Los géneros que presentaron

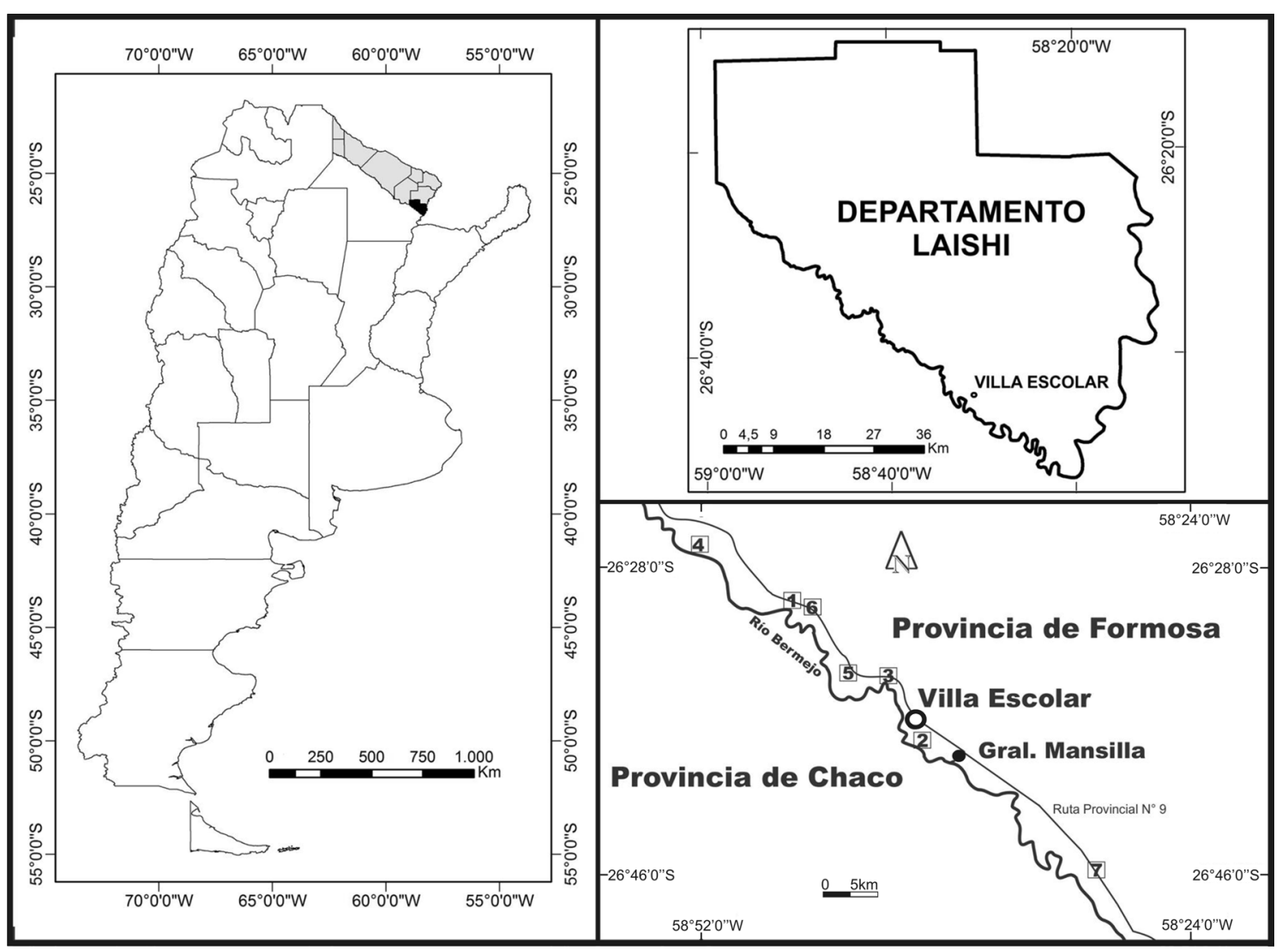

Fig. 1. Ubicación del área de estudio. Con detalles de los sitios de muestreo en campo, cercanos a Villa Escolar, Departamento de Laishi, Formosa. 


\section{S. A. Contreras et al. - Contribución al conocimiento florístico del SE de Formosa}

mayor número de especies de la región fueron Solanum L. (16), Baccharis L. (15), Eupatorium L. (14) y Paspalum L. (13).

\section{Hábito de crecimiento}

Entre las distintas especies registradas predominaron las herbáceas (49\%), seguidas de los arbustos $(12 \%)$, trepadoras $(10 \%)$ y árboles $(9 \%)$. En menor número se hallaron subarbustos $(7 \%)$, epífitas $(2,7 \%)$, palustres $(3 \%)$, acuáticas $(2 \%)$, parásitas $(0,48 \%)$ y palmeras $(0,32 \%)$.

\section{Unidades vegetales}

Sobre un área de $50 \mathrm{~km}^{2}$ alrededor de Villa Escolar se encontraron selvas, bosques, palmares, pastizales hidrófilos, pastizales mesófilos, arbustales y esteros/ambientes acuáticos (Tabla 1). Alrededor de Villa Escolar predominó la vegetación de selva, seguidas por pastizales hidrófilos y esteros/ ambientes acuáticos. Los palmares también fueron comunes, aunque sólo se encontraban en pequeños grupos.

Selvas: Es la unidad con mayor número de especies (208), de las cuales 189 son exclusivas de esta unidad. Todas ellas están distribuidas en 58 familias y 150 géneros. Las familias más numerosas fueron Poaceae (20), Fabaceae (17), Solanaceae (16), Asteraceae (14) y Apocynaceae (11) y los géneros más comunes Solanum (7), Cestrum L. (4), Pavonia Cav. (4) y Setaria P Beauv. (4). Se encontraron 43 especies arbóreas, pertenecientes principalmente a las familias Fabaceae (12), Moraceae (3) y Sapotaceae (3). También un diverso estrato herbáceo (54 especies), representados por Poaceae (20), Asteraceae (5), Euphorbiaceae (3) y Pteridaceae (3); y numerosas especies de enredaderas (37), siendo las más representadas Apocynaceae (8), Sapindacaeae (6), Bignonaceae (4), Convolvulaceae (3) y Passifloraceae (3).

Pastizales: Segunda unidad más rica en especies (202). Los pastizales mesófilos son los que presentaron una mayor riqueza específica, con 132 especies (116 exclusivas) pertenecientes a 91 géneros de 25 familias. Predominan las especies herbáceas (92) y subarbustos (16). Las familias con mayor número de representantes son: Asteraceae (45), Poaceae (21), Fabaceae (19); mientras que Baccharis (11), Eupatorium (6), Desmodium Desv. (4) y Vernonia Schreb. (4) son los géneros con mayor número de especies. Por otra parte, los pastizales hidrófilos presentaron un total de 73 especies (66 exclusivas) pertenecientes a 52 géneros de 24 familias. Predominan las especies herbáceas (55) y palustres (9). Las familias con mayor número de especies son Poaceae (13), Cyperaceae (10), Asteraceae (8) y Fabaceae (8); y los géneros más numerosos son Cyperus (6), Paspalum (4) y Ludwigia (3).

Bosque: Presentaron un total de 69 especies (53 exclusivas), pertenecientes a 50 géneros de 31 familias. Predominaron las especies arbóreas (13) y arbustivas (15). Las familias más ricas en especies fueron Fabaceae (9) y Bromeliaceae (6), y los géneros más comunes fueron Tillandsia L. (4), Acacia Mill. (3), Baccharis (3) y Prosopis L. (3). Entre las especies arbóreas predominaron las Fabaceae (5), Anacardiaceae (2) y Cannabeaceae (2); mientras que entre los arbustos predominaron las Solanaceae (4), Asteraceae (3) y Erythroxylaceae (2).

Esteros/Ambientes acuáticos: Presentaron un total de 48 especies (39 exclusivas), de 38 géneros pertenecientes a 24 familias. Predominaron las especies herbáceas (21), las acuáticas (9) y las palustres (9).

Las especies de Cyperaceae (9), Fabaceae (5) y Pontederiaceae (4) fueron las más abundantes. Los géneros más comunes fueron Cyperus L. (9) y Polygonum L. (3). Entre las especies herbáceas predominaron las Poaceae (3) y las Polygonaceae (3); entre las palustres las Cyperaceae (7), mientras que entre las acuáticas, abundaron las Pontederiaceae (4).

Arbustal: Se recabaron 42 especies (38 exclusivas) de 34 géneros pertenecientes a 18 familias, siendo las especies de Cactaceae (10) y el género Opuntia Mill. (4) los mejores representados. Predominan las especies de herbáceas (20), subarbustos (9) y arbustos (8). Las especies de Poaceae (6) son las más frecuentes entre las herbáceas, las Cactaceae (6) entre los arbustales y las Asteraceae (3), entre los arbustos.

Palmar: Sólo 12 especies (6 exclusivas), fueron encontradas (y citadas), en dicha unidad dentro de los límites estudiados. Predominaron las especies herbáceas (8). Con 9 familias y con mayor número de especies en Fabaceae (2) y Verbenaceae (2). El género con más especies es Glandularia J. F. Gmel. (2). 


\section{Análisis de las imágenes y la vegetación}

El análisis de las imágenes satelitales (Fig. 2), reveló que en el Departamento de Laishi, existe un predominio de zonas bajas, cubiertas por pastizales hidrófilos, esteros y lagunas, observando lagunas en medialuna (cauces abandonados) por migración de cauces de los Ríos Paraguay y Bermejo. La vegetación arbórea se establece en las zonas topográficamente más altas, con orientación lineal en sentido NO-SE, paralelas entre sí, acompañando los cursos de agua. En el límite Este del Departamento se extiende una franja mucho más ancha, con rumbo NE-SO, que acompaña al río Paraguay. También se observan manchones aislados de vegetación arbórea entre los sectores bajos, encontrando isletas de bosques o palmares.

Sobre el límite sur del Departamento entre la Localidad del Colorado y Mansilla, la vegetación arbórea (Sitio 1, 3 y 4), es la que predomina junto a los pajonales (sitio 5 y 7 ) y esteros (sitio 2). Los palmares (sitio 6) son observados como parches entre las distintas unidades mencionadas y en muchos casos, bordeando a las selvas. Por otro lado, en los últimos años, esta zona presenta grandes extensiones agrícolas, especialmente las arroceras, con más de 1000 hectáreas, sobre Villa Escolar (Fig. 3).

El sitio 1 está caracterizado por la presencia de Acacia aroma Hook \& Arn., Celtis L. spp. y Allophylus edulis (A. St.-Hil) Radlk ex Warm., entre otras especies arbóreas. En el estrato herbáceo predominan bromelias y distintas especies de cactáceas. El sitio 3, con abundante presencia de Gleditsia amorphoides (Griseb.) Taub., Allophylus edulis y Piper amalago L., acompañados de Prosopis alba Griseb., Tabernaemontana catharinensis A. DC., Zanthoxylum hyemale (L.) Sarg. y distintas especies de enredadera. En el estrato herbáceo se encontraron especies de gramíneas, ciperáceas, entre otras familias. El sitio 4 se asemeja al 3 por la presencia de Gleditsia amorphoides y Allophylus edulis, aunque la vegetación es mucho más rica en especies, encontrándose además Acanthosyris sp., Achatocarpus praecox Griseb, Astronium balansae Engl., Capparis tweediana (Eichler) Iltis \& Cornejo, Cordia americana (L.) Gottshling \& J.E. Mill., Eugenia uniflora L., Maclura tinctoria (L.) D. Don. ex Steud., Myrcianthes pungens O. Berg, Phyllostylon rhamnoides (J. Poiss) Taub.,
Randia armata (Sw.) DC. y Zanthoxylum hyemale. Además, presentó abundantes bromelias terrestres. En el sitio 6, Copernicia alba Morong ex Morong \& Britton es la especie más abundante acompañada de un estrato herbáceo en el que predominan distintas especies de gramíneas y ciperáceas y la presencia rara de árboles como Celtis spp. y Acacia aroma. Los restantes sitios mostraron una composición de especies similar donde fueron abundantes las especies higrófilas, en los sitios 5 y 7 predominan especies de gramíneas (pajonal) y en el sitio 2 las palustres-acuáticas.

\section{Aspectos fitogeográficos}

La mayoría de las especies encontradas en el área de estudio son netamente chaqueñas o de amplia distribución en Argentina o el continente, pero también se hallaron especies de linaje amazónico (presentes en la Provincia Fitogeográfica del Bosque Paranaense y/o en la Provincia de las Yungas) (Tabla 2) y especies introducidas.

Entre las especies chaqueñas predominan los árboles (Aspidosperma quebracho-blanco Schltdl., Schinopsis balansae Engl., Tabebuia nodosa (Griseb.) Griseb., Zizyphus mistol Griseb., Acacia spp., Prosopis spp.), los arbustos (Opuntia ssp.) y la palmera de caranday (Copernicia alba); de amplia distribución se pueden mencionar las especies Canna glauca L., Canna indica L. y Commelina platyphylla Klotsch ex Seub. Mientras que entre las especies de linaje amazónico, se encuentran especies Paranaenses como los árboles Holocalyx balansae, Ficus luschnathiana, la palmera Syagrus romanzoffiana, y las especies herbáceas Andropogon lateralis. Las especies de las yungas como los árboles Acanthosyris falcata, Agonandra excelsa, Geoffroea decorticans, Phyllostylon rhamnoides, Tabebuia aurea y entre las introducidas se destacan las herbáceas Solanum nigrum L. y Echinochloa colona (L.) Link.

La mayoría de las especies de linaje amazónico halladas en el Departamento Laishi (11\%) (Tabla 2), son principalmente de hábito arbóreo (36), seguidas de herbáceas (12), enredaderas (10), arbustos (6), arbóreo-arbustivo (7), subarbustos (2), epífitas (1) y palmeras (1). El $68 \%$ de las especies no chaqueñas fueron encontradas en la selva que es la unidad de vegetación que posee mayor número de especies. De las restantes especies no chaqueñas, $16 \%$ son de Bosque, $13 \%$ de pastizales mesófilos, 1,3\% de 


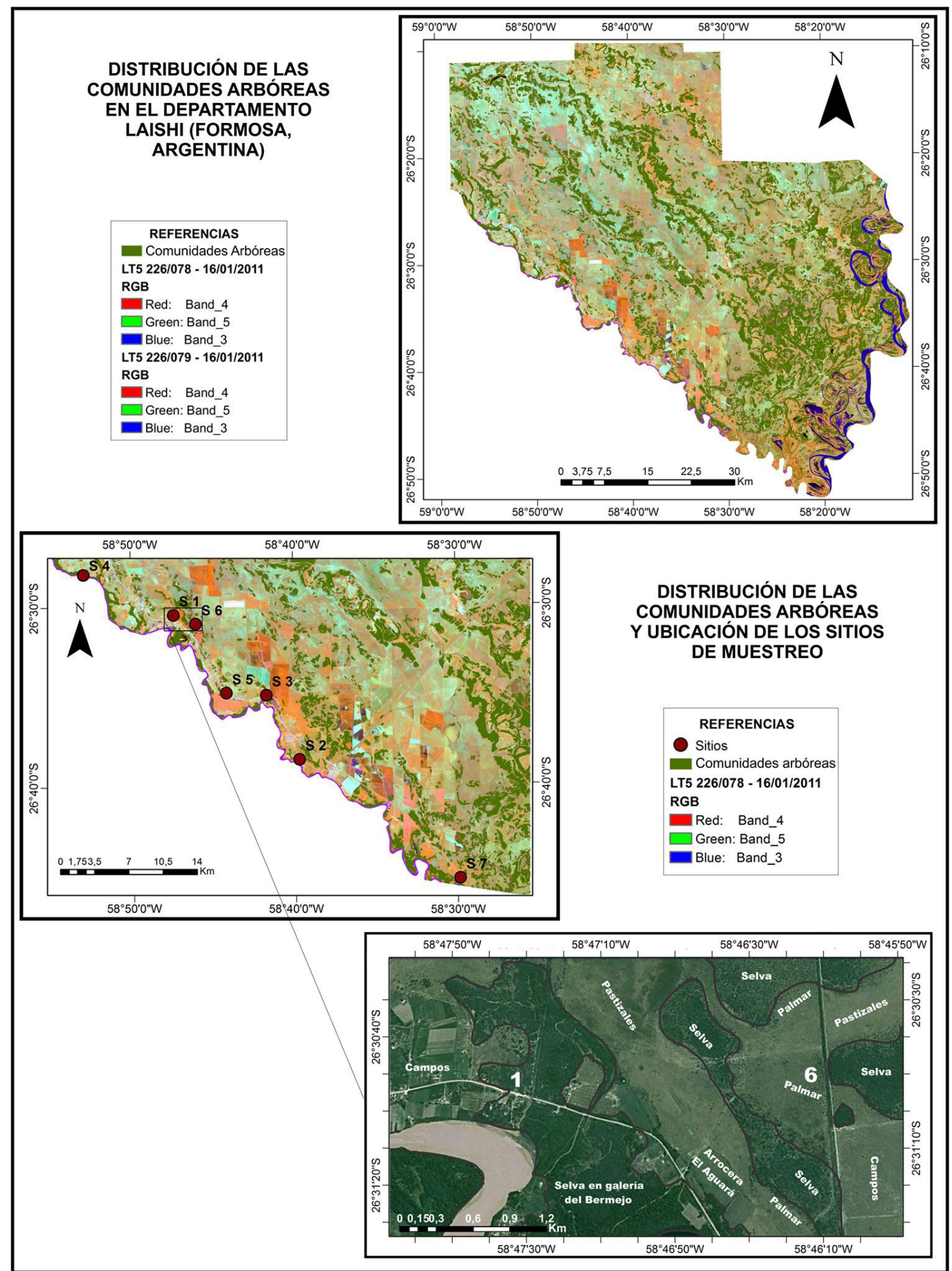

Fig. 2 Imágenes del satélite LANDSAT 5 TM Path/Row 226/078 y 226/079, sobre el Departamento de Laishi y sitios cercanos a Villa Escolar, mostrando la distribución de las comunidades arbóreas. Con mayor detalle se observan las distintas unidades vegetales entre los sitos 1 y 6. 
pastizales hidrófilos y 1,3\% de los arbustales. No se encontraron especies no chaqueñas en palmares y esteros/lagunas.

\section{Discusión}

Los resultados de este trabajo demuestran que la vegetación en el sudeste de la provincia de Formosa es heterogénea, distinguiéndose siete unidades de vegetación, siendo las selvas y los pastizales hidrófilos los que ocupan gran parte del área estudiada. Asimismo, se demuestra que en la región, además de las especies Chaqueñas, convergen especies de linaje amazónico.

\section{Composición florística}

El total de especies encontradas en el área de estudio (625) es mayor al número de especies registradas hasta el momento por Di Giacomo (2005) en la Reserva El Bagual (567). Las familias Asteraceae, Poaceae y Fabaceae y los géneros Baccharis, Solanum y Eupatorium, fueron los que presentaron el mayor número de especies. La abundancia de especies arbóreas y herbáceas, coincide con lo esperado de acuerdo con las unidades de vegetación presentes en la región, siendo las unidades arbóreas (selvas y bosques) las que presentaron no sólo un mayor número de especies sino también la mayor variedad de hábitos de crecimiento.

\section{Unidades de vegetación y Análisis de imágenes}

Los resultados de este trabajo demostraron que, en el área estudiada, la vegetación es heterogénea, siendo las unidades de vegetación arbórea, uno de los componentes principales del Departamento de Laishi, y se encuentran en zonas topográficas más elevadas. Los pastizales hidrófilos y los esteros que están ubicados en zonas topográficas más bajas, también ocupan gran parte del Departamento. Además, el análisis de las imágenes satelitales permite destacar el rol significativo de los principales ríos que atraviesan el área estudiada; teniendo en cuenta la distribución de las comunidades arbóreas (en su mayoría selvas), donde se pueden establecer algunas diferencias. Por un lado, en el sector occidental, estas comunidades poseen una distribución $\mathrm{NO}-\mathrm{SE}$, asociado a paleocauces y al actual curso del río Bermejo. Por otra parte, sobre la porción oriental, se observa una mayor densidad de las mismas cuya distribución es NE - SO asociados al actual río Paraguay y sus cursos abandonados. La asociación de los patrones de diversidad florística con la topografía detectada en el área estudiada concuerda con los patrones espaciales de complejidad estructural y florística propuestos por diversos autores para el Chaco Oriental (Morello \& Adamoli, 1974; Prado, 1993; Placci \& Holz, 2004; Ginzburg \& Adámoli, 2006, Peña Chocarro et al., 2006). Según Ginzburg \& Adámoli (2006), el relieve positivo de los albardones de los ríos permite la instalación de especies leñosas que no pueden prosperar en las áreas inundables.

En relación a las selvas halladas en el extremo sur del Departamento, cercanos a Villa Escolar, las diferencias detectadas tanto en su composición florística como en su distribución en relación a los albardones de los cursos de agua de la región, sugieren que se tratarían de diferentes unidades de vegetación. En este sentido, en los albardones de los ríos alóctonos y autóctonos del Chaco Oriental se distinguieron dos unidades de vegetación: los bosques riparios de inundación y los bosques de albardón (Morello \& Adamoli, 1974; Prado, 1993; Placci \& Holz, 2004; Ginzburg \& Adámoli, 2006, Peña Chocarro et al., 2006). Estos últimos, a su vez, fueron subdivididos en bosque de albardón alto, bajo y de transición Austro-Brasilero (Placci \& Holz, 2004). Aunque los bosques de transición ocupan extensiones en el Este de Formosa (Prado, 1993), el bosque de albardón alto es considerado la comunidad más cercana al clímax climático del Chaco Oriental (Placci \& Holz, 2004). De acuerdo con esta clasificación, los sitios con vegetación arbórea $(1,3$ y 4) cercanos a los cursos de agua (río Bermejo, Canal Sáenz y Desaguadero Bonett, respectivamente) de Villa Escolar serían Bosques de Albardón alto y bajo (sitio 3, sitio 4) y de Transición Austro Brasilero (sitio 1). Este último sitio fue el más diferenciado en cuanto a su composición florística presentando una gran abundancia de Acacia aroma y Celtis spp. En el Chaco Oriental, la explotación de madera permite la subsistencia de especies con aptitud como leñosas colonizadoras como las especies de Acacia y Celtis (Morello \& Adámoli, 1974; Martínez Crovetto, 1980), pudiendo las primeras formar bosquecillos secundarios puros (Bravo et al., 2006). En el área 
estudiada aunque no se encontraron bosques puros de Acacia, la gran abundancia de especies de Acacia y Celtis, así como el menor desarrollo del estrato herbáceo-arbustivo, ponen en evidencia el mayor grado de alteración del sitio 1 respecto de los restantes sitios, debido probablemente a su cercanía a centros urbanos.

Otra de las unidades de vegetación halladas en el área de estudio es el palmar de "Caranday" (Copernicia alba), que se caracteriza por presentar un estrato herbáceo desarrollado y la presencia de algunos árboles, cuyas especies pueden variar de acuerdo con las comunidades vecinas. C. alba es la única palmera de la región, que forma densos y extensos palmares, principalmente en Chaco y Formosa (Cabral \& Castro, 2007), aunque también puede aparecer constituyendo un mosaico con las isletas de bosque (Peña-Chocarro et al., 2006). Los palmares de "caranday" observados en el límite sur del Departamento forman isletas de diferentes extensiones entre las otras unidades, rodeando pastizales o bosques, sin ocupar grandes dimensiones.

Por otra parte, los pastizales hidrófilos detectados en Villa Escolar (sitios 5 y 7), aunque en general se caracterizan por presentar un menor número de especies, difieren entre sí en las especies predominantes. El sitio 5, es un pajonal de Paspalum intermedium y Eragrostis airoides; mientras que en el sitio 7 predomina Panicum prionitis. Este último es muy frecuente en el área muestreada. Finalmente, en los esteros (sitio 2), la especie predominante es Rhynchospora corymbosa, acompañada de Eleocharis montana y otras especies palustres como Pontederia cordata, Canna glauca, Marsilea sp.

Asimismo, aunque en Villa Escolar no se encontraron bosques, arbustales, pastizales mesófilos, dichas unidades de vegetación fueron halladas en áreas aledañas a dicha localidad (Maturo et al., 2005). El Monte Fuerte, típico de la Región Chaqueña, está poco representado en el Departamento, presentando una fisonomía de bosque alto abierto y una menor diversidad (Maturo et al., 2005). La escasa representatividad del Monte Fuerte en el área estudiada se debería probablemente a las características del suelo de la región, ya que este tipo de bosque se asienta sobre suelos salinos o salino/alcalinos (Morello \& Adamoli, 1967), mientras que los montes de
Schinopsis balansae de las planicies del este de la provincia de Formosa, están frecuentemente sometidas a largos períodos de anegamiento, por lo que esta especie normalmente no forma parte de aquellas comunidades de mayor riqueza florística del sector Oriental del Chaco (Biani et al., 2004). También fueron hallados arbustales, como por ejemplo los Blanquizales (sensu Morello \& Adamoli, 1974), que se desarrollan sobre los suelos limo-arcillosos, impermeables y fuertemente salinoalcalinos. Los mismos se caracterizan por poseer escasa vegetación que cubre el suelo formando manchones (Maturo et al., 2005). De los pastizales mesófilos, se detectaron aquellas con predominio de Elionurus muticus ("espartillar") y de Andropogon lateralis, muy comunes en la Región. E. muticus puede formar pastizales puros o sabanas junto a otras especies leñosas como Prosopis affinis, Astronium balansae o Diplokeleba floribunda (Morello \& Adamoli, 1967; Maturo et. al., 2005). Por otra parte, los pastizales de A. lateralis se desarrollan en campos altos sobre los albardones de los ríos, en posiciones más bajas que las selvas en galería, en suelos de texturas medianas a gruesas, arenosos y húmedos pero nunca inundable y están acompañados por numerosas especies herbáceas (Maturo et. al., 2005).

\section{Aspectos fitogeográficos}

Un elevado número de las especies encontradas en el Departamento de Laishi han sido citadas como principales $\mathrm{y} / \mathrm{o}$ abundantes de las provincias fitogeográficas Paranaense y/o de las Yungas (Atlas de los bosques nativos, 2003; Grau, 2006; Molina \& Rúgolo, 2006; Tortorelli, 2009; Moscovich et $a l, 2010)$. En general, el Chaco está caracterizado por un escaso número de endemismos a nivel de familia, siendo las leguminosas (Mimosoideas y Caesalpinoideas) sus formas típicas (Iriondo, 1992). Por otra parte, se ha sugerido que el Chaco Oriental sería una zona de convergencia donde se entremezclan especies de distintas floras (Prado 1993; Spichiger et al., 1995; Peña Chocarro et al., 2006). La presencia de especies de las provincias fitogeográficas Paranaense y/o de las Yungas en el área estudiada muestra claramente la confluencia de especies de linaje chaqueño y amazónico en el sudeste de la provincia de Formosa.

Asimismo, los resultados aquí obtenidos mostraron que las unidades de vegetación arbórea 
Tabla 1. Características generales de cada unidad ambiental.

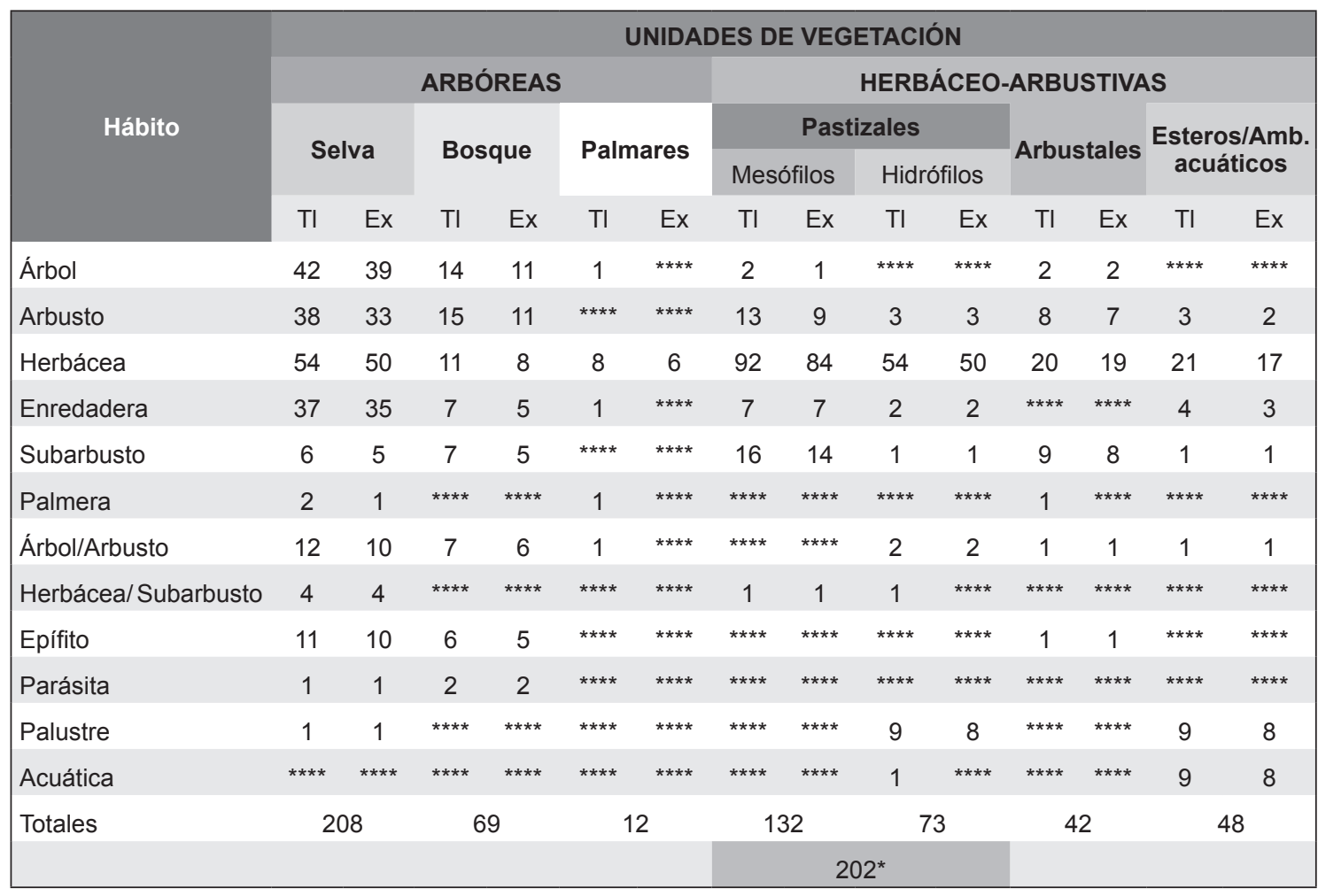

Referencias: $\mathrm{Tl}=$ Total de especies de la Unidad, Ex= Especies que son exclusivas de la Unidad. *Se tuvieron en cuenta solo una vez, las especies que compartían ambas.

son las que presentan un mayor número de especies no chaqueñas, siendo éstas principalmente árboles y enredaderas. Estos resultados están de acuerdo con lo propuesto por Prado (1993) y por Placci \& Holz (2004). El primero de los autores, distinguió entre las unidades de vegetación encontradas en el Chaco Oriental, las unidades no chaqueñas (Selva de inundación, Bosque ribereño), las transicionales (Bosque Transicional Austro-Brasilero) y las chaqueñas (quebrachales, algarrobales, palmares). A su vez, Placci \& Holz (2004) notaron que el Bosque de Inundación presenta pocas especies chaqueñas, siendo la mayoría de linaje extrachaqueño; mientras que en los bosques de albardón hay un recambio parcial de especies con disminución de las de linaje amazónico y un aumento de las de linaje chaqueño, desde el Bosque de Albardón Alto al Bosque de Transición Austro Brasilero, como también se observa en el área estudiada. Este gradiente estaría regulado por la disponibilidad de agua en los suelos de los bosques y por la fluctuación de las napas colgantes durante los períodos húmedos (Placci \& Holz, 2004).

El hecho que las unidades de vegetación arbórea donde se encontraron las especies no chaqueñas, se disponen en dirección NO-SE, siguiendo el curso de los paleocauces (que en la actualidad, salvo el río Bermejo, actúan como cursos autóctonos) y en dirección NNE-SSO en el valle de inundación del río Paraguay en el extremo oriental del Departamento Laishi, sugiere que los ríos alóctonos que confluyen en la región habrían sido importantes vías de migración de las especies de linaje amazónico. En este sentido, dado que algunas especies no chaqueñas encontradas, son especies que también ocurren en las Yungas, el río Bermejo y sus tributarios constituirían la principal vía de transporte de dichas especies al área estudiada. Estos resultados sustentan lo sugerido por Biani et al. (2006) quienes consideran que el río 


\section{S. A. Contreras et al. - Contribución al conocimiento florístico del SE de Formosa}

Bermejo sería la principal ruta de reclutamiento de las especies selváticas, ya que dicho río transporta semillas, frutos y plantas jóvenes desde los bosques montanos de las Sierras Subandinas, ubicados en la parte superior de la Cuenca del Bermejo (Biani et al. 2006). Existe una mayor similitud entre el Bosque de inundación y el Bosque Transicional Austro-Brasileño del Chaco Oriental con el bosque pedemontano subandino, más que con el resto de los bosques típicamente chaqueños observada por Placci \& Holz (2004).

Por otra parte, los ríos Paraná y Paraguay podrían constituir las vías de migración de las especies paranaenses halladas en los bosques de albardón, así como en los pastizales mesófilos del sudeste de Formosa. Dichos ríos constituyen un corredor biogeográfico que nace en ambientes del trópico húmedo y desemboca en regiones templadas húmedas. Este carácter se manifiesta en que todos los bosques en galería del sistema fluvial Paraguay-Paraná tienen linaje amazónico (Oakley et al., 2005). El límite Oriental del Departamento corresponde a dicho sistema fluvial, donde se observa un predominio de selvas en galería del Río Paraguay y un sector donde se mezcla con las selvas de los ríos que vienen del sector occidental. Oackley et al. (2005), advierten que en los bosques en galería y antiguos albardones de la Región, hay una marcada influencia de la Provincia Paranaense y del Dominio de los Bosques estacionales neotropicales.

Tabla 2. Especies compartidas con las Provincias Fitogeográficas Paranaense y de las Yungas.

\begin{tabular}{|c|c|c|}
\hline Especies & Paranaense & Yungas \\
\hline Acalypha communis & $* * *$ & $* * *$ \\
\hline Acanthosyris falcata & & $* * *$ \\
\hline Achatocarpus praecox & $* * *$ & $* * *$ \\
\hline Aechmea distichantha & *** & $* * *$ \\
\hline Agonandra excelsa & & $* * *$ \\
\hline Allophylus edulis & $* * *$ & $* \star *$ \\
\hline Andropogon lateralis & $* * *$ & \\
\hline Arrabidaea corallina & & $* * *$ \\
\hline Astronium balansae & $* * *$ & \\
\hline Baccharis flexuosa & & $* * *$ \\
\hline Celtis iguanea & $* * *$ & $* * *$ \\
\hline Celtis pubescens & $* * *$ & $* * *$ \\
\hline Cissus palmata & $* * *$ & $* * *$ \\
\hline Cissus verticillata & *** & $* * *$ \\
\hline Clematis montevidensis & $* * *$ & $* * *$ \\
\hline Cordia americana & *** & $* * *$ \\
\hline Chloroleucon tenuiflorum & $* * *$ & $* * *$ \\
\hline Chrysophyllum gonocarpum & *** & $* * *$ \\
\hline Croton urucurana & $* * *$ & \\
\hline Diplokeleba floribunda & $* * *$ & \\
\hline Dolichandra cynanchoides & $* * *$ & $* * *$ \\
\hline
\end{tabular}


Bol. Soc. Argent. Bot. 50 (4) 2015

\begin{tabular}{|c|c|c|}
\hline Especies & Paranaense & Yungas \\
\hline Elionurus muticus & $* * *$ & \\
\hline Enterolobium contortisiliquum & $* * *$ & $* * *$ \\
\hline Erythrina crista-galli & $* * *$ & $* * *$ \\
\hline Eugenia moraviana & $* * *$ & $* * *$ \\
\hline Eugenia uniflora & $* * *$ & *** \\
\hline Eupatorium lanigerum & $* * *$ & \\
\hline Fagara naranjillo & $* \star \star$ & $* * *$ \\
\hline Fagara pterota & $* * *$ & $* * *$ \\
\hline Fagara rhoifolia & $* * *$ & $* * *$ \\
\hline Ficus luschnathiana & $* * *$ & \\
\hline Galactia striata & $* * *$ & $* * *$ \\
\hline Geoffroea decorticans & & *** \\
\hline Gleditsia amorphoides & $* * *$ & $* \star *$ \\
\hline Holocalyx balansae & $* * *$ & \\
\hline Hydrocotyle leucocephala & $* * \star$ & \\
\hline Hydrocotyle ranunculoides & $* * *$ & $* * *$ \\
\hline Julocroton subpannosus & $* * *$ & \\
\hline Macfadyena unguis cati & $* * *$ & $* * *$ \\
\hline Maclura tinctoria & $* * *$ & $* * *$ \\
\hline Maytenus ilicifolia & $* * *$ & \\
\hline Myrcianthes pungens & $* * *$ & $* * *$ \\
\hline Ocotea diospyrifolia & $* * *$ & \\
\hline Oplismenus hirtellus & $* * \star$ & $* * *$ \\
\hline Paspalum plicatum & $* * *$ & \\
\hline Peltophorum dubium & $* * *$ & \\
\hline Pharus lappulaceus & $* * *$ & $* * *$ \\
\hline Phytolacca dioica & $* * *$ & \\
\hline Phyllostylon rhamnoides & & $* \star *$ \\
\hline Pisonia zapallo & $* \star *$ & $* * *$ \\
\hline Pithecoctenium cynanchoides & $* * *$ & $* * *$ \\
\hline Pouteria glomerata & $* * *$ & \\
\hline Pseudogynoxys cabrerae & $* * *$ & *** \\
\hline Pterogyne nitens & $* * *$ & $* * *$ \\
\hline Randia armata & $* * *$ & $* * *$ \\
\hline Ruprechtia laxiflora & $* * *$ & $* * *$ \\
\hline
\end{tabular}




\begin{tabular}{|c|c|c|}
\hline Especies & Paranaense & Yungas \\
\hline Sapium haematospermum & $* * *$ & $* \star *$ \\
\hline Schizachiryum spicatum & $* \star *$ & $* * *$ \\
\hline Sebastiania brasiliensis & $* * *$ & $* * *$ \\
\hline Serjania perulacea & & $* * *$ \\
\hline Smilax campestris & $* * *$ & $* * *$ \\
\hline Solanum granulosum-leprosum & $* * *$ & \\
\hline Solanum megalocarpon & $* * \star$ & \\
\hline Syagrus romanzoffiana & $* * *$ & \\
\hline Tabebuia aurea & & $* * *$ \\
\hline Tabebuia heptaphylla & $* * *$ & \\
\hline Tabernaemontana catharinensis & $* * *$ & \\
\hline Terminalia triflora & $* * *$ & $* * *$ \\
\hline Tillandsia meridionalis & $* * *$ & $* * *$ \\
\hline Trichilia catigua & $* * *$ & \\
\hline Trichilia elegans & $* * *$ & \\
\hline Urera baccifera & $* * *$ & $* * *$ \\
\hline Vassobia breviflora & $* * *$ & $* * *$ \\
\hline
\end{tabular}

En otras palabras, la diversidad y distribución de las unidades de vegetación, así como la presencia de especies no chaqueñas en el sudeste de la Provincia de Formosa también sería el resultado de la dinámica de los grandes ríos de la región durante el Cuaternario, la que habría generado pequeñas pero significativas diferencias topográficas sobre la llanura, creando albardones y cursos abandonados. Teniendo en cuenta las características de los albardones, la presencia de un perfil de suelo bien desarrollado y una altura topográfica superior a la máxima alcanzada por el río, aún durante las inundaciones extraordinarias, se ha sugerido que los mismos se habrían formado durante períodos de mayor pluviosidad que la actual, desde hace 1000 a 8000 años, durante el Holoceno (Placci \& Holz, 2004). Asimismo, las variaciones climáticas ocurridas en la llanura Chaco-Pampeana en los últimos 18.000 años y los procesos actuales de modelado actuarían como uno de los principales agentes condicionantes de las características de la flora chaqueña actual (Iriondo, 1995; Morelo \& Matteucci, 1999; Serra, 2002; Biani et al., 2006).

Teniendo en cuenta que las unidades de vegetación hallada en los albardones de los cursos de agua del sudeste de la provincia de Formosa presentan el mayor número de especies, que un alto porcentaje de las especies allí presentes son de linaje no chaqueño y que los albardones se habrían formado durante el Holoceno (Placci \& Holz, 2004), el establecimiento de las unidades de vegetación arbórea en el área estudiada pudo ocurrir rápidamente y en un pasado reciente. El análisis en curso de las asociaciones fitolíticas de las comunidades vegetales del sudeste de la provincia de Formosa, en comparación con el análisis fitolítico de las secuencias sedimentarias recientes de esta región, contribuirá al conocimiento de las variaciones de las comunidades vegetales, como así también los cambios paleoclimáticos y/o paleoambientales del Chaco Oriental ocurridos en el pasado reciente. 
Bol. Soc. Argent. Bot. 50 (4) 2015

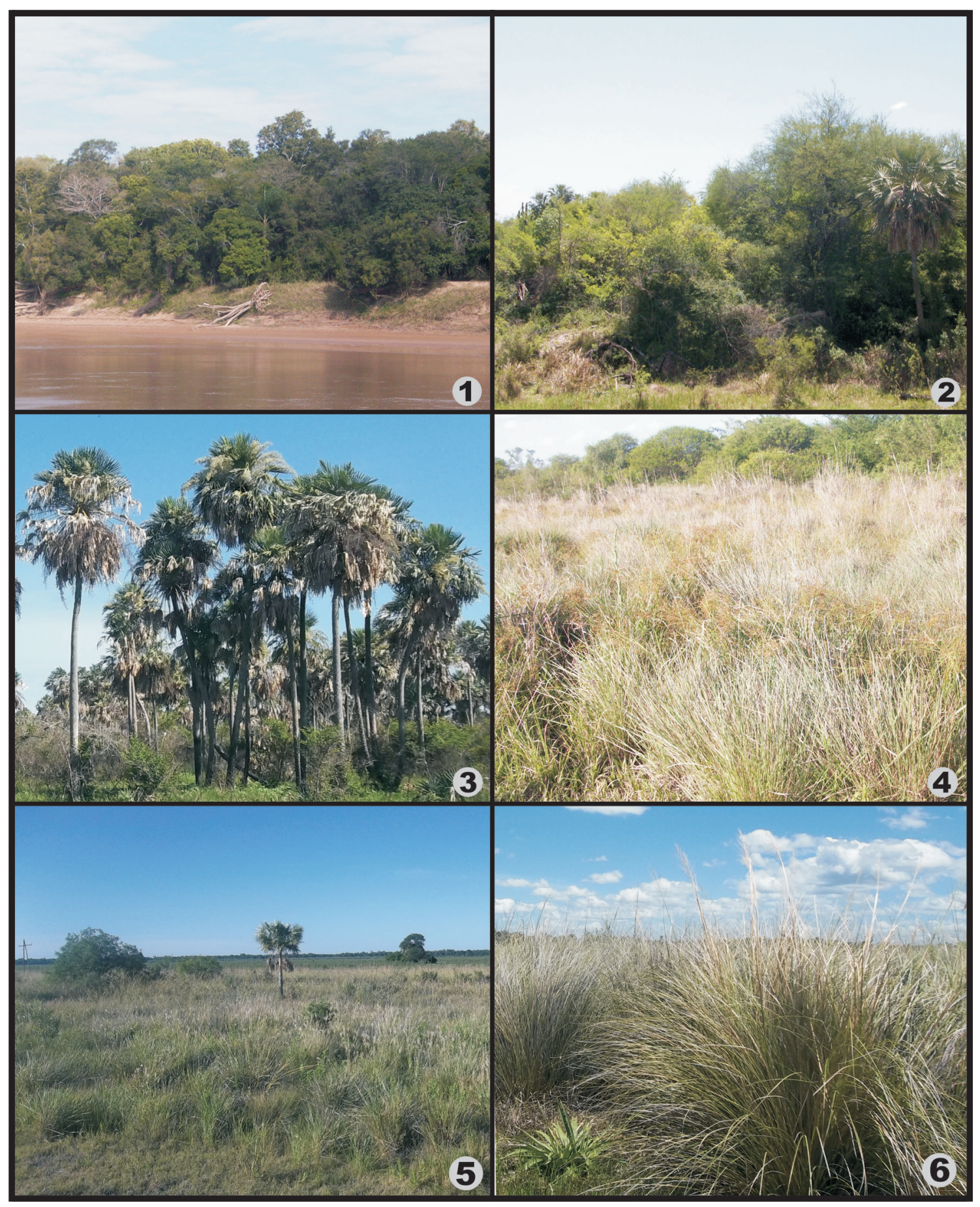

Fig. 3. Unidades vegetales entre la Localidad del Colorado y Gral. Mansilla. 1. Bosque de Albardón sobre el Río Bermejo (Sitio 4). 2. Bosque de Albardón sobre Canal Sáenz (Sitio 1). 3. Palmares de Copernicia alba (Sitio 6). 4. Estero con mayor presencia de Rhynchospora corymbosa (Sitio 2). 5. Pajonal de Paspalum intermedium (Sitio 5) y 6. Pajonal de Panicum prionitis (Sitio 7). (Fotografías: S.A. Contreras). 


\section{Agradecimientos}

Los autores agradecen al Lic. Walter Medina del Instituto de Botánica del Nordeste (UNNECONICET) por colaborar con el procesamiento e identificación de los ejemplares muestreados y depositados en el herbario CTES. A Juan Friedricht, Director del Museo de Ciencias Naturales de Villa Escolar, quien colaboró con la recolección a campo. S.A. Contreras es becaria de CONICET. F.I. Contreras es becario de CONICET-UNNE. A.I. Lutz y A.F. Zucol son miembros de la Carrera del Investigador Científico de CONICET.

Este trabajo fue financiado parcialmente por un proyecto de la Agencia Nacional de Promoción Científica, Tecnológica y de Innovación (ANPCyTFONCyT, PICT N 12-1812).

\section{Bibliografía}

ATLAS DE LOS BOSQUES NATIVOS ARGENTINOS. 2003. Proyecto Bosques Nativos y Áreas Protegidas BIRF 4085-AR. Dirección de Bosques, Secretaría de Ambiente y Desarrollo Sustentable, Buenos Aires.

BIANI, N., J. VESPRINI \& D. PRADO. 2006. Conocimiento sobre el gran Chaco Argentino en el siglo XX. En: ARTURI, M. F., J. L. FRANGI \& J. F. GOYA (eds.), Ecología y Manejo de los bosques de Argentina, pp. 1-19. Editorial de la Universidad Nacional de La Plata.

BRAVO, S., A. GIMÉNEZ \& J. MOGLIA. 2006. Caracterización anatómica del leño y evolución del crecimiento en ejemplares de Acacia aroma y Acacia furcatispina en la Región Chaqueña, Argentina. Bosque 27: 146-154.

BUCHER, E. 1980. Ecología de la fauna Chaqueña. Una revisión. ECOSUR 7: 111-159.

CABRAL E. \& M. CASTRO. 2007. Palmeras Argentinas. Guías para el reconocimiento. L.O.L.A., Buenos Aires.

CABRERA, A. 1971. Fitogeografía de la República Argentina. Bol. Soc. Argent. Bot. 14: 1-42.

CONTRERAS, S.A. 2010. Quaternary palaeoenvironmental reconstruction based on fossil imprints and palynological data from Villa Escolar, Eastern Chaco plain, Argentina. Meeting of the Americas. Eos Trans. AGU, 91 (26), Jt. Assem. Suppl., Abstract 852866. Disponible en: http://www.agu.org/meetings/ja10/ja10sessions/ja10_PP41A.html.

CONTRERAS, S. \& A. LUTZ. 2014. Primer Registro de Equisetites sp. (Equisetaceae) en Sedimentos Cuaternarios del Río Bermejo (Formosa, Argentina). Bol. Soc. Argent. Bot. 49: 381-392.
DI GIACOMO, A. G. 2005. Lista Florística de la Reserva El Bagual. En: DI GIÁCOMO A.G. \& S.F. KRAPOVICKAS (eds.), Temas de Naturaleza y Conservación, pp. 74-87. Monografía de Aves Argentinas, Buenos Aires.

GINZBURG, R. \& J. ADÁMOLI. 2006. Situación ambiental en el Chaco húmedo. En: BROWN, A., U. MARTINEZ ORTÍZ, M. ACERBI \& J. CORCUERA (eds.), La Situación Ambiental Argentina 2005, pp. 103-113. Fundación Vida Silvestre, Buenos Aires.

GORLERI, M.C. 2005. Caracterización climática del Chaco Húmedo. En: DI GIÁCOMO A.G. \& S.F. KRAPOVICKAS (eds.), Temas de Naturaleza y Conservación, pp. 13-25. Monografía de Aves Argentinas, Buenos Aires.

GRAU, H. R. 2006. Dinámica de bosques en el gradiente altitudinal de las Yungas Argentinas. En: ARTURI, M. F., J. L. FRANGI \& J. F. GOYA (eds.), Ecología y Manejo de los bosques de Argentina. pp. 1-30. Editorial de la Universidad Nacional de La Plata.

IRIONDO, M.H. 1992. El Chaco. Holoceno 1: 50-63.

IRIONDO, M.H. 1995. El Cuaternario del Chaco. En: ARGOllo, J. \& P. MOURGUiA (eds.), Climas Cuaternarios en América del Sur, pp. 344. Institut Français de Recherche Scientifique pour le Développement et Coopération, Marseille.

MARTINEZ CROVETTO, R. 1980. Estudios Fitosociológicos en el Sotobosque de los Quebrachales del Nordeste de Corrientes (República Argentina). Bol. Soc. Argent. Bot. 19: 315-329.

MATURO, H., L. OAKLEY \& D. PRADO. 2005. Vegetación y posición fitogeográfica de la Reserva El Bagual. En: DI GIÁCOMO A.G. \& S.F. KRAPOVICKAS (eds.), Temas de Naturaleza y Conservación, pp. 59-73. Monografía de Aves Argentinas, Buenos Aires.

MOLINA, A. \& Z. RÚGOLO. 2006. Flora Chaqueña Argentina (Formosa, Chaco y Santiago del Estero), Familia Gramíneas. Colección Científica del INTA, Argentina.

MORELLO, J. \& J. ADÁMOLI. 1967. Vegetación y ambiente del Nordeste del Chaco Argentino: Guía de viaje, Tramo Resistencia-Puerto Pilcomayo $\mathrm{N}^{\circ} 3$. INTA, Estación Experimental Agropecuaria Colonia Benítez.

MORELLO, J. \& J. ADÁMOLI. 1974. Las Grandes Unidades de Vegetación y Ambiente del Chaco Argentino. Segunda Parte: Vegetación y Ambiente de la Provincia del Chaco. Serie Fitogeográfica $\mathrm{N}^{\circ}$ 13. INTA, Buenos Aires.

MORELLO, J. \& S.D. MATTEUCCI. 1999. Biodiversidad y fragmentación de los bosques en la Argentina. En: MATTEUCCI S.D., O.T. SOLBRIG, J. MORELLO \& G. HALFFTER (eds.), Biodiversidad y uso de la tierra. Conceptos y ejemplos de Latinoamérica, pp. 
463-498. EUDEBA-UNESCO, Buenos Aires.

MORRONE, J. J. 2001. Biogeografía de América Latina y el Caribe. Vol. 3. M\&T: Manuales y Tesis SEA, Zaragoza.

MORRONE, J. J. 2014. Biogeographical regionalisation of the Neotropical region. Zootaxa 3782: 1-110.

MOSCOVICH, F.A, C. DUMMEL, M. PINAZO, O. KNEBEL \& R. ALCARAZ. 2010. Análisis Fitosociológico de un Remanente de Selva Misionera Secundaria en Misiones, Argentina. 14as Jornadas Técnicas Forestales y Ambientales. Facultad de Ciencias Forestales, UNaM y EEA Montecarlo, INTA, Misiones. Disponible en: http:// inta.gob.ar/documentos/analisis-fitosociologico-deun-remanente-de-selva-misionera-secundaria-enmisionesargentina/at_multi_download/file/analisis _fitosociologico_remanente_selva.pdf. [Acceso: 10 septiembre 2014].

OAKLEY, L. J., D. PRADO \& J. ADAMOLI. 2005. Aspectos biogeográficos del Corredor Fluvial Paraguay-Paraná. Serie Miscelánea. INSUGEOCONICET, Tucumán 14:245-258.

PEÑA CHOCARRO, M., J. DE EGEA, M. VERA, H. MATURO \& S. KNAPP. 2006. Guía de árboles y arbustos del Chaco Húmedo. The Natural History Museum, Guyra Paraguay. Fundación Moisés Bertoni y Fundación Hábitat y Desarrollo, Asunción.

PLACCI, L. \& S. HOLZ. 2004. Patrón de paisaje de bosques del Chaco Oriental. En: M. F. ARTURI, J. FRANGI \& J. F. GOYA (eds.), Ecología y manejo de los bosques de Argentina. Editorial de la Universidad Nacional de La Plata.

PRADO, D.E. 1993. What is the Gran Chaco vegetation in South America? I. A review. Contribution to the study of flora and vegetation of the Chaco V. Candollea 48: 145-172.
RUIZ ZAPATA, B., A. ANDRADE OLALLA, M. DORADO VALIÑO, T. MARTÍN ARROYO \& A. VALDEOLMILLOS RODRÍGUEZ. 1996. Reflexiones sobre la Palinología del Cuaternario y su Aplicación en la reconstrucción paleoambiental y paleoclimática. I: Representación polínica de la vegetación. Geogaceta 20: 217-220.

SALAS, L. \& A. CENDRERO. 1988. Estudios de la Correlación existente entre la Degradación del Polen y los Parámetros Climático-edafológicos. Cuaternario y Geomorfología 2: 91-97.

SERRA, P. 2002. El Parque chaqueño y sus factores fisiográficos asociados (Chaco y Formosa). Investigaciones y ensayos geográficos. Revista de geografia, Univ. Nac. Formosa 1: 19-29.

SPICHIGER, R., R. PALESE, A. CHAUTEMS \& L. RAMELLA. 1995. Origin, affinities and diversity hot spots of the Paraguayan dendrofloras. Candollea 50: 515-537.

TORTORELLI, L. 2009. Maderas y Bosques Argentinos. Tomo I. Segunda edición. Orientación Gráfica Editora, Buenos Aires.

ZUlOAGA, F., Z. RÚGOLO \& A. M. ANTON. 2012. Flora Vascular de la República Argentina. Aristidoideae-Pharoideae. Vol. 3, Tomo I. Gráficamente Ediciones. Córdoba.

Recibido el 1 de diciembre de 2014, aceptado el 1 de julio de 2015. 
Apéndice. Listado de especies encontradas en el Departamento de Laishi al SE de Formosa. Unidad vegetal: S (selva), B (Bosque), PI (Palmar), Ar (arbustal), PzM (Pastizal mesófilo), PzH (Pastizal hidrófilo) y E/L (Estero-Lagunas). Hábito: A (árboreo), Arb (Arbusto), A/Arb (árbol-arbusto), SubArb (Subarbusto), He (Herbáceo), HeA (Acuática), HeP (Palustre), He/SubArb (herbáceo-Subarbusto), En (Enredadera), Ep (Epifito), Pal (Palmera) y Par (Parasita). Colección: Cp (campo) y Her (Herbario).

\begin{tabular}{|c|c|c|c|c|}
\hline Especies & $\begin{array}{l}\text { Unidad } \\
\text { Vegetal }\end{array}$ & Hábito & coleccionista y $\mathbf{N}^{\circ}$ & Bibliografía \\
\hline \multicolumn{5}{|l|}{ Pteridophyta } \\
\hline \multicolumn{5}{|l|}{ Marsileaceae } \\
\hline Marsilea sp. & $\mathrm{E} / \mathrm{L}$ & $\mathrm{He}$ & $\begin{array}{l}\text { CP: 20/10/11. Contreras, S. Et al. } 55 \\
\text { (CTES) }\end{array}$ & \\
\hline Marsilea ancyclopoda A. Braun. & $\mathrm{PzH}$ & $\mathrm{He}$ & $\begin{array}{l}\text { Her: 7/10/2002. Di Giácomo, A. } 582 \\
\text { (CTES) }\end{array}$ & Di Giacomo, A., 2005 \\
\hline \multicolumn{5}{|l|}{ Polypodiaceae } \\
\hline Microgramma sp. & S & Ep & $\begin{array}{l}\text { CP: 20/12/11. Contreras, S. Et al. } 60 \\
\text { (CTES) }\end{array}$ & \\
\hline $\begin{array}{l}\text { Microgramma vacciniifolia } \\
\text { (Langsd. \& Fisch.) Copel }\end{array}$ & S & Ep & $* * *$ & Di Giacomo, A., 2005 \\
\hline Polypodium squalidum Vell. & S & Ep & $\begin{array}{l}\text { Her: 20/09/1999. Di Giácomo, A. } 423 \\
\text { (CTES) }\end{array}$ & Di Giacomo, A., 2005 \\
\hline \multicolumn{5}{|l|}{ Pteridaceae } \\
\hline $\begin{array}{l}\text { Doryopteris concolor } \\
\text { (Langsd. \& Fisch.) Kuhn }\end{array}$ & S & $\mathrm{He}$ & $\begin{array}{l}\text { CP: 20/10/11. Contreras, S. Et al. } 47 \\
\text { (CTES) }\end{array}$ & Di Giacomo, A., 2005 \\
\hline $\begin{array}{l}\text { Doryopteris pentagona } \\
\text { Pic. Serm. }\end{array}$ & B & $\mathrm{He}$ & $\begin{array}{l}\text { Her: 27/07/2007. Meza Torres, E. I. } 664 . \\
\text { (CTES) }\end{array}$ & \\
\hline $\begin{array}{l}\text { Hemionitis tomentosa } \\
\text { (Lam.) Raddi }\end{array}$ & S & $\mathrm{He}$ & $\begin{array}{l}\text { Her: 10/07/1999. Di Giácomo, A. } 410 \\
\text { (CTES) }\end{array}$ & Di Giacomo, A., 2005 \\
\hline Pteris denticulata Sw. & S & $\mathrm{He}$ & $\begin{array}{l}\text { Her: 01/11/2001. Di Giácomo, A. } 551 \\
\text { (CTES) }\end{array}$ & Di Giacomo, A., 2005 \\
\hline Trimeria trifoliata (L.) Diels & PzM & $\mathrm{He}$ & $* * *$ & Di Giacomo, A., 2005 \\
\hline \multicolumn{5}{|l|}{ Salviniaceae } \\
\hline Salvinia sp. & $E / L$ & $\mathrm{HeA}$ & $\begin{array}{l}\text { Her: 15/03/2003. Di Giácomo, A. } 595 \\
\text { (CTES) }\end{array}$ & Di Giacomo, A., 2005 \\
\hline \multicolumn{5}{|l|}{ Selaginellaceae } \\
\hline Selaginella sp. & $* * * *$ & $\mathrm{He}$ & $* * *$ & Di Giacomo, A., 2005 \\
\hline \multicolumn{5}{|l|}{ Angiospermae } \\
\hline \multicolumn{5}{|l|}{ Monocotyledoneae } \\
\hline \multicolumn{5}{|l|}{ Alismataceae } \\
\hline $\begin{array}{l}\text { Echinodorus grandiflorus } \\
\text { (Cham. \& Schltdl.) Micheli }\end{array}$ & $\mathrm{PzH}$ & $\mathrm{He}$ & $* * *$ & $\begin{array}{l}\text { Di Giacomo, A., 2005; } \\
\text { Maturo et al., } 2005\end{array}$ \\
\hline $\begin{array}{l}\text { Hydrocleys nymphoides } \\
\text { (Willd.) Buch. }\end{array}$ & $E / L$ & $\mathrm{HeA}$ & $\begin{array}{l}\text { Her: 15/03/2002. Di Giácomo, A. } 562 \\
\text { (CTES) }\end{array}$ & $\begin{array}{l}\text { Di Giacomo, A., 2005; } \\
\text { Maturo et al., } 2005\end{array}$ \\
\hline $\begin{array}{l}\text { Sagittaria montevidensis } \\
\text { Cham. \& Schltdl. }\end{array}$ & $* * * *$ & $\mathrm{HeP}$ & $* * *$ & $\begin{array}{l}\text { Di Giacomo, A., 2005; } \\
\text { Maturo et al., } 2005\end{array}$ \\
\hline Amaryllidaceae & & & & \\
\hline
\end{tabular}




\begin{tabular}{|c|c|c|c|c|}
\hline Especies & $\begin{array}{l}\text { Unidad } \\
\text { Vegetal }\end{array}$ & Hábito & coleccionista y $\mathrm{N}^{\circ}$ & Bibliografía \\
\hline $\begin{array}{l}\text { Habranthus cfr.brachyandrus } \\
\text { (Baker) Sealy }\end{array}$ & PzM & $\mathrm{He}$ & $\begin{array}{l}\text { Her: 20/11/1999. Di Giácomo, A. } 446 \\
\text { (CTES) }\end{array}$ & Di Giacomo, A., 2005 \\
\hline $\begin{array}{l}\text { Nothoscordum cfr. } \\
\text { gracile (Drya.) Stern. }\end{array}$ & $* * * *$ & $\mathrm{He}$ & $\begin{array}{l}\text { Her: 10/10/2001. Di Giácomo, A. } 528 \\
\text { (CTES) }\end{array}$ & \\
\hline Zephyranthes sp. & $\mathrm{Ar}$ & $\mathrm{He}$ & $* * *$ & Di Giacomo, A., 2005 \\
\hline \multicolumn{5}{|l|}{ Araceae } \\
\hline Anthurium paraguayense Engl. & S & $\mathrm{He}$ & $\begin{array}{l}\text { Her: 23/09/1998. Di Giácomo, A. } 402 . \\
\text { (CTES) }\end{array}$ & $\begin{array}{l}\text { Di Giacomo, A., 2005; } \\
\text { Maturo et al., } 2005\end{array}$ \\
\hline Pistia stratiotes L. & $E / L$ & $\mathrm{HeA}$ & $\begin{array}{l}\text { Her: 06/04/2003. Di Giácomo, A. } 609 . \\
\text { (CTES) }\end{array}$ & Di Giacomo, A., 2005 \\
\hline \multicolumn{5}{|l|}{ Arecaceae } \\
\hline $\begin{array}{l}\text { Copernicia alba Morong } \\
\text { ex Morong \& Britton }\end{array}$ & $\begin{array}{l}\mathrm{PI}, \mathrm{S} \\
\mathrm{Ar}\end{array}$ & Pal & $\begin{array}{l}\text { CP: 06/12/12. Contreras, S. Et al. } 101 \\
\text { (CTES) }\end{array}$ & $\begin{array}{l}\text { Di Giacomo, A., 2005; } \\
\text { Maturo et al., } 2005\end{array}$ \\
\hline $\begin{array}{l}\text { Syagrus romanzoffiana } \\
\text { (Cham.) Glassman }\end{array}$ & $S$ & Pal & $* * *$ & $\begin{array}{l}\text { Di Giacomo, A., } 2005 \text {; } \\
\text { Maturo et al., } 2005\end{array}$ \\
\hline \multicolumn{5}{|l|}{ Asparagaceae } \\
\hline Herreria bonplandii Lecomte & B & En & $\begin{array}{l}\text { Her: 25/11/1998. Di Giácomo, A. } 379 . \\
\text { (CTES) }\end{array}$ & \\
\hline \multicolumn{5}{|l|}{ Bromeliaceae } \\
\hline Aechmea distichantha Lem. & B & SubArb & $\begin{array}{l}\text { Her: 30/11/2001. Di Giácomo, A. } 539 . \\
\text { (CTES) }\end{array}$ & $\begin{array}{l}\text { Di Giacomo, A., 2005; } \\
\text { Maturo et al., } 2005\end{array}$ \\
\hline Bromelia hieronymi Mez & $\mathrm{Ar}$ & SubArb & $\begin{array}{l}\text { Her: 10/12/1999. Di Giácomo, A. } 437 . \\
\text { (CTES) }\end{array}$ & Di Giacomo, A., 2005 \\
\hline Bromelia serra Griseb. & B & SubArb & $\begin{array}{l}\text { Her: 30/11/2001. Di Giácomo, A. } 540 . \\
\text { (CTES) }\end{array}$ & $\begin{array}{l}\text { Di Giacomo, A., 2005; } \\
\text { Maturo et al., } 2005\end{array}$ \\
\hline Dyckia ferox Mez & $\operatorname{Ar}$ & SubArb & $\begin{array}{l}\text { Her: 18/11/1999. Di Giácomo, A. } 435 . \\
\text { (CTES) }\end{array}$ & $\begin{array}{l}\text { Di Giacomo, A., 2005; } \\
\text { Maturo et al., } 2006\end{array}$ \\
\hline $\begin{array}{l}\text { Pseudananas sagenarius } \\
\text { (Arrud. Cam.) Camargo }\end{array}$ & $S$ & SubArb & $\begin{array}{l}\text { Her: 01/12/2000. Di Giácomo, A. } 476 . \\
\text { (CTES) }\end{array}$ & $\begin{array}{l}\text { Di Giacomo, A., 2005; } \\
\text { Maturo et al., } 2005\end{array}$ \\
\hline Tillandsia duratii Vis. & B & Ep & $\begin{array}{l}\text { Her: 18/11/1999. Di Giácomo, A. } 434 . \\
\text { (CTES) }\end{array}$ & Di Giacomo, A., 2005 \\
\hline Tillandsia funebris Castellanos & $* * * *$ & Ep & $\begin{array}{l}\text { Her: 00/09/1929. Palavecino, J. A. s. } \\
\text { n. (BA) }\end{array}$ & \\
\hline Tillandsia meridionalis Baker & B & Ep & $* * *$ & Di Giacomo, A., 2005 \\
\hline Tillandsia recurvata $\mathrm{L}$. & B & Ep & $\begin{array}{l}\text { Her: 27/09/2000. Di Giácomo, A. } 463 . \\
\text { (CTES) }\end{array}$ & Di Giacomo, A., 2005 \\
\hline Tillandsia tricholepis Baker & $S$ & Ep & $\begin{array}{l}\text { Her: 03/05/1999. Di Giácomo, A. } 414 . \\
\text { (CTES) }\end{array}$ & Di Giacomo, A., 2005 \\
\hline Tillandsia usneoides (L.) L. & S & Ep & $* * *$ & Di Giacomo, A., 2005 \\
\hline Tillandsia vernicosa Bak. & B & Ep & $\begin{array}{l}\text { Her: 10/05/1999. Di Giácomo, A. } 407 . \\
\text { (CTES) }\end{array}$ & Di Giacomo, A., 2005 \\
\hline \multicolumn{5}{|l|}{ Cannaceae } \\
\hline Canna glauca L. & $E / L$ & $\mathrm{He}$ & CP: 20/10/11. Contreras, S. 57. (CTES) & $\begin{array}{l}\text { Di Giacomo, A., 2005; } \\
\text { Maturo et al., } 2005\end{array}$ \\
\hline
\end{tabular}




\begin{tabular}{|c|c|c|c|c|}
\hline Especies & $\begin{array}{l}\text { Unidad } \\
\text { Vegetal }\end{array}$ & Hábito & coleccionista y $\mathbf{N}^{\circ}$ & Bibliografía \\
\hline Canna indica L. & E/L & $\mathrm{He}$ & $* * *$ & Di Giacomo, A., 2005 \\
\hline \multicolumn{5}{|l|}{ Commelinaceae } \\
\hline Commelina cfr. erecta L. & $\mathrm{PI}$ & $\mathrm{He}$ & $\begin{array}{l}\text { Her, CP: 20/10/2000. Di Giácomo, A. } \\
\text { 467. (CTES); 06/12/12. Contreras, S. et } \\
\text { al. 113. (CTES) }\end{array}$ & Di Giacomo, A., 2005 \\
\hline $\begin{array}{l}\text { Commelina platyphylla } \\
\text { Klotsch ex Seub. }\end{array}$ & $* * * *$ & $\mathrm{He}$ & $\begin{array}{l}\text { Her: 15/03/2003. Di Giácomo, A. } 604 . \\
\text { (CTES) }\end{array}$ & Di Giacomo, A., 2005 \\
\hline Tripogandra Sp. & $S$ & $\mathrm{He}$ & *** & Di Giacomo, A., 2005 \\
\hline \multicolumn{5}{|l|}{ Cyperaceae } \\
\hline $\begin{array}{l}\text { Carex riparia var. } \\
\text { chilensis Brongn. }\end{array}$ & $E / L$ & $\mathrm{He}$ & $* * *$ & $\begin{array}{l}\text { Di Giacomo, A., 2005; } \\
\text { Maturo et al., } 2005\end{array}$ \\
\hline Carex sororia Kunth & $\mathrm{PI}$ & $\mathrm{He}$ & $\begin{array}{l}\text { CP: 06/12/12. Contreras, S. } 117 . \\
\text { (CTES) }\end{array}$ & \\
\hline Cyperus sp. (1) & $E / L$ & $\mathrm{HeP}$ & CP: 20/10/11. Contreras, S. 56. (CTES) & \\
\hline Cyperus sp (2) & $S$ & $\mathrm{HeP}$ & CP: 20/12/11. Contreras, S. 66. (CTES) & \\
\hline Cyperus aggregatus (Willd.) Eld. & $\mathrm{PzH}$ & $\mathrm{HeP}$ & *** & $\begin{array}{l}\text { Di Giacomo, A., 2005; } \\
\text { Maturo et al., } 2005\end{array}$ \\
\hline Cyperus corymbosus Rottb. & $\mathrm{PzH}$ & $\mathrm{HeP}$ & *** & $\begin{array}{l}\text { Di Giacomo, A., 2005; } \\
\text { Maturo et al., } 2005\end{array}$ \\
\hline Cyperus digitatus Roxb. & $E / L$ & $\mathrm{HeP}$ & $\begin{array}{l}\text { Her: 14/01/1980. Guaglianone, E. R. } \\
\text { 711. (SI) }\end{array}$ & Di Giacomo, A., 2005 \\
\hline Cyperus entrerianus Boeck. & $\mathrm{PzH}$ & $\mathrm{HeP}$ & $* * *$ & Di Giacomo, A., 2005 \\
\hline Cyperus fraternus Kunth & $\mathrm{PzH}$ & $\mathrm{HeP}$ & *** & Di Giacomo, A., 2005 \\
\hline Cyperus giganteus Vahl & $\mathrm{E} / \mathrm{L}$ & $\mathrm{HeP}$ & $* * *$ & $\begin{array}{l}\text { Di Giacomo, A., 2005; } \\
\text { Maturo et al., } 2005\end{array}$ \\
\hline Cyperus reflexus Vahl & $\begin{array}{l}\mathrm{E} / \mathrm{L} \\
\mathrm{PzH}\end{array}$ & $\mathrm{HeP}$ & $\begin{array}{l}\text { Her: 14/01/1980. Guaglianone, E. R. } \\
\text { 710. (SI) }\end{array}$ & \\
\hline $\begin{array}{l}\text { Cyperus rigens J. } \\
\text { Presl \& C. Presl }\end{array}$ & $\mathrm{PzH}$ & $\mathrm{HeP}$ & $* * *$ & $\begin{array}{l}\text { Di Giacomo, A., 2005; } \\
\text { Maturo et al., } 2005\end{array}$ \\
\hline Eleocharis contracta Maury & $\mathrm{PzH}$ & $\mathrm{He}$ & $* * *$ & Di Giacomo, A., 2005 \\
\hline $\begin{array}{l}\text { Eleocharis elegans (Kunth) } \\
\text { Roem. \& Schult. }\end{array}$ & $\mathrm{PzH}$ & $\mathrm{He}$ & $* * *$ & Di Giacomo, A., 2005 \\
\hline $\begin{array}{l}\text { Eleocharis montana } \\
\text { (Kunth) Roem. \& Schult. }\end{array}$ & $E / L$ & $\mathrm{He}$ & $\begin{array}{l}\text { CP: } 20 / 10 / 11 \text {. Contreras, S. A. et al. } 50 . \\
\text { (CTES) }\end{array}$ & \\
\hline Fuirena robusta Kunth & $E / L$ & $\mathrm{HeP}$ & $* * *$ & Di Giacomo, A., 2005 \\
\hline $\begin{array}{l}\text { Oxycarium cubense (Poepp. } \\
\text { ex Kunth) Lye f. Paraguayense } \\
\text { (Maury) Pedersen }\end{array}$ & $E / L$ & $\mathrm{HeP}$ & $\begin{array}{l}\text { Her: 14/01/1980. Guaglianone, E. R. } \\
\text { 718. (SI; NY; K) }\end{array}$ & Di Giacomo, A., 2005 \\
\hline $\begin{array}{l}\text { Rhynchospora corymbosa } \\
\text { (L.) Britton }\end{array}$ & $\begin{array}{l}\text { E/L, } \\
\mathrm{PzH}\end{array}$ & $\mathrm{HeP}$ & $\begin{array}{l}\text { CP: 20/10/11. Contreras, S. A. et al. } 51 . \\
\text { (CTES) }\end{array}$ & \\
\hline Rhynchospora scutellata Griseb. & $\mathrm{PzH}$ & $\mathrm{HeP}$ & $* * *$ & $\begin{array}{l}\text { Di Giacomo, A., 2005; } \\
\text { Maturo et al., } 2005\end{array}$ \\
\hline $\begin{array}{l}\text { Schoenoplectus californicus } \\
\text { (C.A. Meyer) Soják }\end{array}$ & $\mathrm{E} / \mathrm{L}$ & $\mathrm{HeP}$ & $\begin{array}{l}\text { Her: 20/10/1999. Di Giácomo, A. } 426 . \\
\text { (CTES) }\end{array}$ & $\begin{array}{l}\text { Di Giacomo, A., 2005; } \\
\text { Maturo et al., } 2005\end{array}$ \\
\hline
\end{tabular}


Bol. Soc. Argent. Bot. 50 (4) 2015

\begin{tabular}{|c|c|c|c|c|}
\hline Especies & $\begin{array}{l}\text { Unidad } \\
\text { Vegetal }\end{array}$ & Hábito & coleccionista y $\mathbf{N}^{\circ}$ & Bibliografía \\
\hline \multicolumn{5}{|l|}{ Dioscoreaceae } \\
\hline Dioscorea coronata Haum. & S & En & $\begin{array}{l}\text { Her: 30/11/1998. Di Giácomo, A. } 387 . \\
\text { (CTES) }\end{array}$ & Di Giacomo, A., 2005 \\
\hline \multicolumn{5}{|l|}{ Hydrocharitaceae } \\
\hline $\begin{array}{l}\text { Limnobium spongia (Bosc) } \\
\text { Steud. ssp. laevigatum } \\
\text { (H.B.K.) Lowden }\end{array}$ & $E / L$ & $\mathrm{HeA}$ & $\begin{array}{l}\text { Her: 15/03/2003. Di Giácomo, A. } 594 . \\
\text { (CTES) }\end{array}$ & Di Giacomo, A., 2005 \\
\hline \multicolumn{5}{|l|}{ Juncaceae } \\
\hline Juncus densiflorus Kunth & $\mathrm{PzH}$ & $\mathrm{HeP}$ & *** & Di Giacomo, A., 2005 \\
\hline \multicolumn{5}{|l|}{ Marantaceae } \\
\hline Maranta sobolifera L. Andersson & S & $\mathrm{He}$ & $* * *$ & Di Giacomo, A., 2005 \\
\hline Thalia geniculata L. & $E / L$ & $\mathrm{HeP}$ & $\begin{array}{l}\text { Her: 18/04/2000. Di Giácomo, A. } 469 \\
\text { (CTES) }\end{array}$ & $\begin{array}{l}\text { Di Giacomo, A., 2005; } \\
\text { Maturo et al., } 2005\end{array}$ \\
\hline \multicolumn{5}{|l|}{ Orchidaceae } \\
\hline Brassavola tuberculata Hook. & $B, S$ & Ep & $\begin{array}{l}\text { Her: 10/12/1999. Di Giácomo, A. } 441 \\
\text { (CTES) }\end{array}$ & Di Giacomo, A., 2005 \\
\hline $\begin{array}{l}\text { Campylocentrum cfr. Neglectum } \\
\text { (Rchb. F. \& Warm.) Cogn. }\end{array}$ & B & Ep & $* * *$ & Di Giacomo, A., 2005 \\
\hline Cyclopogon elatus (Sw.) Schltr. & $* * * *$ & $\mathrm{He}$ & $* * *$ & Di Giacomo, A., 2005 \\
\hline Oncidium pumilum Lindl. & $\mathrm{S}$ & Ep & $\begin{array}{l}\text { Her: 18/11/1999. Di Giácomo, A. } 436 \\
\text { (CTES) }\end{array}$ & Di Giacomo, A., 2005 \\
\hline Sacoila lanceolata (Aubl.) Garay & $\mathrm{Ar}$ & Ep & $\begin{array}{l}\text { Her: 30/09/1998. Di Giácomo, A. } 404 \\
\text { (CTES) }\end{array}$ & Di Giacomo, A., 2005 \\
\hline \multicolumn{5}{|l|}{ Poaceae } \\
\hline Andropogon bicornis L. & B & $\mathrm{He}$ & $* * *$ & $\begin{array}{l}\text { Di Giacomo, A., 2005; } \\
\text { Zuloaga et al., } 2012\end{array}$ \\
\hline Andropogon lateralis Nees & PzM & $\mathrm{He}$ & $\begin{array}{l}\text { Her: 15/05/2002. Di Giácomo, A. } 567 \\
\text { (CTES) }\end{array}$ & $\begin{array}{l}\text { Di Giacomo, A., 2005; } \\
\text { Maturo et al., 2005; } \\
\text { Molina, 2006; Zuloaga } \\
\text { et al., } 2012\end{array}$ \\
\hline $\begin{array}{l}\text { Andropogon selloanus } \\
\text { (Hack.) Hack. }\end{array}$ & PzM & $\mathrm{He}$ & $* * *$ & $\begin{array}{l}\text { Di Giacomo, A., 2005; } \\
\text { Maturo et al., } 2005\end{array}$ \\
\hline $\begin{array}{l}\text { Anthaenantia lanata } \\
\text { (Kunth) Benth. }\end{array}$ & PzM & $\mathrm{He}$ & $* * *$ & Di Giacomo, A., 2005 \\
\hline $\begin{array}{l}\text { Arundinella hispida } \\
\text { (Willd.) Kuntze }\end{array}$ & PzM & $\mathrm{He}$ & $* * *$ & $\begin{array}{l}\text { Di Giacomo, A., 2005; } \\
\text { Maturo et al., } 2005\end{array}$ \\
\hline $\begin{array}{l}\text { Axonopus fissifolius } \\
\text { (Raddi) Kuhlm. }\end{array}$ & $\mathrm{S}$ & $\mathrm{He}$ & $* * *$ & $\begin{array}{l}\text { Di Giacomo, A., 2005; } \\
\text { Molina, } 2006\end{array}$ \\
\hline $\begin{array}{l}\text { Axonopus suffultus (J.C. } \\
\text { Mikan ex Trin.) Parodi }\end{array}$ & PzM & $\mathrm{He}$ & $* * *$ & $\begin{array}{l}\text { Di Giacomo, A., 2005; } \\
\text { Maturo et al., } 2005\end{array}$ \\
\hline $\begin{array}{l}\text { Bothriochloa exaristata } \\
\text { (Nash) Henrard }\end{array}$ & $\mathrm{PzH}$ & $\mathrm{He}$ & $* * *$ & Di Giacomo, A., 2005 \\
\hline
\end{tabular}




\begin{tabular}{|c|c|c|c|c|}
\hline Especies & $\begin{array}{l}\text { Unidad } \\
\text { Vegetal }\end{array}$ & Hábito & coleccionista y $\mathbf{N}^{\circ}$ & Bibliografía \\
\hline $\begin{array}{l}\text { Briza uniolae (Nees) } \\
\text { Nees ex Steud. }\end{array}$ & PzM & $\mathrm{He}$ & *** & $\begin{array}{l}\text { Di Giacomo, A., 2005; } \\
\text { Maturo et al., } 2005\end{array}$ \\
\hline Cenchrus echinatus L. & **** & $\mathrm{He}$ & $* * *$ & $\begin{array}{l}\text { Di Giacomo, A., 2005; } \\
\text { Molina, } 2006\end{array}$ \\
\hline $\begin{array}{l}\text { Cenchrus nervosum } \\
\text { (Nees) Kuntze }\end{array}$ & $\mathrm{S}$ & $\mathrm{He}$ & $\begin{array}{l}\text { Her: 20/04/1997. Di Giácomo, A. } 160 \\
\text { (CTES) }\end{array}$ & $\begin{array}{l}\text { Di Giacomo, A., 2005; } \\
\text { Zuloaga et al., } 2012\end{array}$ \\
\hline Chloris barbata (L.) SW. & PzM & $\mathrm{He}$ & $* * *$ & Di Giacomo, A., 2005 \\
\hline Chloris canterae Arechav. & $\mathrm{Ar}$ & $\mathrm{He}$ & *** & $\begin{array}{l}\text { Di Giacomo, A., 2005; } \\
\text { Molina, } 2006\end{array}$ \\
\hline Chloris ciliata Sw. & $\mathrm{Ar}$ & $\mathrm{He}$ & $* * *$ & $\begin{array}{l}\text { Di Giacomo, A., } 2005 \text {; } \\
\text { Maturo et al., } 2005\end{array}$ \\
\hline $\begin{array}{l}\text { Chloris halophila var. } \\
\text { Humilis Chr. Müll. }\end{array}$ & $\mathrm{S}$ & $\mathrm{He}$ & *** & $\begin{array}{l}\text { Molina, 2006; Zuloaga } \\
\text { et al, } 2012\end{array}$ \\
\hline Chloris pycnothrix Trin. & $* * * * *$ & $\mathrm{He}$ & $\begin{array}{l}\text { Her: 18/02/2000. Di Giácomo, A. } 468 \\
\text { (CTES) }\end{array}$ & Molina, 2006 \\
\hline $\begin{array}{l}\text { Cynodon dactylon } \\
\text { (L.) var. Dactylon }\end{array}$ & **** & $\mathrm{He}$ & $* * *$ & Molina, 2006 \\
\hline $\begin{array}{l}\text { Deyeuxia viridiflavescens (Poir.) } \\
\text { Kunth Var. montevidensis } \\
\text { (Nees) Cabrera \& Rúgolo }\end{array}$ & **** & $\mathrm{He}$ & $* * *$ & $\begin{array}{l}\text { Di Giacomo, A., 2005; } \\
\text { Molina, } 2006\end{array}$ \\
\hline Digitaria violascens Link & $* * * *$ & $\mathrm{He}$ & $* * *$ & Di Giacomo, A., 2005 \\
\hline Echinochloa colona (L.) Link & $\mathrm{S}$ & $\mathrm{He}$ & $\begin{array}{l}\text { CP: 25/06/11. Contreras, S. A. et al. } 28 . \\
\text { (CTES) }\end{array}$ & \\
\hline $\begin{array}{l}\text { Echinochloa crus-galli (L.) } \\
\text { P. Beauv. var. crus-galli }\end{array}$ & $\mathrm{PzH}$ & $\mathrm{He}$ & $\begin{array}{l}\text { Her: 02/02/2007. Paula Souza, J. } 8154 \\
\text { (ESA; SI; CTES) }\end{array}$ & Di Giacomo, A., 2005 \\
\hline $\begin{array}{l}\text { Echinochloa crus-galli } \\
\text { (L.) P. Beauv. var. mitis } \\
\text { (Pursh) Peterm. }\end{array}$ & $\mathrm{S}$ & $\mathrm{He}$ & $\begin{array}{l}\text { CP: 25/06/11. Contreras, S. A. et al. } 17 . \\
\text { (CTES) }\end{array}$ & \\
\hline Eleusine tristachya (Lam.) Lam. & PzM & $\mathrm{He}$ & *** & $\begin{array}{l}\text { Di Giacomo, A., 2005; } \\
\text { Molina, } 2006\end{array}$ \\
\hline $\begin{array}{l}\text { Elionurus muticus } \\
\text { (Spreng.) Kuntze }\end{array}$ & PzM & $\mathrm{He}$ & Her: 03/1918. Jörgensen, P. 2883 (SI) & $\begin{array}{l}\text { Di Giacomo, A., 2005; } \\
\text { Maturo et al., 2005; } \\
\text { Molina, } 2006\end{array}$ \\
\hline $\begin{array}{l}\text { Eragrostis bahiensis } \\
\text { Schard. Ex Schult. }\end{array}$ & **** & $\mathrm{He}$ & *** & Di Giacomo, A., 2005 \\
\hline Eragrostis lugensNees & $* * * *$ & $\mathrm{He}$ & $* * *$ & Molina, 2006 \\
\hline Erianthus trinii (Hack.) Hack. & PzM & $\mathrm{He}$ & $* * *$ & $\begin{array}{l}\text { Di Giacomo, A., } 2005 \text {; } \\
\text { Maturo et al., } 2005\end{array}$ \\
\hline Eriochloa montevidensis Griseb. & PL & $\mathrm{He}$ & $\begin{array}{l}\text { CP: 25/06/11. Contreras, S. A. et al. } 18 . \\
\text { (CTES) }\end{array}$ & \\
\hline $\begin{array}{l}\text { Eriochloa punctata (L.) } \\
\text { E. Desv ex Ham }\end{array}$ & $\mathrm{PzH}$ & $\mathrm{He}$ & $* * *$ & $\begin{array}{l}\text { Di Giacomo, A., 2005; } \\
\text { Maturo et al., } 2005\end{array}$ \\
\hline
\end{tabular}


Bol. Soc. Argent. Bot. 50 (4) 2015

\begin{tabular}{|c|c|c|c|c|}
\hline Especies & $\begin{array}{l}\text { Unidad } \\
\text { Vegetal }\end{array}$ & Hábito & coleccionista y $\mathbf{N}^{\circ}$ & Bibliografía \\
\hline $\begin{array}{l}\text { Eustachys distichophylla } \\
\text { (Lag.) Nees }\end{array}$ & PzM & $\mathrm{He}$ & $* * *$ & $\begin{array}{l}\text { Di Giacomo, A., 2005; } \\
\text { Maturo et al., 2005; } \\
\text { Molina, } 2006\end{array}$ \\
\hline $\begin{array}{l}\text { Hymenachne amplexicualis } \\
\text { (Rudge) Nees }\end{array}$ & $E / L$ & $\mathrm{He}$ & Her: 03/1918. Jörgensen, P. 2879 (SI) & $\begin{array}{l}\text { Di Giacomo, A., 2005; } \\
\text { Molina, 2006; Zuloaga } \\
\text { et al., } 2012\end{array}$ \\
\hline $\begin{array}{l}\text { Hymenachne pernambucense } \\
\text { (Spreng.) Zuloaga }\end{array}$ & $E / L$ & $\mathrm{He}$ & $* * *$ & $\begin{array}{l}\text { Di Giacomo, A., 2005; } \\
\text { Zuloaga et al., } 2012\end{array}$ \\
\hline Imperata brasiliensis Trin. & PzM & $\mathrm{He}$ & $\begin{array}{l}\text { Her: 10/09/1999. Di Giácomo, A. } 425 \\
\text { (CTES) }\end{array}$ & $\begin{array}{l}\text { Di Giacomo, A., 2005; } \\
\text { Maturo et al., 2005; } \\
\text { Zuloaga et al., } 2012\end{array}$ \\
\hline Lasiacis sp. & S & $\mathrm{He}$ & $\begin{array}{l}\text { CP: 20/12/11. Contreras, S. A. et al. } 79 . \\
\text { (CTES) }\end{array}$ & \\
\hline $\begin{array}{l}\text { Lasiacis sorghoidea (Desv. } \\
\text { ex Ham.) Hitchc. \& Chase }\end{array}$ & S & $\mathrm{He}$ & $\begin{array}{l}\text { Her, CP: 00/1918. Jörgensen, P. } 2875 \\
\text { (SI); 04/09. Contreras, S. A. et al. } 3 . \\
\text { (CTES) }\end{array}$ & $\begin{array}{l}\text { Di Giacomo, A., 2005; } \\
\text { Maturo et al., } 2005\end{array}$ \\
\hline Leersia hexandra Sw. & $\mathrm{PzH}$ & $\mathrm{He}$ & $* * *$ & Di Giacomo, A., 2005 \\
\hline $\begin{array}{l}\text { Leptochloa chloridiformis } \\
\text { (Hack.) Parodi }\end{array}$ & S & $\mathrm{He}$ & $* * *$ & Di Giacomo, A., 2005 \\
\hline Leptochloa virgata (L.) P. Beauv. & B & $\mathrm{He}$ & Her: 03/1918. Jörgensen, P. 2887 (SI) & Molina, 2006 \\
\hline $\begin{array}{l}\text { Oplismenus hirtellus } \\
\text { (L.) P.Beauv. }\end{array}$ & S & $\mathrm{He}$ & $\begin{array}{l}\text { Her, CP: 01/10/1979. Piccinini, B. } 3427 \\
\text { (BAB; SI); 20/12/11. Contreras, S. A. et } \\
\text { al. 89. (CTES) }\end{array}$ & Di Giacomo, A., 2005; \\
\hline Oryza latifolia Desv. & S & $\mathrm{He}$ & $* * *$ & $\begin{array}{l}\text { Di Giacomo, A., 2005; } \\
\text { Maturo et al., 2005; } \\
\text { Molina, } 2006\end{array}$ \\
\hline Panicum bergii Arechav. & PzM & $\mathrm{He}$ & $\begin{array}{l}\text { CP: 25/06/11. Contreras, S. A. et al. } 19 . \\
\text { (CTES) }\end{array}$ & Di Giacomo, A., 2005 \\
\hline Panicum prionitis Nees & $\begin{array}{l}\mathrm{E} / \mathrm{L} \\
\mathrm{PzH}\end{array}$ & $\mathrm{He}$ & $\begin{array}{l}\text { CP: 06/12/12. Contreras, S. A. et al. } \\
\text { 121. (CTES) }\end{array}$ & Di Giacomo, A., 2005; \\
\hline Panicum trichanthum Nees & B & $\mathrm{He}$ & $\begin{array}{l}\text { CP: } 25 / 06 / 11 . \text { Contreras, S. A. et al. } 16 . \\
\text { (CTES) }\end{array}$ & Molina, 2006 \\
\hline $\begin{array}{l}\text { Pappophorum pappiferum } \\
\text { (Lam.) Kuntze }\end{array}$ & $\mathrm{Ar}$ & $\mathrm{He}$ & $* * *$ & Di Giacomo, A., 2005 \\
\hline Paspalum almum Chase & $* * * *$ & $\mathrm{He}$ & $* * *$ & Molina, 2006 \\
\hline $\begin{array}{l}\text { Paspalum buckleyanum } \\
\text { Vasey, Bull. }\end{array}$ & PzM & $\mathrm{He}$ & $* * *$ & Di Giacomo, A., 2005 \\
\hline Paspalum conjugatum Berg. & $S$ & $\mathrm{He}$ & $* * *$ & $\begin{array}{l}\text { Di Giacomo, A., 2005; } \\
\text { Molina, } 2006\end{array}$ \\
\hline Paspalum denticulatum Trin. & $* * * *$ & $\mathrm{He}$ & *** & $\begin{array}{l}\text { Di Giacomo, A., 2005; } \\
\text { Molina, } 2006\end{array}$ \\
\hline Paspalum inaequivalve Raddi & S & $\mathrm{He}$ & $* * *$ & $\begin{array}{l}\text { Di Giacomo, A., 2005; } \\
\text { Molina, } 2006\end{array}$ \\
\hline
\end{tabular}




\begin{tabular}{|c|c|c|c|c|}
\hline Especies & $\begin{array}{l}\text { Unidad } \\
\text { Vegetal }\end{array}$ & Hábito & coleccionista y $\mathbf{N}^{\circ}$ & Bibliografía \\
\hline $\begin{array}{l}\text { Paspalum intermedium } \\
\text { Munro ex Monrong }\end{array}$ & $\mathrm{PzH}$ & $\mathrm{He}$ & $\begin{array}{l}\text { CP: 06/12/12. Contreras, S. A. et al. } 92 . \\
\text { (CTES) }\end{array}$ & $\begin{array}{l}\text { Di Giacomo, A., 2005; } \\
\text { Maturo et al., } 2005\end{array}$ \\
\hline $\begin{array}{l}\text { Paspalum notatum Flüggé } \\
\text { var. latiflorum Döll }\end{array}$ & $\mathrm{PzH}$ & $\mathrm{He}$ & $* * *$ & Di Giacomo, A., 2005 \\
\hline Paspalum plicatulumMichx. & $\mathrm{PzH}$ & $\mathrm{He}$ & $* * *$ & $\begin{array}{l}\text { Di Giacomo, A., 2005; } \\
\text { Molina, } 2006\end{array}$ \\
\hline Paspalum rufum Ness \& Steud. & $\mathrm{PzH}$ & $\mathrm{He}$ & *** & Di Giacomo, A., 2005 \\
\hline Paspalum simplex Morong. & $* * * *$ & $\mathrm{He}$ & $* * *$ & Di Giacomo, A., 2005 \\
\hline $\begin{array}{l}\text { Paspalum stellatum Humb. } \\
\text { \& Bonpl. ex Flüggé }\end{array}$ & $* * * *$ & $\mathrm{He}$ & $* * *$ & $\begin{array}{l}\text { Di Giacomo, A., 2005; } \\
\text { Molina, 2006; Zuloaga } \\
\text { et al., } 2012\end{array}$ \\
\hline Paspalum urvillei Steud. & PzM & $\mathrm{He}$ & $* * *$ & $\begin{array}{l}\text { Di Giacomo, A., 2005; } \\
\text { Molina, } 2006\end{array}$ \\
\hline $\begin{array}{l}\text { Paspalum wrightii } \\
\text { Hitchc. \& Chase }\end{array}$ & PzM & $\mathrm{He}$ & $* * *$ & $\begin{array}{l}\text { Di Giacomo, A., 2005; } \\
\text { Zuloaga et al, } 2012\end{array}$ \\
\hline Pharus lappulaceus Aubl. & S & $\mathrm{He}$ & $\begin{array}{l}\text { CP: 20/12/11. Contreras, S. A. et al. } 85 . \\
\text { (CTES) }\end{array}$ & $\begin{array}{l}\text { Di Giacomo, A., 2005; } \\
\text { Maturo et al., } 2005\end{array}$ \\
\hline $\begin{array}{l}\text { Schizachyrium condensatum } \\
\text { (Kunth) Nees }\end{array}$ & PzM & $\mathrm{He}$ & $* * *$ & $\begin{array}{l}\text { Di Giacomo, A., 2005; } \\
\text { Molina, 2006; Zuloaga } \\
\text { et al, } 2012\end{array}$ \\
\hline $\begin{array}{l}\text { Schizachiryum } \\
\text { glaziovii Peichoto }\end{array}$ & PzM & $\mathrm{He}$ & $* * *$ & $\begin{array}{l}\text { Di Giacomo, A., 2005; } \\
\text { Zuloaga et al, } 2012\end{array}$ \\
\hline $\begin{array}{l}\text { Schizachyrium microstachyum } \\
\text { (Desv. ex Ham.) Roseng; } \\
\text { B. R. Arrill. \& Izag. subsp. } \\
\text { microstachyum }\end{array}$ & $* * * *$ & $\mathrm{He}$ & $\begin{array}{l}\text { Her: 03/02/1996. Di Giácomo, A. } 23 \\
\text { (CTES) }\end{array}$ & Molina, 2006 \\
\hline $\begin{array}{l}\text { Schizachyrium microstachyum } \\
\text { sub sp. elongatum }\end{array}$ & **** & $\mathrm{He}$ & $* * *$ & Di Giacomo, A., 2005 \\
\hline $\begin{array}{l}\text { Schizachiryum spicatum } \\
\text { (Spreng.) Verter }\end{array}$ & PzM & $\mathrm{He}$ & $* * *$ & $\begin{array}{l}\text { Di Giacomo, A., 2005; } \\
\text { Maturo et al., } 2005\end{array}$ \\
\hline Setaria sp. & PL & $\mathrm{He}$ & $\begin{array}{l}\text { CP: 06/12/12. Contreras, S. A. et al. } 115 . \\
\text { (CTES) }\end{array}$ & \\
\hline Setaria fiebrigii R.A.W. Herrm. & S & $\mathrm{He}$ & $\begin{array}{l}\text { Her: 06/10/2011. Aliscioni, S. S. et al. } \\
\text { 851. (BAA) }\end{array}$ & $\begin{array}{l}\text { Di Giacomo, A., 2005; } \\
\text { Maturo et al., 2005; } \\
\text { Molina, 2006; Zuloaga } \\
\text { et al., } 2012\end{array}$ \\
\hline Setaria hassleri Hack. & $S$ & $\mathrm{He}$ & $\begin{array}{l}\text { Her: 02/1918. Jörgensen, P. } 2438 \text { SI; } \\
\text { BA; LIL; MO; US) }\end{array}$ & $\begin{array}{l}\text { Molina, 2006; Zuloaga } \\
\text { et al., } 2012\end{array}$ \\
\hline Setaria lachnea (Nees) Kunth & S & $\mathrm{He}$ & $\begin{array}{l}\text { Her, CP: 03/1918. Jörgensen, P. } 2414 \\
\text { (SI; US); 25/06/11. Contreras, S. A. et al. } \\
\text { 15. (CTES) }\end{array}$ & \\
\hline
\end{tabular}


Bol. Soc. Argent. Bot. 50 (4) 2015

\begin{tabular}{|c|c|c|c|c|}
\hline Especies & $\begin{array}{l}\text { Unidad } \\
\text { Vegetal }\end{array}$ & Hábito & coleccionista y $\mathbf{N}^{\circ}$ & Bibliografía \\
\hline Setaria macrostachya Kunth & **** & $\mathrm{He}$ & *** & $\begin{array}{l}\text { Molina, 2006; Zuloaga } \\
\text { et al., } 2012\end{array}$ \\
\hline Setaria magna Griseb. & $* * * *$ & $\mathrm{He}$ & $\begin{array}{l}\text { Her: 00/03/1918. Jörgensen, P. } 2890 . \\
\text { (SI; LIL; MO; US) }\end{array}$ & $\begin{array}{l}\text { Molina, 2006; Zuloaga } \\
\text { et al., } 2012\end{array}$ \\
\hline $\begin{array}{l}\text { Setaria parvifolia } \\
\text { (Poir.) Kerguélen }\end{array}$ & $S$ & $\mathrm{He}$ & $\begin{array}{l}\text { CP: 25/06/11. Contreras, S. A. et al. } 26 \text {. } \\
\text { (CTES) }\end{array}$ & Maturo et al., 2005 \\
\hline $\begin{array}{l}\text { Setaria parviflora (Poir.) } \\
\text { Kerguélen var. parviflora }\end{array}$ & PzM & $\mathrm{He}$ & $\begin{array}{l}\text { Her: 10/09/1997. Di Giácomo, A. } 262 \\
\text { (CTES) }\end{array}$ & Molina, 2006 \\
\hline $\begin{array}{l}\text { Setaria vulpiseta (Lam.) } \\
\text { Roem. \& Schult. }\end{array}$ & B & $\mathrm{He}$ & $* * *$ & $\begin{array}{l}\text { Di Giacomo, A., 2005; } \\
\text { Molina, } 2006\end{array}$ \\
\hline $\begin{array}{l}\text { Sorghastrum setosum } \\
\text { (Griseb.) Hitchc. }\end{array}$ & $\mathrm{PzH}$ & $\mathrm{He}$ & $* * *$ & $\begin{array}{l}\text { Di Giacomo, A., 2005; } \\
\text { Maturo et al., } 2005\end{array}$ \\
\hline Sporobolus indicus (L.) R.Br. & $* * * *$ & $\mathrm{He}$ & $* * *$ & $\begin{array}{l}\text { Di Giacomo, A., 2005; } \\
\text { Molina, } 2006\end{array}$ \\
\hline $\begin{array}{l}\text { Sporobolus pyramidatus } \\
\text { (Lam.)Hitchc. }\end{array}$ & $\operatorname{Ar}$ & $\mathrm{He}$ & $* * *$ & $\begin{array}{l}\text { Di Giacomo, A., 2005; } \\
\text { Maturo et al., 2005; } \\
\text { Molina, } 2006\end{array}$ \\
\hline Steinchisma hians (Elliott) Nash & $\mathrm{PzH}$ & $\mathrm{He}$ & *** & $\begin{array}{l}\text { Di Giacomo, A., 2005; } \\
\text { Maturo et al., } 2005\end{array}$ \\
\hline Steinchisma laxa (Sw.) Zuloaga & S & $\mathrm{He}$ & $* * *$ & Molina, 2006 \\
\hline $\begin{array}{l}\text { Stephostachys mertensii } \\
\text { Roth Zuloaga \& Morrone }\end{array}$ & S & $\mathrm{He}$ & $* * *$ & $\begin{array}{l}\text { Molina, 2006; Zuloaga } \\
\text { et al., } 2012\end{array}$ \\
\hline Trichloris crinita (Lag.) Parodi & $\mathrm{Ar}$ & $\mathrm{He}$ & $* * *$ & Di Giacomo, A., 2005 \\
\hline $\begin{array}{l}\text { Tridens brasiliensis } \\
\text { Nees. Ex Steud }\end{array}$ & PzM & $\mathrm{He}$ & $* * *$ & Di Giacomo, A., 2005 \\
\hline $\begin{array}{l}\text { Tripogon spicatus } \\
\text { (Nees) Ekman }\end{array}$ & $\operatorname{Ar}$ & $\mathrm{He}$ & $\begin{array}{l}\text { Her: 20/02/2002. Di Giácomo, A. } 558 \\
\text { (CTES) }\end{array}$ & $\begin{array}{l}\text { Di Giacomo, A., 2005; } \\
\text { Maturo et al., } 2005\end{array}$ \\
\hline \multicolumn{5}{|l|}{ Pontederiaceae } \\
\hline Eichhornia azurea Sw. & $E / L$ & $\mathrm{HeA}$ & $\begin{array}{l}\text { Her: 20/05/2002. Di Giácomo, A. } 569 \\
\text { (CTES) }\end{array}$ & Di Giacomo, A., 2005 \\
\hline $\begin{array}{l}\text { Eichhornia crassipes } \\
\text { (Mart.) Solms }\end{array}$ & $E / L$ & $\mathrm{HeA}$ & $\begin{array}{l}\text { Her: 06/04/2003. Di Giácomo, A. } \\
608 \text { (CTES) }\end{array}$ & Di Giacomo, A., 2005 \\
\hline Pontederia cordata L. & $\begin{array}{l}\mathrm{E} / \mathrm{L} \\
\mathrm{PzH}\end{array}$ & $\mathrm{HeA}$ & $\begin{array}{l}\text { Her, CP: 10/05/2002. Di Giácomo, A. } \\
564 \text { (CTES); Contreras, S. A. et al. } 58 . \\
\text { (CTES) }\end{array}$ & $\begin{array}{l}\text { Di Giacomo, A., 2005; } \\
\text { Maturo et al., } 2005\end{array}$ \\
\hline Pontederia rotundifolia L. F. & $E / L$ & $\mathrm{HeA}$ & $* * *$ & Di Giacomo, A., 2005 \\
\hline \multicolumn{5}{|l|}{ Smilacaceae } \\
\hline Smilax campestris Griseb. & $\mathrm{S}$ & En & $\begin{array}{l}\text { Her, CP: 08/10/1999. Di Giácomo, A. } \\
424 \text { (CTES); 20/12/11. Contreras, S. A. } \\
\text { et al. 74. (CTES) }\end{array}$ & Di Giacomo, A., 2005 \\
\hline \multicolumn{5}{|l|}{ Typhaceae } \\
\hline Typha domingensis Pers. & $E / L$ & $\mathrm{HeP}$ & $* * *$ & Di Giacomo, A., 2005 \\
\hline
\end{tabular}




\begin{tabular}{|c|c|c|c|c|}
\hline Especies & $\begin{array}{l}\text { Unidad } \\
\text { Vegetal }\end{array}$ & Hábito & coleccionista y $\mathbf{N}^{\circ}$ & Bibliografía \\
\hline \multicolumn{5}{|l|}{ Dicotyledoneae } \\
\hline \multicolumn{5}{|l|}{ Acanthaceae } \\
\hline Dicliptera tweediana Nees & S & SubArb & $* * *$ & Di Giacomo, A., 2005 \\
\hline Hygrophila guianensis Nees & $\mathrm{PzH}$ & $\mathrm{He}$ & $\begin{array}{l}\text { Her: 20/10/2000. Di Giácomo, A. } 473 . \\
\text { (CTES) }\end{array}$ & Di Giacomo, A., 2005 \\
\hline Justicia brasiliana Roth. & S & Arb & $* * *$ & Di Giacomo, A., 2005 \\
\hline $\begin{array}{l}\text { Justicia laevilinguis } \\
\text { (Nees) Lindau }\end{array}$ & $\mathrm{PzH}$ & $\mathrm{He}$ & $* * *$ & Di Giacomo, A., 2005 \\
\hline Ruellia coerulea Morong & S & $\mathrm{He}$ & $* * *$ & Di Giacomo, A., 2005 \\
\hline Ruellia geminiflora Kunth & $\mathrm{B}, \mathrm{S}$ & $\mathrm{He}$ & $* * *$ & Di Giacomo, A., 2005 \\
\hline Stenandrium dulce (Cav.) Nees & PzM & $\mathrm{He}$ & $\begin{array}{l}\text { Her: 20/11/1999. Di Giácomo, A. } 450 . \\
\text { (CTES) }\end{array}$ & Di Giacomo, A., 2005 \\
\hline \multicolumn{5}{|l|}{ Achatocarpaceae } \\
\hline Achatocarpus praecox Griseb. & $B, S$ & A & $\begin{array}{l}\text { CP: } 20 / 12 / 11 \text {. Contreras, S. A. et al. } 65 . \\
\text { (CTES) }\end{array}$ & $\begin{array}{l}\text { Di Giacomo, A., } 2005 \\
\text { Maturo et al., } 2005\end{array}$ \\
\hline \multicolumn{5}{|l|}{ Amaranthaceae } \\
\hline Alternanthera pungens Kunth & $* * * *$ & $\mathrm{He}$ & $* * *$ & Di Giacomo, A., 2005 \\
\hline Chenopodium cfr. album L. & $* * * * *$ & $\mathrm{He}$ & $* * *$ & Di Giacomo, A., 2005 \\
\hline Chenopodium ambrosioides L. & $* * * * *$ & $\mathrm{He}$ & $\begin{array}{l}\text { Her: 05/06/1999. Di Giácomo, A. } 369 . \\
\text { (CTES) }\end{array}$ & Di Giacomo, A., 2005 \\
\hline Gomphrena perennis L. & $* * * *$ & $\mathrm{He}$ & $\begin{array}{l}\text { Her: 25/09/1998. Di Giácomo, A. } 382 . \\
\text { (CTES) }\end{array}$ & Di Giacomo, A., 2005 \\
\hline Gomphrena pulchella Mart. & $\mathrm{Ar}$ & $\mathrm{He}$ & $* * *$ & Di Giacomo, A., 2005 \\
\hline $\begin{array}{l}\text { Holmbergia tweedii } \\
\text { (Moq.) Speg. }\end{array}$ & B & Arb & $\begin{array}{l}\text { Her: 15/03/2003. Di Giácomo, A. } 593 . \\
\text { (CTES) }\end{array}$ & \\
\hline $\begin{array}{l}\text { Iresine diffusa Humb. } \\
\text { \& Bonpl. ex Willd }\end{array}$ & $E / L$ & SubArb & $* * *$ & Di Giacomo, A., 2005 \\
\hline $\begin{array}{l}\text { Pfaffia glomerata } \\
\text { (Spreng.) Pedersen }\end{array}$ & $\begin{array}{l}\mathrm{PzH} \\
\mathrm{PzM}\end{array}$ & $\mathrm{He}$ & $\begin{array}{l}\text { Her: 18/09/1998. Di Giácomo, A. } 395 . \\
\text { (CTES) }\end{array}$ & Di Giacomo, A., 2005 \\
\hline $\begin{array}{l}\text { Pfaffia tuberosa } \\
\text { (Spreng.) Hicken }\end{array}$ & PzM & $\mathrm{He}$ & $* * *$ & Di Giacomo, A., 2005 \\
\hline \multicolumn{5}{|l|}{ Anacardiaceae } \\
\hline Astronium balansae Engl. & S & A & $\begin{array}{l}\text { Her: 10/12/2001. Di Giácomo, A. } 546 . \\
\text { (CTES) }\end{array}$ & $\begin{array}{l}\text { Di Giacomo, A., } 2005 \text {; } \\
\text { Maturo et al., } 2005\end{array}$ \\
\hline Schinopsis balansae Engl. & B & A & $\begin{array}{l}\text { Her: 06/02/2002. Di Giácomo, A. } 555 . \\
\text { (CTES) }\end{array}$ & $\begin{array}{l}\text { Di Giacomo, A., 2005; } \\
\text { Maturo et al., } 2005\end{array}$ \\
\hline $\begin{array}{l}\text { Schinus fasciculata } \\
\text { (Griseb.) I. M. Johnst. }\end{array}$ & B & A & $* * *$ & $\begin{array}{l}\text { Di Giacomo, A., } 2005 \text {; } \\
\text { Maturo et al., } 2006\end{array}$ \\
\hline \multicolumn{5}{|l|}{ Annonaceae } \\
\hline Rollania emarginata Schltdl. & $S$ & A/Arb & $* * *$ & $\begin{array}{l}\text { Di Giacomo, A., } 2005 \text {; } \\
\text { Maturo et al., } 2005\end{array}$ \\
\hline \multicolumn{5}{|l|}{ Apiaceae } \\
\hline $\begin{array}{l}\text { Cyclospermum leptophyllum } \\
\text { (Pers.) Sprague }\end{array}$ & $* * \star * *$ & $\mathrm{He}$ & $* * *$ & Di Giacomo, A., 2005 \\
\hline
\end{tabular}




\begin{tabular}{|c|c|c|c|c|}
\hline Especies & $\begin{array}{l}\text { Unidad } \\
\text { Vegetal }\end{array}$ & Hábito & coleccionista y $\mathrm{N}^{\circ}$ & Bibliografía \\
\hline Eryngium sp. & $\begin{array}{l}\mathrm{E} / \mathrm{L} \\
\mathrm{PzH}\end{array}$ & $\mathrm{He}$ & $\begin{array}{l}\text { CP: 06/12/12. Contreras, S. A. et al. } 100 . \\
\text { (CTES) }\end{array}$ & \\
\hline $\begin{array}{l}\text { Eryngium coronatum } \\
\text { Hook. \& Arn. }\end{array}$ & $* * * *$ & $\mathrm{He}$ & $\begin{array}{l}\text { Her: 19/11/1996. López, María G. } 124 . \\
\text { (CTES) }\end{array}$ & \\
\hline Eryngium ebracteatum Lam. & $\mathrm{PzH}$ & $\mathrm{He}$ & $* * *$ & Di Giacomo, A., 2005 \\
\hline Eryngium eburneum Done. & $\mathrm{PzH}$ & $\mathrm{He}$ & $\begin{array}{l}\text { Her: 30/11/2001. Di Giácomo, A. } 541 . \\
\text { (CTES) }\end{array}$ & Di Giacomo, A., 2005 \\
\hline $\begin{array}{l}\text { Eryngium elegans } \\
\text { Cham. \& Schltdl. }\end{array}$ & PzM & $\mathrm{He}$ & $* * *$ & Di Giacomo, A., 2005 \\
\hline \multicolumn{5}{|l|}{ Apocynaceae } \\
\hline Asclepias mellodora A. St.-Hill. & PzM & $\mathrm{He}$ & *** & Di Giacomo, A., 2005 \\
\hline $\begin{array}{l}\text { Aspidosperma quebracho- } \\
\text { blanco Schltdl. }\end{array}$ & B & A & $\begin{array}{l}\text { Her: 15/10/2001. Di Giácomo, A. } 536 . \\
\text { (CTES) }\end{array}$ & $\begin{array}{l}\text { Di Giacomo, A., 2005; } \\
\text { Maturo et al., } 2005\end{array}$ \\
\hline $\begin{array}{l}\text { Forsteronia glabrescens } \\
\text { Müll. Arg. }\end{array}$ & $\mathrm{S}$ & En & $\begin{array}{l}\text { Her: 20/10/2001. Di Giácomo, A. } 538 . \\
\text { (CTES) }\end{array}$ & \\
\hline $\begin{array}{l}\text { Funastrum clausum } \\
\text { (Jacq.) Schltr. }\end{array}$ & S & En & Her: 01/10/2012. ${ }^{* * * *}$, 18. (BAA) & Di Giacomo, A., 2005 \\
\hline $\begin{array}{l}\text { Gonolobus rostratus } \\
\text { (Vahl) Roem. \& Schult. }\end{array}$ & S & En & $* * *$ & Di Giacomo, A., 2005 \\
\hline $\begin{array}{l}\text { Macrosiphonia petraea } \\
\text { (A. St. Hil.) K. Schum. }\end{array}$ & PzM & $\mathrm{He}$ & $* * *$ & Di Giacomo, A., 2005 \\
\hline $\begin{array}{l}\text { Mandevilla angustifolia } \\
\text { (Malme) Woodson }\end{array}$ & $E / L$ & En & *** & Di Giacomo, A., 2005 \\
\hline $\begin{array}{l}\text { Metastelma diffusum } \\
\text { (Gillies ex Hook.) Dcne. }\end{array}$ & S & En & $\begin{array}{l}\text { Her: 10/01/2003. Di Giácomo, A. } 585 . \\
\text { (CTES) }\end{array}$ & Di Giacomo, A., 2005 \\
\hline Oxypetalum capitatum Mart. & $\mathrm{PzM}$ & $\mathrm{He}$ & $* * *$ & Di Giacomo, A., 2005 \\
\hline $\begin{array}{l}\text { Oxypetalum crispum } \\
\text { Wight ex Hook \& Arn. }\end{array}$ & PzM & $\mathrm{He}$ & $* * *$ & Di Giacomo, A., 2005 \\
\hline Oxypetalum erianthum Decne. & $S$ & En & $* * *$ & Di Giacomo, A., 2005 \\
\hline $\begin{array}{l}\text { Rhabdadenia ragonesei } \\
\text { Woodson }\end{array}$ & $E / L$ & En & $\begin{array}{l}\text { Her: 11/10/2011. Aliscioni, S. S. } 853 . \\
\text { (BAA) }\end{array}$ & $\begin{array}{l}\text { Di Giacomo, A., 2005; } \\
\text { Maturo et al., } 2005\end{array}$ \\
\hline Rojasia gracilis (Morong) Malme & $S$ & En & $* * *$ & Di Giacomo, A., 2005 \\
\hline Roulinia convolvulacea Decne. & S & En & $\begin{array}{l}\text { Her: 06/05/2005. Deginani, N. B. } 1990 . \\
\text { (SI) }\end{array}$ & \\
\hline $\begin{array}{l}\text { Schubertia grandiflora } \\
\text { Mart. Ex Zucc. }\end{array}$ & $S$ & En & $* * *$ & Di Giacomo, A., 2005 \\
\hline $\begin{array}{l}\text { Tabernaemontana } \\
\text { catharinensis A. DC. }\end{array}$ & $S$ & A & $\begin{array}{l}\text { Her, CP: } 17 / 12 / 1998 \text {. Di Giácomo, A. } \\
\text { 388. (CTES), 04/09 Contreras, S. A. et } \\
\text { al. 4. (CTES) }\end{array}$ & \\
\hline $\begin{array}{l}\text { Telminostelma foetidum (Cav.) } \\
\text { Fontella \& E. A. Schwarz }\end{array}$ & $* * * *$ & En & $* * *$ & Di Giacomo, A., 2005 \\
\hline \multicolumn{5}{|l|}{ Araliaceae } \\
\hline $\begin{array}{l}\text { Hydrocotyle leucocephala } \\
\text { Cham. \& Schltdl. }\end{array}$ & S & $\mathrm{He}$ & $* * *$ & Di Giacomo, A., 2005 \\
\hline Hydrocotyle ranunculoides L.f. & S & $\mathrm{He}$ & $\begin{array}{l}\text { Her: 25/10/2002. Di Giácomo, A. } 580 \\
\text { (CTES) }\end{array}$ & Di Giacomo, A., 2005 \\
\hline \multicolumn{5}{|l|}{ Aristolochiaceae } \\
\hline Aristolochia fimbriata Cham. & $* \star * *$ & En & $\begin{array}{l}\text { Her: **/03/1918. Jörgensen, P. } 2340 . \\
\text { (SI-035389) }\end{array}$ & \\
\hline
\end{tabular}




\begin{tabular}{|c|c|c|c|c|}
\hline Especies & $\begin{array}{l}\text { Unidad } \\
\text { Vegetal }\end{array}$ & Hábito & coleccionista y $\mathbf{N}^{\circ}$ & Bibliografía \\
\hline \multicolumn{5}{|l|}{ Asteraceae } \\
\hline Achyrocline alata (Kunth) DC. & PzM & SubArb & $* * *$ & Di Giacomo, A., 2005 \\
\hline $\begin{array}{l}\text { Acmella decumbens } \\
\text { (Sm.) Jansen }\end{array}$ & PzM & $\mathrm{He}$ & $* * *$ & $\begin{array}{l}\text { Di Giacomo, A., 2005; } \\
\text { Maturo et al., } 2005\end{array}$ \\
\hline Ambrosia elatior L. & S & $\mathrm{He}$ & $\begin{array}{l}\text { Her: 15/12/1967. Piccinini, B. } 1154 . \\
\text { (BAB) }\end{array}$ & Di Giacomo, A., 2005 \\
\hline $\begin{array}{l}\text { Aspilia montevidensis } \\
\text { (Spreng.) Kuntze. }\end{array}$ & PzM & $\mathrm{He}$ & $* * *$ & Di Giacomo, A., 2005 \\
\hline Aspilia pascalioides Griseb. & PzM & $\mathrm{He}$ & $\begin{array}{l}\text { Her: 25/11/2003. Di Giácomo, A. } 611 . \\
\text { (CTES) }\end{array}$ & $\begin{array}{l}\text { Di Giacomo, A., 2005; } \\
\text { Maturo et al., } 2005\end{array}$ \\
\hline $\begin{array}{l}\text { Aspilia silphioides (Hook. } \\
\text { \& Arn.) Benth. \& Hook. }\end{array}$ & PzM & $\mathrm{He}$ & $\begin{array}{l}\text { Her: 12/01/2000. Di Giácomo, A. } 456 . \\
\text { (CTES) }\end{array}$ & Di Giacomo, A., 2005 \\
\hline $\begin{array}{l}\text { Aster squamatus } \\
\text { (Spreng.) Hieron. }\end{array}$ & PzM & $\mathrm{He}$ & $* * *$ & Di Giacomo, A., 2005 \\
\hline $\begin{array}{l}\text { Baccharidastrum triplinervium } \\
\text { (Lees.) Cabrera }\end{array}$ & **** & SubArb & *** & Di Giacomo, A., 2005 \\
\hline Baccharis af. Caprariifolia DC. & PzM & $\mathrm{He}$ & $* * *$ & Di Giacomo, A., 2005 \\
\hline Baccharis coridifolia DC. & PzM & $\mathrm{He}$ & $* * *$ & Di Giacomo, A., 2005 \\
\hline Baccharis dracunculifolia DC. & S, PzM & Arb & $\begin{array}{l}\text { Her: 05/03/2003. Di Giácomo, A. } 597 . \\
\text { (CTES) }\end{array}$ & Di Giacomo, A., 2005 \\
\hline Baccharis flexuosa Baker & $\mathrm{B}, \mathrm{PzM}$ & $\mathrm{He}$ & $\begin{array}{l}\text { Her: 30/11/2003. Di Giácomo, A. } 612 . \\
\text { (CTES) }\end{array}$ & Di Giacomo, A., 2005 \\
\hline Baccharis medullosa DC. & $\mathrm{PzH}$ & $\mathrm{He}$ & $\begin{array}{l}\text { Her: 20/03/1998. Di Giácomo, A. } 322 . \\
\text { (CTES) }\end{array}$ & Di Giacomo, A., 2005 \\
\hline $\begin{array}{l}\text { Baccharis microcephala } \\
\text { (Less.) DC. }\end{array}$ & PzM & Arb & $* * *$ & Di Giacomo, A., 2005 \\
\hline Baccharis notosergila Griseb. & $\mathrm{PzH}$ & $\mathrm{He}$ & $* * *$ & Di Giacomo, A., 2005 \\
\hline Baccharis pingraea DC. & PzM & $\mathrm{He}$ & $\begin{array}{l}\text { Her: 20/12/1998. Di Giácomo, A. } 310 \\
\text { (CTES) }\end{array}$ & Di Giacomo, A., 2005 \\
\hline Baccharis punctulata DC. & PzM & Arb & $* * *$ & Di Giacomo, A., 2005 \\
\hline Baccharis rhexioides H.B.K. & $B, S$ & Arb & $\begin{array}{l}\text { Her: 10/07/1999. Di Giácomo, A. } 409 \\
\text { (CTES) }\end{array}$ & Di Giacomo, A., 2005 \\
\hline Baccharis rufescens Sprengel & PzM & Arb & $\begin{array}{l}\text { Her: 20/12/1998. Di Giácomo, A. } 309 \\
\text { (CTES) }\end{array}$ & Di Giacomo, A., 2005 \\
\hline $\begin{array}{l}\text { Baccharis salicifolia } \\
\text { (Ruiz \& Pav.) Pers. }\end{array}$ & $\mathrm{PzM}, \mathrm{Ar}$ & Arb & $\begin{array}{l}\text { Her: 10/03/2003. Di Giácomo, A. } 600 \\
\text { (CTES) }\end{array}$ & $\begin{array}{l}\text { Di Giacomo, A., 2005; } \\
\text { Maturo et al., } 2005\end{array}$ \\
\hline Baccharis spicata (Lam.) Baill. & PzM & SubArb & $\begin{array}{l}\text { Her: 15/03/2003. Di Giácomo, A. } 603 \\
\text { (CTES) }\end{array}$ & $\begin{array}{l}\text { Di Giacomo, A., 2005; } \\
\text { Maturo et al., } 2006\end{array}$ \\
\hline Baccharis tridentata Vahl & PzM & Arb & $\begin{array}{l}\text { Her: 10/03/2003. Di Giácomo, A. } 601 \\
\text { (CTES) }\end{array}$ & $\begin{array}{l}\text { Di Giacomo, A., } 2005 ; \\
\text { Maturo et al., } 2006\end{array}$ \\
\hline Baccharis trinervis (Lam.) Pers. & B & Arb & $\begin{array}{l}\text { Her: 20/11/1998. Di Giácomo, A. } 320 \\
\text { (CTES) }\end{array}$ & Di Giacomo, A., 2005 \\
\hline Bidens pilosa L. & $* \star \star \star *$ & $\mathrm{He}$ & $* * *$ & Di Giacomo, A., 2005 \\
\hline Calea cymosa Less. & PzM & $\mathrm{He}$ & $\begin{array}{l}\text { Her: 23/11/1998. Di Giácomo, A. } 401 \\
\text { (CTES) }\end{array}$ & $\begin{array}{l}\text { Di Giacomo, A., 2005; } \\
\text { Maturo et al., } 2005\end{array}$ \\
\hline
\end{tabular}




\begin{tabular}{|c|c|c|c|c|}
\hline Especies & $\begin{array}{l}\text { Unidad } \\
\text { Vegetal }\end{array}$ & Hábito & coleccionista y $\mathbf{N}^{\circ}$ & Bibliografía \\
\hline $\begin{array}{l}\text { Centaurea tweediei } \\
\text { Hook. \& Arn. }\end{array}$ & PzM & $\mathrm{He}$ & $* * *$ & Di Giacomo, A., 2005 \\
\hline Chaptalia nutans (L.) Pol. & S & $\mathrm{He}$ & *** & Di Giacomo, A., 2005 \\
\hline Conyza bonariensis (L.) Cronq. & $* * * *$ & $\mathrm{He}$ & $* * *$ & Di Giacomo, A., 2005 \\
\hline Conyza chilensis Spreng. & $\mathrm{PzH}$ & $\mathrm{He}$ & $\begin{array}{l}\text { Her: **/03/1918. Jorgensen, P. } 2917 \\
\text { (SI) }\end{array}$ & Di Giacomo, A., 2005 \\
\hline Cyclolepis genistoides Don & $\mathrm{Ar}$ & Arb & $\begin{array}{l}\text { Her: 28/09/2003. Di Giácomo, A. } 613 \\
\text { (CTES) }\end{array}$ & Di Giacomo, A., 2005 \\
\hline Eclipta prostrata (L.) L. & $\begin{array}{l}\mathrm{E} / \mathrm{L} \\
\mathrm{PzH}\end{array}$ & $\mathrm{He}$ & $\begin{array}{l}\text { Her: 10/12/2001. Di Giácomo, A. } 548 \\
\text { (CTES) }\end{array}$ & Di Giacomo, A., 2005 \\
\hline Egletes viscosa (L.) Less. & S & $\mathrm{He}$ & $\begin{array}{l}\text { Her: 15/12/1967. Piccinini, B. } 1156 \\
\text { (BAB) }\end{array}$ & \\
\hline $\begin{array}{l}\text { Erechtites hieracifolia (L.) } \\
\text { Raf. ex DC. Var. Cacalioides } \\
\text { (Fisch. ex Spreng.) Griseb. }\end{array}$ & $* * * *$ & $\mathrm{He}$ & $* * *$ & Di Giacomo, A., 2005 \\
\hline Erigeron tweediei Hook. \& Arn. & PzM & $\mathrm{He}$ & $\begin{array}{l}\text { Her: 10/12/2003. Di Giácomo, A. } 614 \\
\text { (CTES) }\end{array}$ & Di Giacomo, A., 2005 \\
\hline Eupatorium arnottianum Griseb. & $* * * *$ & SubArb & $* * *$ & Di Giacomo, A., 2005 \\
\hline $\begin{array}{l}\text { Eupatorium candolleanum } \\
\text { Hook. \& Arn., p.p }\end{array}$ & $\mathrm{PzH}$ & $\mathrm{He}$ & $* * *$ & $\begin{array}{l}\text { Di Giacomo, A., 2005; } \\
\text { Maturo et al., } 2005\end{array}$ \\
\hline $\begin{array}{l}\text { Eupatorium clematideum } \\
\text { Griseb. }\end{array}$ & $* * * *$ & $\mathrm{He}$ & $* * *$ & Di Giacomo, A., 2005 \\
\hline $\begin{array}{l}\text { Eupatorium hecatanthum } \\
\text { (DC.) Baker }\end{array}$ & S & $\mathrm{He}$ & $* * *$ & Di Giacomo, A., 2005 \\
\hline Eupatorium inulifolium Kunth & PzM & Arb & $\begin{array}{l}\text { Her: }{ }^{* *} / 03 / 1918 . \text { Jorgensen, P. } 2911 \\
\text { (SI-19691; SI-19692) }\end{array}$ & $\begin{array}{l}\text { Di Giacomo, A., 2005; } \\
\text { Maturo et al., } 2006\end{array}$ \\
\hline Eupatorium ivifolium L. & $\mathrm{B}, \mathrm{PzM}$ & SubArb & $\begin{array}{l}\text { Her: **/03/1918. Jorgensen, P. } 2907 \\
\text { (SI-19466) }\end{array}$ & Di Giacomo, A., 2005 \\
\hline Eupatorium laevigatum Lam. & $\begin{array}{l}\text { E/L, } \\
\text { PzM }\end{array}$ & Arb & $\begin{array}{l}\text { Her: }{ }^{* *} / 03 / 1918 . \text { Jorgensen, P. } 2909 \\
\text { (SI-19457; -19456) }\end{array}$ & Di Giacomo, A., 2005 \\
\hline $\begin{array}{l}\text { Eupatorium lanigerum } \\
\text { Hook. \& Arn. }\end{array}$ & PzM & $\mathrm{He}$ & $\begin{array}{l}\text { Her: 00/1915. Jorgensen, P. } 2763 \text { (SI- } \\
\text { 19574) }\end{array}$ & Di Giacomo, A., 2005 \\
\hline $\begin{array}{l}\text { Eupatorium } \\
\text { macrocephalum Less. }\end{array}$ & PzM & $\mathrm{He}$ & $* * *$ & Di Giacomo, A., 2005 \\
\hline Eupatorium megaphyllum Baker & $S$ & $\begin{array}{c}\mathrm{He} / \\
\text { SubArb }\end{array}$ & $* * *$ & Di Giacomo, A., 2005 \\
\hline Eupatorium militare B. L. Rob. & $* * * *$ & $\mathrm{He}$ & $* * *$ & Di Giacomo, A., 2005 \\
\hline $\begin{array}{l}\text { Eupatorium oblongifolium } \\
\text { (Spreng.) Baker }\end{array}$ & $\mathrm{PzH}$ & $\mathrm{He}$ & $\begin{array}{l}\text { CP: 06/12/12. Contreras, S. A. et al. } 126 . \\
\text { (CTES) }\end{array}$ & \\
\hline Eupatorium polystachyum DC. & PzM & Arb & $\begin{array}{l}\text { Her: 05/03/2003. Di Giácomo, A. } 599 \\
\text { (CTES) }\end{array}$ & Di Giacomo, A., 2005 \\
\hline Eupatorium verbenaceum DC. & B & Arb & $\begin{array}{l}\text { Her: **/03/1918. Jörgensen, P. } 2908 \\
\text { (LIL; LP; SI-020332; SI-020333) }\end{array}$ & \\
\hline Flaveria bidentis (L.) Kuntze & $* * * *$ & $\mathrm{He}$ & *** & Di Giacomo, A., 2005 \\
\hline $\begin{array}{l}\text { Gamochaeta cfr. calviceps } \\
\text { (Fernald) Cabrera }\end{array}$ & PzM & $\mathrm{He}$ & $\begin{array}{l}\text { Her: 10/09/2001. Di Giácomo, A. } 518 . \\
\text { (CTES) }\end{array}$ & $\begin{array}{l}\text { Di Giacomo, A., 2005; } \\
\text { Maturo et al., } 2005\end{array}$ \\
\hline $\begin{array}{l}\text { Gymnocoronis spilanthoides } \\
\text { (Hook. \& Arn.) DC. var. } \\
\text { subcordata (DC.) Baker }\end{array}$ & $\mathrm{PzH}$ & $\mathrm{He}$ & $\begin{array}{l}\text { Her: 14/01/1980. Guaglianone, E. R. } \\
714 \text { (SI-025642) }\end{array}$ & Di Giacomo, A., 2005 \\
\hline
\end{tabular}




\begin{tabular}{|c|c|c|c|c|}
\hline Especies & $\begin{array}{l}\text { Unidad } \\
\text { Vegetal }\end{array}$ & Hábito & coleccionista y $\mathrm{N}^{\circ}$ & Bibliografía \\
\hline $\begin{array}{l}\text { Holocheilus hieracioides } \\
\text { (D. Don) Cabrera }\end{array}$ & PzM & $\mathrm{He}$ & *** & Di Giacomo, A., 2005 \\
\hline $\begin{array}{l}\text { Micropsis dasycarpa } \\
\text { (Griseb.) Beauv. }\end{array}$ & S & $\mathrm{He}$ & $\begin{array}{l}\text { Her: 10/09/2001. Di Giácomo, A. } 516 \\
\text { (CTES) }\end{array}$ & Di Giacomo, A., 2005 \\
\hline Mikania cordifolia (L. f.) Willd. & S & En & $* * *$ & Di Giacomo, A., 2005 \\
\hline Mikania micrantha H.B.K. & PzM & En & $\begin{array}{l}\text { Her: 10/03/2003. Di Giácomo, A. } 602 \\
\text { (CTES) }\end{array}$ & Di Giacomo, A., 2005 \\
\hline Mikania thapsoides DC. & S & SubArb & $\begin{array}{l}\text { Her: }{ }^{* *} / 03 / 1918 . \text { Jörgensen, P. } 2730 \\
(\text { SI-029084) }\end{array}$ & Di Giacomo, A., 2005 \\
\hline Mikania variifolia Hieron. & S & En & $* * *$ & Di Giacomo, A., 2005 \\
\hline $\begin{array}{l}\text { Noticastrum acuminatum } \\
\text { (DC.) Cuatrec. }\end{array}$ & PzM & $\mathrm{He}$ & $\begin{array}{l}\text { Her: }{ }^{*} / 02 / 1918 . \text { Jörgensen, P. } 2925 \\
\text { (SI-038881) }\end{array}$ & \\
\hline $\begin{array}{l}\text { Orthopappus angustifolius } \\
\text { (Sw.) Gleason }\end{array}$ & PzM & $\mathrm{He}$ & $* * *$ & Di Giacomo, A., 2005 \\
\hline Picrosia longifolia D. Don & $* * * *$ & $\mathrm{He}$ & $\begin{array}{l}\text { Her: }{ }^{*} / 03 / 1918 \text {. Jörgensen, P. } 2913 \\
(\text { SI-039460) }\end{array}$ & \\
\hline Pluchea sagittalis (Lam.) Cabr. & PzM & $\mathrm{He}$ & $\begin{array}{l}\text { Her: 15/11/1998. Di Giácomo, A. } 298 \\
\text { (CTES) }\end{array}$ & Di Giacomo, A., 2005 \\
\hline $\begin{array}{l}\text { Porophyllum ruderale } \\
\text { (Jacq.) Cass. }\end{array}$ & PzM & $\mathrm{He}$ & $\begin{array}{l}\text { Her: }{ }^{* *} / 03 / 1918 . \text { Jörgensen, P. } 2915 \\
(\text { (SI-039715) }\end{array}$ & Di Giacomo, A., 2005 \\
\hline $\begin{array}{l}\text { Pseudogynoxys cabrerae } \\
\text { H. Rob. \& Cuatrec. }\end{array}$ & S & SubArb & $* * *$ & Di Giacomo, A., 2005 \\
\hline $\begin{array}{l}\text { Pterocaulon alopecuroides } \\
\text { (Lam.) DC. }\end{array}$ & PzM & $\mathrm{He}$ & *** & Di Giacomo, A., 2005 \\
\hline Pterocaulon polystachyum DC. & PzM & $\mathrm{He}$ & *** & Di Giacomo, A., 2005 \\
\hline Pterocaulon virgatum (L.) DC. & PzM & $\mathrm{He}$ & *** & Di Giacomo, A., 2005 \\
\hline Senecio grisebachii Baker & **** & $\mathrm{He}$ & *** & Di Giacomo, A., 2005 \\
\hline Senecio pinnatus Poir. & $\operatorname{Ar}$ & $\mathrm{He}$ & *** & Di Giacomo, A., 2005 \\
\hline $\begin{array}{l}\text { Solidago chilensis Meyen var. } \\
\text { megapotamica (DC.) Cabrera }\end{array}$ & PzM & $\mathrm{He}$ & *** & Di Giacomo, A., 2005 \\
\hline Spilanthes stolonifera DC. & $* * * *$ & $\mathrm{He}$ & $\begin{array}{l}\text { Her: **/01/1918. Jörgensen, P. } 2920 \\
(\mathrm{SI}-050804)\end{array}$ & \\
\hline Stevia entreriensis Hieron. & PzM & $\mathrm{He}$ & $* * *$ & Di Giacomo, A., 2005 \\
\hline $\begin{array}{l}\text { Tessaria dodoneifolia } \\
\text { (Hook. \& Arn.) Cabrera }\end{array}$ & $\operatorname{Ar}$ & Arb & $\begin{array}{l}\text { Her: 12/12/2003. Di Giácomo, A. } 615 \\
\text { (CTES) }\end{array}$ & $\begin{array}{l}\text { Di Giacomo, A., 2005; } \\
\text { Maturo et al., } 2005\end{array}$ \\
\hline $\begin{array}{l}\text { Tessaria integrifolia Ruiz \& Pav. } \\
\text { var. ambigua (DC.) S. E. Freire }\end{array}$ & $* * * *$ & A & *** & Di Giacomo, A., 2005 \\
\hline Trixis pallida Less. & PzM & SubArb & $\begin{array}{l}\text { Her: 30/10/1999. Di Giácomo, A. } 427 \\
\text { (CTES) }\end{array}$ & Di Giacomo, A., 2005 \\
\hline Verbesina subcordata DC. & PzM & SubArb & $\begin{array}{l}\text { Her: 16/01/2000. Di Giácomo, A. } 460 \\
\text { (CTES) }\end{array}$ & Di Giacomo, A., 2005 \\
\hline Vernonia cognata Less. & PzM & SubArb & $* * *$ & Di Giacomo, A., 2005 \\
\hline Vernonia chamaedrys Less. & PzM & SubArb & *** & $\begin{array}{l}\text { Di Giacomo, A., 2005; } \\
\text { Maturo et al., } 2005\end{array}$ \\
\hline Vernonia flexuosa Sims & PzM & SubArb & *** & Di Giacomo, A., 2005 \\
\hline Vernonia incana Less. & $\mathrm{PzH}$ & $\mathrm{He}$ & *** & $\begin{array}{l}\text { Di Giacomo, A., 2005; } \\
\text { Maturo et al., } 2005\end{array}$ \\
\hline
\end{tabular}


Bol. Soc. Argent. Bot. 50 (4) 2015

\begin{tabular}{|c|c|c|c|c|}
\hline Especies & $\begin{array}{l}\text { Unidad } \\
\text { Vegetal }\end{array}$ & Hábito & coleccionista y $\mathbf{N}^{\circ}$ & Bibliografía \\
\hline Vernonia nitidula Less. & PzM & Arb & $* * *$ & Di Giacomo, A., 2005 \\
\hline $\begin{array}{l}\text { Vernonia scorpioides } \\
\text { (Lam.) Pers. }\end{array}$ & S & Arb & $* * *$ & Di Giacomo, A., 2005 \\
\hline Xanthium spinosum $\mathrm{L}$. & $* * * *$ & $\mathrm{He}$ & $\begin{array}{l}\text { Her: 30/09/1998. Di Giácomo, A. } 405 \\
\text { (CTES) }\end{array}$ & Di Giacomo, A., 2005 \\
\hline $\begin{array}{l}\text { Zexmenia arnottii } \\
\text { (Baker) Hassl. }\end{array}$ & PzM & SubArb & $* * *$ & Maturo et al., 2005 \\
\hline \multicolumn{5}{|l|}{ Begoniaceae } \\
\hline Begonia cucullata Willd. & S & $\mathrm{He}$ & $* * *$ & Di Giacomo, A., 2005 \\
\hline \multicolumn{5}{|l|}{ Bignoniaceae } \\
\hline $\begin{array}{l}\text { Arrabidaea corallina } \\
\text { (Jacq.) Sandw. }\end{array}$ & $\mathrm{B}, \mathrm{S}$ & En & $\begin{array}{l}\text { Her: 15/09/1999. Di Giácomo, A. } 428 \\
\text { (CTES) }\end{array}$ & $\begin{array}{l}\text { Di Giacomo, A., } 2005 ; \\
\text { Maturo et al., } 2005\end{array}$ \\
\hline $\begin{array}{l}\text { Dolichandra } \\
\text { cynanchoides Cham. }\end{array}$ & S & En & *** & $\begin{array}{l}\text { Di Giacomo, A., } 2005 ; \\
\text { Maturo et al., } 2005\end{array}$ \\
\hline $\begin{array}{l}\text { Macfadyena unguis- } \\
\text { cati (L.) A. H. Gentry }\end{array}$ & $\mathrm{S}$ & En & $* * *$ & $\begin{array}{l}\text { Di Giacomo, A., } 2005 ; \\
\text { Maturo et al., } 2005\end{array}$ \\
\hline $\begin{array}{l}\text { Pithecoctenium } \\
\text { cynanchoides DC. }\end{array}$ & $\mathrm{S}$ & En & $\begin{array}{l}\text { CP: 20/10/11. Contreras, S. A. et al. } 48 . \\
\text { (CTES) }\end{array}$ & Di Giacomo, A., 2005 \\
\hline $\begin{array}{l}\text { Tabebuia aurea (Silva Manso) } \\
\text { Benth. \& Hook. f. ex S. Moore }\end{array}$ & PzM & A & $* * *$ & Di Giacomo, A., 2005 \\
\hline $\begin{array}{l}\text { Tabebuia heptaphylla } \\
\text { (Vell.) Toledo }\end{array}$ & S & A & $* * *$ & Di Giacomo, A., 2005 \\
\hline $\begin{array}{l}\text { Tabebuia nodosa } \\
\text { (Griseb.) Griseb. }\end{array}$ & B & A & $* * *$ & $\begin{array}{l}\text { Di Giacomo, A., } 2005 \text {; } \\
\text { Maturo et al., } 2005\end{array}$ \\
\hline \multicolumn{5}{|l|}{ Boraginaceae } \\
\hline $\begin{array}{l}\text { Cordia americana (L.) } \\
\text { Gottschling \& J.S. Mill. }\end{array}$ & S & A & $\begin{array}{l}\text { Her, CP: 18/06/11 Contreras, S. et al. 32; } \\
\text { 30/09/2001. Di Giácomo, A. } 525 \text { (CTES) }\end{array}$ & $\begin{array}{l}\text { Di Giacomo, A., } 2005 ; \\
\text { Maturo et al., } 2005\end{array}$ \\
\hline $\begin{array}{l}\text { Heliotropium curassavicum L. } \\
\text { var. argentinum I.M. Johnst. }\end{array}$ & $\mathrm{Ar}$ & $\mathrm{He}$ & $\begin{array}{l}\text { Her: 27/01/1970. Hunziker, A. T. } 20236 \\
\text { (CORD) }\end{array}$ & \\
\hline $\begin{array}{l}\text { Heliotropium leiocarpum } \\
\text { Morong. }\end{array}$ & S & SubArb & $* * *$ & Di Giacomo, A., 2005 \\
\hline Heliotropium indicum L. & $* * * * *$ & SubArb & $\begin{array}{l}\text { Her: 15/06/1999. Di Giácomo, A. } 406 \\
\text { (CTES) }\end{array}$ & Di Giacomo, A., 2005 \\
\hline Heliotropium procumbens Mill. & $\mathrm{S}, \mathrm{Ar}$ & $\mathrm{He}$ & $\begin{array}{l}\text { Her: 20/02/2002. Di Giácomo, A. } 557 \\
\text { (CTES) }\end{array}$ & $\begin{array}{l}\text { Di Giacomo, A., } 2005 ; \\
\text { Maturo et al., } 2005\end{array}$ \\
\hline $\begin{array}{l}\text { Tournefortia rubicunda } \\
\text { Salzm. ex DC. }\end{array}$ & S & Arb & $* * *$ & Di Giacomo, A., 2005 \\
\hline Tournefortia salzmannii DC. & S & Arb & $* * *$ & Di Giacomo, A., 2005 \\
\hline \multicolumn{5}{|l|}{ Brassicaceae } \\
\hline Capparis flexuosa L. & S & A/Arb & $* * *$ & $\begin{array}{l}\text { Di Giacomo, A., } 2005 ; \\
\text { Maturo et al., } 2005\end{array}$ \\
\hline Capparis retusa Griseb. & B & A/Arb & $* * *$ & $\begin{array}{l}\text { Di Giacomo, A., } 2005 \text {; } \\
\text { Maturo et al., } 2005\end{array}$ \\
\hline
\end{tabular}




\begin{tabular}{|c|c|c|c|c|}
\hline Especies & $\begin{array}{l}\text { Unidad } \\
\text { Vegetal }\end{array}$ & Hábito & coleccionista y $\mathbf{N}^{\circ}$ & Bibliografía \\
\hline Capparis tweediana Eichler & $B, S$ & A/Arb & $\begin{array}{l}\text { CP: 18/10/11. Contreras, S. A. et al. } 34 \text {. } \\
\text { (CTES) }\end{array}$ & $\begin{array}{l}\text { Di Giacomo, A., 2005; } \\
\text { Maturo et al., } 2005\end{array}$ \\
\hline Cleome cfr. serrata Jacq. & $S$ & $\mathrm{He}$ & $* * *$ & Di Giacomo, A., 2005 \\
\hline Cleome trachycarpa Klotchtz & S & $\mathrm{He}$ & $\begin{array}{l}\text { Her: 05/02/2002. Di Giácomo, A. } 552 \\
\text { (CTES) }\end{array}$ & Di Giacomo, A., 2005 \\
\hline Lepidium aletes J. F. Macbr. & $* * * * *$ & $\mathrm{He}$ & $* * *$ & Di Giacomo, A., 2005 \\
\hline $\begin{array}{l}\text { Lepidium gracile (Chodat } \\
\text { \& Hassl.) Boelcke }\end{array}$ & ***** & $\mathrm{He}$ & $\begin{array}{l}\text { Her: 15/11/1998. Di Giácomo, A. } 358 \\
\text { (CTES) }\end{array}$ & \\
\hline \multicolumn{5}{|l|}{ Cactaceae } \\
\hline $\begin{array}{l}\text { Brasiliopuntia schulzii (A. } \\
\text { Cast. \& Lelong) Backeb. }\end{array}$ & $B, S$ & Arb & $\begin{array}{l}\text { Her: 22/07/1999. Di Giácomo, A. } 411 \\
\text { (CTES) }\end{array}$ & $\begin{array}{l}\text { Di Giacomo, A., 2005; } \\
\text { Maturo et al., } 2005\end{array}$ \\
\hline $\begin{array}{l}\text { Cereus forbesii Otto } \\
\text { ex C.F. Forst. }\end{array}$ & $\operatorname{Ar}$ & Arb & $\begin{array}{l}\text { Her: 10/12/1999. Di Giácomo, A. } 438 \\
\text { (CTES) }\end{array}$ & \\
\hline Cereus stenogonus K. Schum. & B & SubArb & $* * *$ & $\begin{array}{l}\text { Di Giacomo, A., } 2005 \text {; } \\
\text { Maturo et al., } 2005\end{array}$ \\
\hline $\begin{array}{l}\text { Cleistocactus baumannii } \\
\text { (Lem.) Lem. }\end{array}$ & $\mathrm{Ar}$ & $\mathrm{He}$ & $\begin{array}{l}\text { Her: 18/11/1999. Di Giácomo, A. } 432 \\
\text { (CTES) }\end{array}$ & $\begin{array}{l}\text { Di Giacomo, A., 2005; } \\
\text { Maturo et al., } 2005\end{array}$ \\
\hline $\begin{array}{l}\text { Echinopsis rhodotricha } \\
\text { K. Schum. }\end{array}$ & $\mathrm{Ar}$ & SubArb & $\begin{array}{l}\text { Her: 18/11/1999. Di Giácomo, A. } 433 \\
\text { (CTES) }\end{array}$ & $\begin{array}{l}\text { Di Giacomo, A., 2005; } \\
\text { Maturo et al., } 2005\end{array}$ \\
\hline $\begin{array}{l}\text { Harrisia bonplandii } \\
\text { (Pfeiff.) Britton \& Rose }\end{array}$ & $\mathrm{Ar}$ & SubArb & $* * *$ & $\begin{array}{l}\text { Di Giacomo, A., 2005; } \\
\text { Maturo et al., } 2005\end{array}$ \\
\hline $\begin{array}{l}\text { Harrisia cfr. martinii } \\
\text { (Latour.) Britton \& Rose }\end{array}$ & $\operatorname{Ar}$ & SubArb & $\begin{array}{l}\text { Her: 18/11/1999. Di Giácomo, A. } 431 \\
\text { (CTES) }\end{array}$ & Di Giacomo, A., 2005 \\
\hline $\begin{array}{l}\text { Monvillea cavendischii } \\
\text { (Monv.) Britton \& Rose }\end{array}$ & $\mathrm{Ar}$ & SubArb & $\begin{array}{l}\text { Her: 10/12/1999. Di Giácomo, A. } 440 \\
\text { (CTES) }\end{array}$ & Di Giacomo, A., 2005 \\
\hline $\begin{array}{l}\text { Monvillea spegazzinii (F.A.C. } \\
\text { Weber) Britton \& Rose }\end{array}$ & $\mathrm{B}, \mathrm{Ar}$ & SubArb & $\begin{array}{l}\text { Her: 18/02/2000. Di Giácomo, A. } 452 \\
\text { (CTES) }\end{array}$ & Di Giacomo, A., 2005 \\
\hline $\begin{array}{l}\text { Opuntia anacantha Speg. Var } \\
\text { retrosa (Speg.) R. Kiesling }\end{array}$ & $\mathrm{Ar}$ & SubArb & *** & Di Giacomo, A., 2005 \\
\hline $\begin{array}{l}\text { Opuntia cardiosperma } \\
\text { K. Schum. }\end{array}$ & $\mathrm{Ar}$ & Arb & $\begin{array}{l}\text { Her: 22/07/1999. Di Giácomo, A. } 412 \\
\text { (CTES) }\end{array}$ & $\begin{array}{l}\text { Di Giacomo, A., 2005; } \\
\text { Maturo et al., } 2005\end{array}$ \\
\hline Opuntia cfr. chaquensis Speg. & $\operatorname{Ar}$ & Arb & $\begin{array}{l}\text { Her: 10/12/1999. Di Giácomo, A. } 439 \\
\text { (CTES) }\end{array}$ & \\
\hline $\begin{array}{l}\text { Opuntia elata Hort. } \\
\text { Berol. Ex Salm-Dyck }\end{array}$ & $\mathrm{Ar}$ & Arb & $* * *$ & Di Giacomo, A., 2005 \\
\hline Rhipalis aculeata F. A. C. Weber & $* * * *$ & Ep & *** & Di Giacomo, A., 2005 \\
\hline $\begin{array}{l}\text { Rhipalis lumbricoides (Lem.) } \\
\text { Lem. Ex Salm-Dyck }\end{array}$ & $\mathrm{S}$ & Ep & 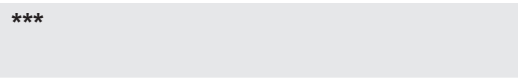 & Di Giacomo, A., 2005 \\
\hline Rhipalis schaferi Br. et Rose & $\mathrm{S}$ & Ep & $\begin{array}{l}\text { Her: 15/12/1967. Piccinini, B. } 1159 \\
\text { (BAB) }\end{array}$ & \\
\hline \multicolumn{5}{|l|}{ Campanulaceae } \\
\hline Lobelia xalapensis Kunth & ***** & $\mathrm{He}$ & $\begin{array}{l}\text { Her: 30/06/1999. Di Giácomo, A. } 417 \\
\text { (CTES) }\end{array}$ & Di Giacomo, A., 2005 \\
\hline $\begin{array}{l}\text { Wahlenbergia linarioides } \\
\text { (Lam.) DC. }\end{array}$ & $* * * *$ & $\mathrm{He}$ & $\begin{array}{l}\text { Her: 12/10/1998. Di Giácomo, A. } 380 \\
\text { (CTES) }\end{array}$ & Di Giacomo, A., 2005 \\
\hline
\end{tabular}


Bol. Soc. Argent. Bot. 50 (4) 2015

\begin{tabular}{|c|c|c|c|c|}
\hline Especies & $\begin{array}{l}\text { Unidad } \\
\text { Vegetal }\end{array}$ & Hábito & coleccionista y $\mathbf{N}^{\circ}$ & Bibliografía \\
\hline \multicolumn{5}{|l|}{ Cannabaceae } \\
\hline Celtis iguanea (Jacq.) Sarg. & B & A & $* * *$ & Di Giacomo, A., 2005 \\
\hline $\begin{array}{l}\text { Celtis pubescens (Humb. } \\
\text { \& Bonpl.) Spreng. }\end{array}$ & B & A & *** & Di Giacomo, A., 2005 \\
\hline \multicolumn{5}{|l|}{ Caryophyllaceae } \\
\hline $\begin{array}{l}\text { Cerastium rivulariastrum } \\
\text { Moeschl \& Pedersen }\end{array}$ & $* * * *$ & $\mathrm{He}$ & $* * *$ & Di Giacomo, A., 2005 \\
\hline $\begin{array}{l}\text { Polycarpon suffruticosum } \\
\text { Griseb. }\end{array}$ & B & $\mathrm{He}$ & $\begin{array}{l}\text { Her: 15/06/1999. Di Giácomo, A. } 408 \\
\text { (CTES) }\end{array}$ & Di Giacomo, A., 2005 \\
\hline Spergula ramosa (Cambess.) D. & $* * * *$ & $\mathrm{He}$ & $* * *$ & Di Giacomo, A., 2005 \\
\hline \multicolumn{5}{|l|}{ Celastraceae } \\
\hline $\begin{array}{l}\text { Hippocratea andina } \\
\text { (Miers) J. F. Macbr. }\end{array}$ & $\mathrm{S}$ & Arb & *** & Di Giacomo, A., 2005 \\
\hline $\begin{array}{l}\text { Maytenus ilicifolia C. } \\
\text { Mart. ex Reiss. }\end{array}$ & B & A/Arb & $\begin{array}{l}\text { Her: 15/09/1998. Di Giácomo, A. } 385 \\
\text { (CTES) }\end{array}$ & $\begin{array}{l}\text { Di Giacomo, A., 2005; } \\
\text { Maturo et al., } 2005\end{array}$ \\
\hline Maytenus vitis-idaea Griseb. & $\mathrm{Ar}$ & A/Arb & $* * *$ & $\begin{array}{l}\text { Di Giacomo, A., } 2005 \text {; } \\
\text { Maturo et al., } 2005\end{array}$ \\
\hline \multicolumn{5}{|l|}{ Combretaceae } \\
\hline Terminalia triflora (Griseb.) LIllo & S & A & *** & Di Giacomo, A., 2005 \\
\hline \multicolumn{5}{|l|}{ Convolvulaceae } \\
\hline $\begin{array}{l}\text { Convolvulus crenatifolius } \\
\text { Ruiz \& Pav. }\end{array}$ & S, PL & En & $\begin{array}{l}\text { Her, CP: 10/12/2001. Di Giácomo, A. } \\
549 \text { (CTES); 06/12/2012. Contreras, S. } \\
\text { A. et al. 107. (CTES) }\end{array}$ & Di Giacomo, A., 2005 \\
\hline $\begin{array}{l}\text { Dichondra microcalyx } \\
\text { (Hallier f.) Fabris }\end{array}$ & S, PzM & $\mathrm{He}$ & $\begin{array}{l}\text { Her, CP: 10/10/2001. Di Giácomo, A. } \\
532 \text { (CTES); 20/10/2011. Contreras, S. } \\
\text { A. et al. 42. (CTES) }\end{array}$ & Di Giacomo, A., 2005 \\
\hline Evolvulus nummularius (L.) L. & $* * * *$ & $\mathrm{He}$ & $\begin{array}{l}\text { Her: 21/03/2003. Di Giácomo, A. } 606 \\
\text { (CTES) }\end{array}$ & Di Giacomo, A., 2005 \\
\hline Evolvulus sericeus Sw. & PzM & $\mathrm{He}$ & $\begin{array}{l}\text { Her: 20/11/1999. Di Giácomo, A. } 444 \\
\text { (CTES) }\end{array}$ & Di Giacomo, A., 2005 \\
\hline Ipomoea alba L. & S & En & $\begin{array}{l}\text { Her: 15/12/1999. Di Giácomo, A. } 454 \\
\text { (CTES) }\end{array}$ & Di Giacomo, A., 2005 \\
\hline Ipomoea amnicola Morong & B & En & $* * *$ & Di Giacomo, A., 2005 \\
\hline Ipomoea cairica (L.) Sweet & S & En & $\begin{array}{l}\text { Her: 12/01/2000. Di Giácomo, A. } 459 \\
\text { (CTES) }\end{array}$ & Di Giacomo, A., 2005 \\
\hline $\begin{array}{l}\text { Ipomoea grandifolia } \\
\text { (Dasnmer) O'Donell }\end{array}$ & S & En & $\begin{array}{l}\text { Her: 15/02/2003. Di Giácomo, A. } 590 \\
\text { (CTES) }\end{array}$ & Di Giacomo, A., 2005 \\
\hline Ipomoea nil (L.) Roth & $* * * * *$ & En & $\begin{array}{l}\text { Her: 25/04/1999. Di Giácomo, A. } 399 \\
\text { (CTES) }\end{array}$ & Di Giacomo, A., 2005 \\
\hline Ipomoea platensis Ker & B & En & $\begin{array}{l}\text { Her: 25/04/1999. Di Giácomo, A. } 377 \\
\text { (CTES) }\end{array}$ & Di Giacomo, A., 2005 \\
\hline \multicolumn{5}{|l|}{ Cucurbitaceae } \\
\hline $\begin{array}{l}\text { Cayaponia bonariensis } \\
\text { (Mill.) Mart. Crov. }\end{array}$ & S & En & $\begin{array}{l}\text { Her: 15/02/2003. Di Giácomo, A. } 587 \\
\text { (CTES) }\end{array}$ & Di Giacomo, A., 2005 \\
\hline Cayaponia podantha Cogn. & S & En & $* * *$ & Di Giacomo, A., 2005 \\
\hline Ceratosanthes hiariana Cogn. & B & En & $\begin{array}{l}\text { Her: 15/10/1999. Di Giácomo, A. } 449 \\
\text { (CTES) }\end{array}$ & Di Giacomo, A., 2005 \\
\hline
\end{tabular}




\begin{tabular}{|c|c|c|c|c|}
\hline Especies & $\begin{array}{l}\text { Unidad } \\
\text { Vegetal }\end{array}$ & Hábito & coleccionista y $\mathbf{N}^{\circ}$ & Bibliografía \\
\hline $\begin{array}{l}\text { Cucurbitella asperata (Gillies } \\
\text { ex Hook. \& Arn.) Walp. }\end{array}$ & $* * * * *$ & $\mathrm{He}$ & $\begin{array}{l}\text { Her: 06/05/2005. Deginani, N. B. } 1993 \\
\text { (SI) }\end{array}$ & \\
\hline Melothria cucumis Vell. & PzM & En & $\begin{array}{l}\text { Her: 15/12/1998. Di Giácomo, A. } 386 \\
\text { (CTES) }\end{array}$ & Di Giacomo, A., 2005 \\
\hline \multicolumn{5}{|l|}{ Elatinaceae } \\
\hline $\begin{array}{l}\text { Elatine triandra Schkuhr var. } \\
\text { brachysperma (A. Gray) Fassett }\end{array}$ & **** & $\mathrm{HeA}$ & $\begin{array}{l}\text { Her: 00/1970. Pedersen, T. M. } 8374 \\
\text { (CTES; C) }\end{array}$ & \\
\hline \multicolumn{5}{|l|}{ Erythroxylaceae } \\
\hline $\begin{array}{l}\text { Erythroxylum aff. cuneifolium } \\
\text { (Mart.) O.E. Schulz }\end{array}$ & B & Arb & $\begin{array}{l}\text { Her: 15/10/2001. Di Giácomo, A. } 534 \\
\text { (CTES) }\end{array}$ & Di Giacomo, A., 2005 \\
\hline $\begin{array}{l}\text { Erythroxylum microphyllum } \\
\text { A. St.-Hil. }\end{array}$ & B & Arb & $* * *$ & Di Giacomo, A., 2005 \\
\hline \multicolumn{5}{|l|}{ Euphorbiaceae } \\
\hline Acalypha communis Muell. Arg. & $\mathrm{B}, \mathrm{PzM}$ & $\mathrm{He}$ & $\begin{array}{l}\text { Her: 15/11/1998. Di Giácomo, A. } 383 \\
\text { (CTES) }\end{array}$ & Di Giacomo, A., 2005 \\
\hline Bernardia Iorentzii Müll. & S & $\mathrm{He}$ & $\begin{array}{l}\text { Her: 15/12/1967. Piccinini, B. } 1151 \\
\text { (BAB) }\end{array}$ & \\
\hline Caperonia cordata A. St.-Hil. & $\mathrm{PzH}$ & $\mathrm{He}$ & $\begin{array}{l}\text { Her: 19/03/2006. Aliscioni, S. S. } 581 \\
\text { (SI; FAVE; CTES; BAA) }\end{array}$ & Di Giacomo, A., 2005 \\
\hline $\begin{array}{l}\text { Caperonia palustris } \\
\text { (L.) A. St.-Hil. }\end{array}$ & 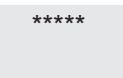 & $\mathrm{He}$ & $\begin{array}{l}\text { Her: }{ }^{*} / 03 / 1918 . \text { Jörgensen, P. } 2851 \\
\text { (LIL; BA) }\end{array}$ & \\
\hline Croton aff. Gracilipes Baill. & S & $\mathrm{He}$ & $* * *$ & Di Giacomo, A., 2005 \\
\hline Croton bonplandianus Baill. & S & $\mathrm{He}$ & $\begin{array}{l}\text { Her: 27/01/1970. Hunziker, A. T. } 20235 \\
\text { (CORD; CORD) }\end{array}$ & Di Giacomo, A., 2005 \\
\hline Croton lobatus L. & $\mathrm{PzH}$ & $\mathrm{He}$ & $\begin{array}{l}\text { Her: 10/01/2000. Di Giácomo, A. } 455 \\
\text { (CTES) }\end{array}$ & Di Giacomo, A., 2005 \\
\hline Croton urucurana Baill. & S & $\mathrm{He}$ & $\begin{array}{l}\text { Her: 27/01/1970. Hunziker, A. T. } 20240 \\
\text { (CORD; CORD) }\end{array}$ & \\
\hline Euphorbia hypericifolia L. & PzM & $\mathrm{He}$ & $* * *$ & Di Giacomo, A., 2005 \\
\hline $\begin{array}{l}\text { Euphorbia stenophylla } \\
\text { (Klotzch) Boissier }\end{array}$ & $\mathrm{Ar}$ & $\mathrm{He}$ & $\begin{array}{l}\text { Her: 20/02/2002. Di Giácomo, A. } 559 \\
\text { (CTES) }\end{array}$ & Di Giacomo, A., 2005 \\
\hline Julocroton humilis Didr. & PzM & SubArb & $* * *$ & Di Giacomo, A., 2005 \\
\hline $\begin{array}{l}\text { Julocroton subpannosus } \\
\text { Müll. Arg. }\end{array}$ & PzM & SubArb & *** & Di Giacomo, A., 2005 \\
\hline Manihot anisophylla Müll. Arg. & S & Arb & $* * *$ & Di Giacomo, A., 2005 \\
\hline $\begin{array}{l}\text { Sapium haematospermum } \\
\text { Müll. Arg. }\end{array}$ & S & A & $\star * *$ & Di Giacomo, A., 2005 \\
\hline Sebastiania brasiliensis Spreng. & S & Arb & $\begin{array}{l}\text { Her: 30/11/1998. Di Giácomo, A. } 384 \\
\text { (CTES) }\end{array}$ & Di Giacomo, A., 2005 \\
\hline Tragia melochioides Griseb. & PzM & $\mathrm{He}$ & $\begin{array}{l}\text { Her: 25/01/2004. Di Giácomo, A. } 610 \\
\text { (CTES) }\end{array}$ & Di Giacomo, A., 2005 \\
\hline \multicolumn{5}{|l|}{ Fabaceae } \\
\hline $\begin{array}{l}\text { Acacia aroma Gillies } \\
\text { ex Hook. \& Arn. }\end{array}$ & S, PL & A/Arb & CP: 25/06/11. Contreras et al. 21 (CTES) & Di Giacomo, A., 2005 \\
\hline $\begin{array}{l}\text { Acacia bonariensis Gillies } \\
\text { ex Hook. \& Arn. }\end{array}$ & B & A/Arb & *** & Di Giacomo, A., 2005 \\
\hline Acacia caven (Mol.) Mol. & B & A/Arb & $\begin{array}{l}\text { Her: 10/06/1999. Di Giácomo, A. } 419 \\
\text { (CTES) }\end{array}$ & Di Giacomo, A., 2005 \\
\hline
\end{tabular}


Bol. Soc. Argent. Bot. 50 (4) 2015

\begin{tabular}{|c|c|c|c|c|}
\hline Especies & $\begin{array}{l}\text { Unidad } \\
\text { Vegetal }\end{array}$ & Hábito & coleccionista y $\mathbf{N}^{\circ}$ & Bibliografía \\
\hline Acacia praecox Griseb. & B & A/Arb & $\begin{array}{l}\text { Her: 20/05/1999. Di Giácomo, A. } 421 \\
\text { (CTES) }\end{array}$ & $\begin{array}{l}\text { Di Giacomo, A., 2005; } \\
\text { Maturo et al., } 2005\end{array}$ \\
\hline Aeschynomene americana L. & $\mathrm{PzH}$ & $\mathrm{He}$ & $* * *$ & $\begin{array}{l}\text { Di Giacomo, A., 2005; } \\
\text { Maturo et al., } 2005\end{array}$ \\
\hline $\begin{array}{l}\text { Aeschynomene } \\
\text { denticulata Rudd }\end{array}$ & $\mathrm{PzH}$ & $\mathrm{He}$ & $* * *$ & $\begin{array}{l}\text { Di Giacomo, A., 2005; } \\
\text { Maturo et al., } 2005\end{array}$ \\
\hline $\begin{array}{l}\text { Albizia inundata (Mart.) } \\
\text { Barneby \& J.W.Grimes }\end{array}$ & S & $A$ & $\begin{array}{l}\text { Her: 10/10/2001. Di Giácomo, A. } 535 \\
\text { (CTES) }\end{array}$ & $\begin{array}{l}\text { Di Giacomo, A., 2005; } \\
\text { Maturo et al., } 2005\end{array}$ \\
\hline $\begin{array}{l}\text { Caesalpinia paraguariensis } \\
\text { (D. Parodi) Burkart }\end{array}$ & B & A & $\begin{array}{l}\text { Her: 06/02/2002. Di Giácomo, A. } 554 \\
\text { (CTES) }\end{array}$ & $\begin{array}{l}\text { Di Giacomo, A., 2005; } \\
\text { Maturo et al., } 2005\end{array}$ \\
\hline $\begin{array}{l}\text { Calopogonium sericeum } \\
\text { (Benth.) Chodat \& Hassl. }\end{array}$ & PzM & $\begin{array}{c}\mathrm{He} / \\
\text { SubArb }\end{array}$ & $* * *$ & Di Giacomo, A., 2005 \\
\hline $\begin{array}{l}\text { Chamaecrista nictitans } \\
\text { (L.) Moench }\end{array}$ & $\mathrm{PzH}$ & $\mathrm{He}$ & *** & $\begin{array}{l}\text { Di Giacomo, A., 2005; } \\
\text { Maturo et al., } 2005\end{array}$ \\
\hline $\begin{array}{l}\text { Chloroleucon tenuiflorum } \\
\text { (Benth.) Barneby \& J.W. Grimes }\end{array}$ & S & A & $\begin{array}{l}\text { Her: 15/09/2001. Di Giácomo, A. } 520 \\
\text { (CTES) }\end{array}$ & Di Giacomo, A., 2005 \\
\hline Crotalaria incana L. & PzM & $\mathrm{He}$ & $\begin{array}{l}\text { Her: 15/10/2000. Di Giácomo, A. } 471 \\
\text { (CTES) }\end{array}$ & Di Giacomo, A., 2005 \\
\hline Crotalaria pilosa Mill. & $\mathrm{PzH}$ & $\mathrm{He}$ & $* * *$ & Di Giacomo, A., 2005 \\
\hline Crotalaria stipularia Desv. & PzM & $\mathrm{He}$ & *** & Di Giacomo, A., 2005 \\
\hline Desmanthus virgatus (L.) Willd. & $\begin{array}{l}\mathrm{PzH} \\
\mathrm{PzM}\end{array}$ & $\begin{array}{c}\mathrm{He} / \\
\text { SubArb }\end{array}$ & $\begin{array}{l}\text { CP: 06/12/12. Contreras et al. } 127 \\
\text { (CTES) }\end{array}$ & Di Giacomo, A., 2005 \\
\hline Desmodium affine Schltdl. & S & $\mathrm{He}$ & $\begin{array}{l}\text { Her: 12/02/2000. Di Giácomo, A. } 466 \\
\text { (CTES) }\end{array}$ & Di Giacomo, A., 2005 \\
\hline $\begin{array}{l}\text { Desmodium barbatum } \\
\text { (L.) Benth. }\end{array}$ & PzM & $\mathrm{He}$ & $\begin{array}{l}\text { Her: 20/01/2003. Di Giácomo, A. } 586 \\
\text { (CTES) }\end{array}$ & $\begin{array}{l}\text { Di Giacomo, A., 2005; } \\
\text { Maturo et al., } 2006\end{array}$ \\
\hline $\begin{array}{l}\text { Desmodium cuneatum } \\
\text { Hook. \& Arn. }\end{array}$ & PzM & $\mathrm{He}$ & *** & $\begin{array}{l}\text { Di Giacomo, A., 2005; } \\
\text { Maturo et al., } 2006\end{array}$ \\
\hline Desmodium incanum DC. & $\begin{array}{l}\text { PzM, } \\
\text { PL }\end{array}$ & $\mathrm{He}$ & $\begin{array}{l}\text { CP: 06/12/12. Contreras et al. } 109 \\
\text { (CTES) }\end{array}$ & Di Giacomo, A., 2005 \\
\hline Desmodium pachyrhizum Vogel & PzM & $\mathrm{He}$ & $* * *$ & Di Giacomo, A., 2005 \\
\hline $\begin{array}{l}\text { Dolichopsis } \\
\text { paraguariensis Hassl. }\end{array}$ & $\mathrm{PzH}$ & En & *** & Di Giacomo, A., 2005 \\
\hline $\begin{array}{l}\text { Enterolobium contortisiliquum } \\
\text { (Vell.) Morong }\end{array}$ & $\mathrm{S}$ & A & $\begin{array}{l}\text { Her: 10/10/2001. Di Giácomo, A. } 529 \\
\text { (CTES) }\end{array}$ & $\begin{array}{l}\text { Di Giacomo, A., } 2005 \text {; } \\
\text { Maturo et al., } 2005\end{array}$ \\
\hline $\begin{array}{l}\text { Eriosema tacuaremboense } \\
\text { Arechav. }\end{array}$ & PzM & $\mathrm{He}$ & $\begin{array}{l}\text { Her: 20/11/1999. Di Giácomo, A. } 443 \\
\text { (CTES) }\end{array}$ & Di Giacomo, A., 2005 \\
\hline Erythrina crista-galli L. & $\mathrm{B}, \mathrm{PzM}$ & A & $\begin{array}{l}\text { Her: 30/09/2002. Di Giácomo, A. } 574 \\
\text { (CTES) }\end{array}$ & \\
\hline Erythrina dominguezii Hassl. & S & A & $* * *$ & Di Giacomo, A., 2005 \\
\hline Galactia striata (Jacq.) Urb. & PzM & En & $* * *$ & Di Giacomo, A., 2005 \\
\hline $\begin{array}{l}\text { Geoffroea decorticans (Gill. } \\
\text { ex Hook. \& Arn.) Burk. }\end{array}$ & $\operatorname{Ar}$ & A & $\begin{array}{l}\text { Her: 10/06/1999. Di Giácomo, A. } 420 \\
\text { (CTES) }\end{array}$ & $\begin{array}{l}\text { Di Giacomo, A., } 2005 \text {; } \\
\text { Maturo et al., } 2005\end{array}$ \\
\hline
\end{tabular}




\begin{tabular}{|c|c|c|c|c|}
\hline Especies & $\begin{array}{l}\text { Unidad } \\
\text { Vegetal }\end{array}$ & Hábito & coleccionista y $\mathbf{N}^{\circ}$ & Bibliografía \\
\hline $\begin{array}{l}\text { Gleditsia amorphoides } \\
\text { (Griseb.) Taub. }\end{array}$ & S & A & $\begin{array}{l}\text { Her, CP: } 15 / 09 / 2001 \text {. Di Giácomo, A. } \\
519 \text { (CTES); }{ }^{* *} / 08 / 2009 \text {. Contreras et al. } \\
14 \text { (CTES) }\end{array}$ & $\begin{array}{l}\text { Di Giacomo, A., 2005; } \\
\text { Maturo et al., } 2005\end{array}$ \\
\hline Holocalyx balansae Micheli & $\mathrm{s}$ & A & *** & $\begin{array}{l}\text { Di Giacomo, A., 2005; } \\
\text { Maturo et al., } 2005\end{array}$ \\
\hline $\begin{array}{l}\text { Indigofera asperifolia } \\
\text { Bong. ex Benth. }\end{array}$ & PzM & $\mathrm{He}$ & *** & Di Giacomo, A., 2005 \\
\hline Indigofera suffruticosa Mill. & PzM & SubArb & *** & Di Giacomo, A., 2005 \\
\hline $\begin{array}{l}\text { Inga verna Willd. Subsp. } \\
\text { affinis (DC.) T. D. Penn. }\end{array}$ & S & A & *** & Di Giacomo, A., 2005 \\
\hline $\begin{array}{l}\text { Macroptilium erythroloma } \\
\text { (Mart. ex Benth.) Urb. }\end{array}$ & S & En & $\begin{array}{l}\text { Her: 25/10/2002. Di Giácomo, A. } 589 \\
\text { (CTES) }\end{array}$ & Di Giacomo, A., 2005 \\
\hline $\begin{array}{l}\text { Macroptilium lathyroides } \\
\text { (L.) Urb. }\end{array}$ & $E / L$ & En & $* * *$ & Di Giacomo, A., 2005 \\
\hline $\begin{array}{l}\text { Microlobius foetidus (Jacq.) } \\
\text { M. Souza \& G. Andrade }\end{array}$ & $\mathrm{s}$ & A & $\begin{array}{l}\text { Her: 25/09/2001. Di Giácomo, A. } 524 \\
\text { (CTES) }\end{array}$ & $\begin{array}{l}\text { Di Giacomo, A., 2005; } \\
\text { Maturo et al., } 2005\end{array}$ \\
\hline Mimosa pigra L. & $E / L$ & Arb & *** & Di Giacomo, A., 2005 \\
\hline $\begin{array}{l}\text { Peltophorum dubium } \\
\text { (Spreng.) Taub. }\end{array}$ & S & A & *** & Di Giacomo, A., 2005 \\
\hline Prosopis affinis Spreng. & S & A & $\begin{array}{l}\text { Her: 15/01/2000. Di Giácomo, A. } 458 \\
\text { (CTES) }\end{array}$ & Di Giacomo, A., 2005 \\
\hline Prosopis alba Griseb. & $B, S$ & A & $\begin{array}{l}\text { CP: } 20 / 12 / 11 \text {. Contreras et al. } 59 \\
\text { (CTES) }\end{array}$ & Di Giacomo, A., 2005 \\
\hline Prosopis kuntzei Harms & B & A & $\begin{array}{l}\text { Her: 15/10/2001. Di Giácomo, A. } 537 \\
\text { (CTES) }\end{array}$ & $\begin{array}{l}\text { Di Giacomo, A., 2005; } \\
\text { Maturo et al., } 2005\end{array}$ \\
\hline Prosopis nigra (Griseb.) Hieron. & B & A & $\begin{array}{l}\text { Her: 20/05/1999. Di Giácomo, A. } 422 \\
\text { (CTES) }\end{array}$ & $\begin{array}{l}\text { Di Giacomo, A., 2005; } \\
\text { Maturo et al., } 2005\end{array}$ \\
\hline Pterogyne nitens Tul. & S & A & *** & Di Giacomo, A., 2005 \\
\hline $\begin{array}{l}\text { Rhynchosia corylifolia } \\
\text { Mart. ex Benth. }\end{array}$ & PzM & $\mathrm{He}$ & $\begin{array}{l}\text { Her: 23/11/1998. Di Giácomo, A. } 400 \\
\text { (CTES) }\end{array}$ & $\begin{array}{l}\text { Di Giacomo, A., 2005; } \\
\text { Maturo et al., } 2005\end{array}$ \\
\hline Rhynchosia edulis Griseb. & PzM & En & *** & Di Giacomo, A., 2005 \\
\hline Senna bicapsularis L. & B & Arb & $\begin{array}{l}\text { Her: 27/04/1999. Di Giácomo, A. } 374 \\
\text { (CTES) }\end{array}$ & \\
\hline Senna occidentalis (L.) Link & S & $\mathrm{He}$ & *** & Di Giacomo, A., 2005 \\
\hline Sesbania exasperata Kunth & $E / L$ & A/Arb & *** & $\begin{array}{l}\text { Di Giacomo, A., 2005; } \\
\text { Maturo et al., } 2005\end{array}$ \\
\hline Sesbania virgata (Cav.) Pers. & $\mathrm{PzH}$ & A/Arb & $\begin{array}{l}\text { CP: 06/12/12. Contreras et al. } 125 \\
\text { (CTES) }\end{array}$ & \\
\hline $\begin{array}{l}\text { Stylosanthes guianensis } \\
\text { (Aubl.) Sw. var. guianensis }\end{array}$ & PzM & $\mathrm{He}$ & $* * *$ & Di Giacomo, A., 2005 \\
\hline $\begin{array}{l}\text { Stylosanthes } \\
\text { montevidensis Vogel }\end{array}$ & $\mathrm{PzH}$ & $\mathrm{He}$ & *** & Di Giacomo, A., 2005 \\
\hline Tephrosia adunca Benth. & PzM & $\mathrm{He}$ & *** & Di Giacomo, A., 2005 \\
\hline Vicea gramínea Smith en Rees & $E / L$ & $\mathrm{He}$ & CP: 20/10/11. Contreras et al. 52 (CTES) & \\
\hline Vicea macrogramínea Burkat. & PzM & En & *** & Di Giacomo, A., 2005 \\
\hline
\end{tabular}


Bol. Soc. Argent. Bot. 50 (4) 2015

\begin{tabular}{|c|c|c|c|c|}
\hline Especies & $\begin{array}{l}\text { Unidad } \\
\text { Vegetal }\end{array}$ & Hábito & coleccionista y $\mathbf{N}^{\circ}$ & Bibliografía \\
\hline Vigna caracalla (L.) Verdc. & S & En & $* * *$ & Di Giacomo, A., 2005 \\
\hline $\begin{array}{l}\text { Vigna longifolia } \\
\text { (Benth.) Verdcourt }\end{array}$ & $E / L$ & En & $* * *$ & Di Giacomo, A., 2005 \\
\hline Zornia pardina Mohl. & PzM & $\mathrm{He}$ & $\begin{array}{l}\text { Her: 15/01/2000. Di Giácomo, A. } 457 \\
\text { (CTES) }\end{array}$ & Di Giacomo, A., 2005 \\
\hline \multicolumn{5}{|l|}{ Gesneriaceae } \\
\hline $\begin{array}{l}\text { Sinningia tubiflora } \\
\text { (Hook.) Fritsch }\end{array}$ & $\mathrm{Ar}$ & $\mathrm{He}$ & $* * *$ & $\begin{array}{l}\text { Di Giacomo, A., 2005; } \\
\text { Maturo et al., } 2005\end{array}$ \\
\hline $\begin{array}{l}\text { Sinningia warmingii } \\
\text { (Hiern) Chautems }\end{array}$ & $\mathrm{Ar}$ & $\mathrm{He}$ & $* * *$ & Di Giacomo, A., 2005 \\
\hline \multicolumn{5}{|l|}{ Hydrophyllaceae } \\
\hline Hydrolea elatior Schott & $\mathrm{PzH}$ & $\mathrm{He}$ & $* * *$ & Di Giacomo, A., 2005 \\
\hline \multicolumn{5}{|l|}{ Lamiaceae } \\
\hline Hyptis lappacea Benth & $\mathrm{PzH}$ & $\mathrm{He}$ & $* * *$ & Di Giacomo, A., 2005 \\
\hline Hyptis lorentziana O. Hoffm. & $\mathrm{PzH}$ & $\mathrm{He}$ & $* * *$ & Di Giacomo, A., 2005 \\
\hline Salvia nervosa Benth. & $\mathrm{Ar}$ & $\mathrm{He}$ & $* * *$ & Di Giacomo, A., 2005 \\
\hline Scutellaria racemosa Pers. & $\mathrm{PzH}$ & $\mathrm{He}$ & $\begin{array}{l}\text { Her: 22/09/1967. Krapovickas, A. } 13188 . \\
\text { (SI) }\end{array}$ & Di Giacomo, A., 2005 \\
\hline Stachys arvensis (L.) L. & $S$ & $\mathrm{He}$ & $\begin{array}{l}\text { Her: 20/10/1999. Di Giácomo, A. } 430 \\
\text { (CTES) }\end{array}$ & Di Giacomo, A., 2005 \\
\hline \multicolumn{5}{|l|}{ Lauraceae } \\
\hline $\begin{array}{l}\text { Nectandra angustifolia (Schrad.) } \\
\text { Nees \& Mart. ex Nees }\end{array}$ & $S$ & A & $\begin{array}{l}\text { Her: 10/03/2003. Di Giácomo, A. } 592 \\
\text { (CTES) }\end{array}$ & $\begin{array}{l}\text { Di Giacomo, A., 2005; } \\
\text { Maturo et al., } 2005\end{array}$ \\
\hline $\begin{array}{l}\text { Ocotea diospyrifolia } \\
\text { (Meisn.) Mez }\end{array}$ & $S$ & A & $* * *$ & Di Giacomo, A., 2005 \\
\hline \multicolumn{5}{|l|}{ Lentibulariaceae } \\
\hline Utricularia gibba L. & $E / L$ & $\mathrm{HeA}$ & $\begin{array}{l}\text { Her: 10/09/2001. Di Giácomo, A. } 515 \\
\text { (CTES) }\end{array}$ & Di Giacomo, A., 2005 \\
\hline \multicolumn{5}{|l|}{ Loasaceae } \\
\hline $\begin{array}{l}\text { Blumenbachia latifolia } \\
\text { Cambess. }\end{array}$ & $* * * *$ & $\mathrm{He}$ & $\begin{array}{l}\text { Her: 20/09/2001. Di Giácomo, A. } 523 \\
\text { (CTES) }\end{array}$ & Di Giacomo, A., 2005 \\
\hline \multicolumn{5}{|l|}{ Lythraceae } \\
\hline Cuphea racemosa (L.f.) Spreng. & $* * * *$ & $\mathrm{He}$ & $* * *$ & Di Giacomo, A., 2005 \\
\hline Heimia salicifolia (Kunth) Link & $\begin{array}{l}\text { S, B } \\
\text { PzM }\end{array}$ & Arb & $\begin{array}{l}\text { Her, CP: 11/10/2011. Aliscioni, S. S. } \\
\text { 855. (BAA); 25/06/11. Contreras et al. } \\
\text { 22(CTES) }\end{array}$ & Di Giacomo, A., 2005 \\
\hline $\begin{array}{l}\text { Pleurophora saccocarpa } \\
\text { Koehne }\end{array}$ & PzM & Arb & $* * *$ & Di Giacomo, A., 2005 \\
\hline \multicolumn{5}{|l|}{ Malpighiaceae } \\
\hline Heteropterys glabra Hook. \& Arn & $\mathrm{PzH}$ & Arb & $* * *$ & Di Giacomo, A., 2005 \\
\hline $\begin{array}{l}\text { Heteropterys hypericifolia } \\
\text { A. Juss. }\end{array}$ & $\mathrm{PzH}$ & Arb & *** & Di Giacomo, A., 2005 \\
\hline \multicolumn{5}{|l|}{ Malvaceae } \\
\hline Dorstenia brasiliensis Lam. & S & Arb & $* * *$ & Di Giacomo, A., 2005 \\
\hline Abutilon pauciflorum A. St.-Hil. & $S$ & Arb & $* * *$ & Di Giacomo, A., 2005 \\
\hline
\end{tabular}




\begin{tabular}{|c|c|c|c|c|}
\hline Especies & $\begin{array}{l}\text { Unidad } \\
\text { Vegetal }\end{array}$ & Hábito & coleccionista y $\mathrm{N}^{\circ}$ & Bibliografía \\
\hline Ceiba chodatii (Hassl.) Ravenna & $\mathrm{Ar}$ & A & $* * *$ & Di Giacomo, A., 2005 \\
\hline $\begin{array}{l}\text { Cienfuegosia drummondii } \\
\text { (A. Gray) Lewton }\end{array}$ & PzM & $\mathrm{He}$ & $\begin{array}{l}\text { Her: 14/12/1995. González, A. M. et al. } \\
\text { (CTES) }\end{array}$ & $\begin{array}{l}\text { Di Giacomo, A., } 2005 \\
\text { Maturo et al., } 2005\end{array}$ \\
\hline Corchorus argutus Kunth & $\mathrm{PzH}$ & SubArb & $* * *$ & Di Giacomo, A., 2005 \\
\hline Hibiscus striatus Cav. & $E / L$ & Arb & $* * *$ & $\begin{array}{l}\text { Di Giacomo, A., } 2005 \\
\text { Maturo et al., } 2005\end{array}$ \\
\hline $\begin{array}{l}\text { Krapovickasia urticifolia } \\
\text { (A. St. Hil.) Krapov. }\end{array}$ & PzM & $\mathrm{He}$ & $\begin{array}{l}\text { Her: 20/11/1999. Di Giácomo, A. } 447 \\
\text { (CTES) }\end{array}$ & Di Giacomo, A., 2005 \\
\hline $\begin{array}{l}\text { Malvastrum coromandelianum } \\
\text { (L.) Garcke }\end{array}$ & S & $\begin{array}{c}\mathrm{He} / \\
\text { SubArb }\end{array}$ & $\begin{array}{l}\text { CP: 18/10/11. Contreras et al. } 36 \\
\text { (CTES) }\end{array}$ & Di Giacomo, A., 2005 \\
\hline Melochia ministella Cristobal & PzM & SubArb & $* * *$ & Di Giacomo, A., 2005 \\
\hline $\begin{array}{l}\text { Melochia pyramidata L. var. } \\
\text { Hieronymi K. Schum. }\end{array}$ & PzM & SubArb & $* * *$ & Di Giacomo, A., 2005 \\
\hline Modiola caroliniana (L.) G. Don & B & $\mathrm{He}$ & $\begin{array}{l}\text { Her: 30/09/2001. Di Giácomo, A. } 526 \\
\text { (CTES) }\end{array}$ & Di Giacomo, A., 2005 \\
\hline Pavonia hastata Cav. & S & Arb & $* * *$ & Di Giacomo, A., 2005 \\
\hline Pavonia morongii S. Moore & B & SubArb & *** & Di Giacomo, A., 2005 \\
\hline Pavonia narcissi Krapov. & $\mathrm{B}$ & Arb & $* * *$ & Di Giacomo, A., 2005 \\
\hline $\begin{array}{l}\text { Pavonia patuliloba } \\
\text { Chodat \& Hassl. }\end{array}$ & $\mathrm{S}$ & Arb & $\begin{array}{l}\text { CP: 25/06/11. Contreras et al. } 23 \\
\text { (CTES) }\end{array}$ & \\
\hline Pavonia sepiumSt. Hil. & S & Arb & CP: 20/12/11. Contreras et al. 72 (CTES) & \\
\hline Pavonia xanthogloea Ekman & $S$ & Arb & CP: 20/12/11. Contreras et al. 84 (CTES) & \\
\hline Sida Monteiroi Krapov. & $\operatorname{Ar}$ & SubArb & $\begin{array}{l}\text { Her: 20/02/2002. Di Giácomo, A. } 556 \\
\text { (CTES) }\end{array}$ & Di Giacomo, A., 2005 \\
\hline Sida spinosa L. & $* * * *$ & SubArb & $* * *$ & Di Giacomo, A., 2005 \\
\hline $\begin{array}{l}\text { Sidastrum multiflorum } \\
\text { (Jacq.) Fryxell }\end{array}$ & $* * * *$ & Arb & *** & Di Giacomo, A., 2005 \\
\hline $\begin{array}{l}\text { Sphaeralcea bonariensis } \\
\text { (Cav.) Griseb. }\end{array}$ & $* * * *$ & SubArb & $\begin{array}{l}\text { Her: 03/05/1999. Di Giácomo, A. } 415 \\
\text { (CTES) }\end{array}$ & Di Giacomo, A., 2005 \\
\hline Waltheria douradinha A. St.-Hil. & PzM & SubArb & $* * *$ & Di Giacomo, A., 2005 \\
\hline $\begin{array}{l}\text { Wissadula subpeltata } \\
\text { (Kuntze) R. E. Fr. }\end{array}$ & **** & Arb & $* * *$ & Di Giacomo, A., 2005 \\
\hline \multicolumn{5}{|l|}{ Melastomataceae } \\
\hline $\begin{array}{l}\text { Tibouchina gracilis } \\
\text { (Bonpl.) Cogniaux }\end{array}$ & $\mathrm{B}, \mathrm{PzM}$ & $\mathrm{He}$ & $\begin{array}{l}\text { Her: 15/12/1967. Piccinini, B. et al. } \\
1163 \text { (BAB) }\end{array}$ & Di Giacomo, A., 2005 \\
\hline \multicolumn{5}{|l|}{ Meliaceae } \\
\hline Trichilia catigua A. Juss. & S & A & $\begin{array}{l}\text { Her: 15/12/1967. Piccinini, B. et al. } 1165 \\
\text { (BAB) }\end{array}$ & $\begin{array}{l}\text { Di Giacomo, A., } 2005 \\
\text { Maturo et al., } 2005\end{array}$ \\
\hline Trichilia elegans Adr. Juss. & S & A & $\begin{array}{l}\text { Her: 25/04/1999. Di Giácomo, A. } 376 \\
\text { (CTES) }\end{array}$ & Di Giacomo, A., 2005 \\
\hline \multicolumn{5}{|l|}{ Menispermaceae } \\
\hline Cissampelos pareira L. & $S$ & En & $\begin{array}{l}\text { Her, CP: 15/10/2002. Di Giácomo, A. } \\
578 \text { (CTES); 20/10/11. Contreras, S. A. } \\
\text { et al. 49. (CTES) }\end{array}$ & Di Giacomo, A., 2005 \\
\hline Hyperbaena hassleri Diels & $* * * * *$ & En & Her: ${ }^{* * *}$ Pedersen, T. M. 1263 (US) & \\
\hline Menyanthaceae & & & & \\
\hline
\end{tabular}


Bol. Soc. Argent. Bot. 50 (4) 2015

\begin{tabular}{|c|c|c|c|c|}
\hline Especies & $\begin{array}{l}\text { Unidad } \\
\text { Vegetal }\end{array}$ & Hábito & coleccionista y $\mathbf{N}^{\circ}$ & Bibliografía \\
\hline Nymphoides indica (L.) Kuntze & E/L & $\mathrm{He}$ & $* * *$ & $\begin{array}{l}\text { Di Giacomo, A., 2005; } \\
\text { Maturo et al., } 2005\end{array}$ \\
\hline \multicolumn{5}{|l|}{ Moraceae } \\
\hline Dorstenia brasiliensis Lam. & S & $\mathrm{He}$ & $* * *$ & Di Giacomo, A., 2005 \\
\hline Ficus Iuschnathiana (Miq.) Miq. & S & A & $* * *$ & $\begin{array}{l}\text { Di Giacomo, A., } 2005 \text {; } \\
\text { Maturo et al., } 2005\end{array}$ \\
\hline Maclura tinctoria (L.) Steud. & $\mathrm{S}$ & A & $\begin{array}{l}\text { CP: } 20 / 12 / 11 \text {. Contreras, S. A. et al. } 82 . \\
\text { (CTES) }\end{array}$ & $\begin{array}{l}\text { Di Giacomo, A., 2005; } \\
\text { Maturo et al., } 2005\end{array}$ \\
\hline $\begin{array}{l}\text { Sorocea sprucei (Baill.) } \\
\text { J. F. Macbr. }\end{array}$ & S & A & $* * *$ & $\begin{array}{l}\text { Di Giacomo, A., 2005; } \\
\text { Maturo et al., } 2005\end{array}$ \\
\hline \multicolumn{5}{|l|}{ Myrsinaceae } \\
\hline $\begin{array}{l}\text { Myrsine laetevirens } \\
\text { (Mez.). Arechav. }\end{array}$ & $S$ & A & $* * *$ & $\begin{array}{l}\text { Di Giacomo, A., 2005; } \\
\text { Maturo et al., } 2005\end{array}$ \\
\hline \multicolumn{5}{|l|}{ Myrtaceae } \\
\hline Eugenia moraviana O. Berg & $S$ & A/Arb & $* * *$ & $\begin{array}{l}\text { Di Giacomo, A., 2005; } \\
\text { Maturo et al., } 2005\end{array}$ \\
\hline Eugenia uniflora L. & S & A/Arb & $\begin{array}{l}\text { CP: 18/10/11. Contreras, S. A. et al. } 33 . \\
\text { (CTES) }\end{array}$ & $\begin{array}{l}\text { Di Giacomo, A., 2005; } \\
\text { Maturo et al., } 2005\end{array}$ \\
\hline $\begin{array}{l}\text { Myrcianthes pungens } \\
\text { (O. Berg) D. Legrand }\end{array}$ & S & A & $\begin{array}{l}\text { CP: 18/10/11. Contreras, S. A. et al. } 38 . \\
\text { (CTES) }\end{array}$ & $\begin{array}{l}\text { Di Giacomo, A., 2005; } \\
\text { Maturo et al., } 2005\end{array}$ \\
\hline \multicolumn{5}{|l|}{ Nyctaginaceae } \\
\hline Pisonia aculeata L. & S & Arb & $* * *$ & Di Giacomo, A., 2005 \\
\hline Pisonia zapallo Griseb. & S & $A$ & $* * *$ & $\begin{array}{l}\text { Di Giacomo, A., 2005; } \\
\text { Maturo et al., } 2005\end{array}$ \\
\hline \multicolumn{5}{|l|}{ Nymphaeaceae } \\
\hline $\begin{array}{l}\text { Nymphaea cfr. prolifera } \\
\text { Wiersema }\end{array}$ & $E / L$ & $\mathrm{He}$ & $\begin{array}{l}\text { Her: 10/04/2002. Di Giácomo, A. } 563 \\
\text { (CTES) }\end{array}$ & Di Giacomo, A., 2005 \\
\hline \multicolumn{5}{|l|}{ Onagraceae } \\
\hline $\begin{array}{l}\text { Ludwigia bonariensis } \\
\text { (Micheli) H. Hara }\end{array}$ & $E / L$ & $\mathrm{He}$ & $\begin{array}{l}\text { Her: 02/02/2007. Paula Souza, J. } 8151 \\
\text { (CTES-CTES0008410) }\end{array}$ & \\
\hline $\begin{array}{l}\text { Ludwigia lagunae } \\
\text { (Morong) Hara }\end{array}$ & $\mathrm{PzH}$ & $\mathrm{He}$ & $* * *$ & $\begin{array}{l}\text { Di Giacomo, A., 2005; } \\
\text { Maturo et al., } 2005\end{array}$ \\
\hline Ludwigia leptocarpa (Nutt.) Hara & $\mathrm{PzH}$ & $\mathrm{He}$ & $* * *$ & $\begin{array}{l}\text { Di Giacomo, A., } 2005 \text {; } \\
\text { Maturo et al., } 2005\end{array}$ \\
\hline $\begin{array}{l}\text { Ludwigia neograndiflora } \\
\text { (Munz) Hara }\end{array}$ & $\mathrm{PzH}$ & $\mathrm{He}$ & $* * *$ & $\begin{array}{l}\text { Di Giacomo, A., 2005; } \\
\text { Maturo et al., } 2005\end{array}$ \\
\hline Oenothera affinis Camb. & PzM & $\mathrm{He}$ & $\begin{array}{l}\text { Her: 22/11/1998. Di Giácomo, A. } 391 \\
\text { (CTES) }\end{array}$ & Di Giacomo, A., 2005 \\
\hline Oenothera parodiana Munz & PzM & $\mathrm{He}$ & $\begin{array}{l}\text { Her: 22/11/1998. Di Giácomo, A. } 393 \\
\text { (CTES) }\end{array}$ & Di Giacomo, A., 2005 \\
\hline
\end{tabular}




\begin{tabular}{|c|c|c|c|c|}
\hline Especies & $\begin{array}{l}\text { Unidad } \\
\text { Vegetal }\end{array}$ & Hábito & coleccionista y $\mathbf{N}^{\circ}$ & Bibliografía \\
\hline \multicolumn{5}{|l|}{ Opiliaceae } \\
\hline Agonandra excelsa Griseb. & PzM & Arb & $\begin{array}{l}\text { Her: 30/09/2002. Di Giácomo, A. } 576 \\
\text { (CTES) }\end{array}$ & \\
\hline \multicolumn{5}{|l|}{ Oxalidaceae } \\
\hline Oxalis conorrhiza Jacq. & $* * * *$ & $\mathrm{He}$ & $\begin{array}{l}\text { Her: 15/08/2000. Di Giácomo, A. } 465 \\
\text { (CTES) }\end{array}$ & Di Giacomo, A., 2005 \\
\hline Oxalis hispidula Zucc. & $* * * * *$ & $\mathrm{He}$ & $\begin{array}{l}\text { Her: 15/08/2000. Di Giácomo, A. } 464 \\
\text { (CTES) }\end{array}$ & Di Giacomo, A., 2005 \\
\hline Oxalis niederleinii R. Knuth & S & $\mathrm{He}$ & $\begin{array}{l}\text { CP: 20/10/11. Contreras, S. A. et al. } 43 . \\
\text { (CTES) }\end{array}$ & \\
\hline \multicolumn{5}{|l|}{ Passifloraceae } \\
\hline Passiflora caerulea L. & $* * * *$ & En & $* * *$ & Di Giacomo, A., 2005 \\
\hline Passiflora cincinnata Mast. & S & En & $* * *$ & Di Giacomo, A., 2005 \\
\hline Passiflora elegans Mast. & $\mathrm{S}$ & En & $* * *$ & Di Giacomo, A., 2005 \\
\hline Passiflora foetida L. & PzM & En & $* * *$ & Di Giacomo, A., 2005 \\
\hline Passiflora misera Kunth & $\mathrm{PzM}$ & En & $* * *$ & Di Giacomo, A., 2005 \\
\hline Passiflora suberosa L. & S & En & $\begin{array}{l}\text { Her: 15/05/2002. Di Giácomo, A. } 568 \\
\text { (CTES) }\end{array}$ & Di Giacomo, A., 2005 \\
\hline Turnera grandiflora (Urb.) Arbo & PzM & $\mathrm{He}$ & $\begin{array}{l}\text { Her: 00/1995. González, A. M. } 1 \\
\text { (CTES) }\end{array}$ & $\begin{array}{l}\text { Di Giacomo, A., 2005; } \\
\text { Maturo et al., } 2005\end{array}$ \\
\hline \multicolumn{5}{|l|}{ Phytolaccaceae } \\
\hline Petiveria alliacea $L$. & S & $\mathrm{He}$ & $* * *$ & $\begin{array}{l}\text { Di Giacomo, A., 2005; } \\
\text { Maturo et al., } 2004\end{array}$ \\
\hline Phytolacca dioica L. & S & A & $* * *$ & $\begin{array}{l}\text { Di Giacomo, A., } 2005 \text {; } \\
\text { Maturo et al., } 2005\end{array}$ \\
\hline Rivinia humilis $L$. & S & $\mathrm{He}$ & $* * *$ & Di Giacomo, A., 2005 \\
\hline \multicolumn{5}{|l|}{ Piperaceae } \\
\hline Peperomia aceroana C. DC. & $\mathrm{S}$ & Ep & $* * *$ & $\begin{array}{l}\text { Di Giacomo, A., } 2005 \text {; } \\
\text { Maturo et al., } 2005\end{array}$ \\
\hline Peperomia blanda (Jacq.) Kunth & S & Ep & $* * *$ & Di Giacomo, A., 2005 \\
\hline Peperomia barbarana C. DC. & $* * * *$ & $\mathrm{He}$ & $\begin{array}{l}\text { Her: 25/05/2002. Di Giácomo, A. } 571 \\
\text { (CTES) }\end{array}$ & Di Giacomo, A., 2005 \\
\hline Piper amalago L. & S & Arb & $\begin{array}{l}\text { Her, CP: **/03/1918. Jörgensen, P. } 2344 \\
\text { (SI; SI); 20/12/11. Contreras, S. A. et al. } \\
\text { 73. (CTES) }\end{array}$ & $\begin{array}{l}\text { Di Giacomo, A., } 2005 \text {; } \\
\text { Maturo et al., } 2005\end{array}$ \\
\hline \multicolumn{5}{|l|}{ Plantaginaceae } \\
\hline Plantago myosuros Lam. & PzM & $\mathrm{He}$ & $* * *$ & Di Giacomo, A., 2005 \\
\hline \multicolumn{5}{|l|}{ Polygalaceae } \\
\hline Monnina tristaniana A. St.-Hil. & PzM & $\mathrm{He}$ & Her: **/03/1918. Jörgensen, P. 3011 (SI) & Di Giacomo, A., 2005 \\
\hline Polygala duarteana A. St.-Hil. & $\mathrm{PzM}$ & $\mathrm{He}$ & $* * *$ & Di Giacomo, A., 2005 \\
\hline Polygala extraaxillaris Chodat. & PzM & $\mathrm{He}$ & $* * *$ & $\begin{array}{l}\text { Di Giacomo, A., 2005; } \\
\text { Maturo et al., } 2005\end{array}$ \\
\hline
\end{tabular}




\begin{tabular}{|c|c|c|c|c|}
\hline Especies & $\begin{array}{l}\text { Unidad } \\
\text { Vegetal }\end{array}$ & Hábito & coleccionista y $\mathbf{N}^{\circ}$ & Bibliografía \\
\hline $\begin{array}{l}\text { Polygala molluginifolia } \\
\text { A. St.-Hil. \& Moq. }\end{array}$ & $E / L$ & $\mathrm{He}$ & $\begin{array}{l}\text { CP: 20/10/11. Contreras, S. A. et al. } 54 \text {. } \\
\text { (CTES) }\end{array}$ & \\
\hline \multicolumn{5}{|l|}{ Polygonaceae } \\
\hline Polygonum acuminatum Kunth & $E / L$ & $\mathrm{He}$ & $* * *$ & Di Giacomo, A., 2005 \\
\hline $\begin{array}{l}\text { Polygonum hydropiperoides } \\
\text { Michx. Var. Setaceum } \\
\text { (Baldwin ex Elliott) Gleason }\end{array}$ & $E / L$ & $\mathrm{He}$ & $* * *$ & Di Giacomo, A., 2005 \\
\hline Polygonum punctatum Elliott & $E / L$ & $\mathrm{He}$ & $* * *$ & Di Giacomo, A., 2005 \\
\hline Rumex paraguayensis D. Parodi & $\mathrm{PzH}$ & $\mathrm{He}$ & $\begin{array}{l}\text { Her: 20/10/2000. Di Giácomo, A. } 472 \\
\text { (CTES) }\end{array}$ & Di Giacomo, A., 2005 \\
\hline Ruprechtia apetala Weddell & B & A & $\begin{array}{l}\text { Her: 25/09/2002. Di Giácomo, A. } 575 \\
\text { (CTES) }\end{array}$ & Di Giacomo, A., 2005 \\
\hline Ruprechtia laxiflora Meisn. & S & $A$ & $* * *$ & Di Giacomo, A., 2005 \\
\hline Ruprechtia triflora Griseb. & B & A/Arb & $\begin{array}{l}\text { Her: 20/09/2001. Di Giácomo, A. } 521 \\
\text { (CTES) }\end{array}$ & $\begin{array}{l}\text { Di Giacomo, A., 2005; } \\
\text { Maturo et al., } 2005\end{array}$ \\
\hline \multicolumn{5}{|l|}{ Portulacaceae } \\
\hline Portulaca cryptopetala Speg. & $\mathrm{Ar}$ & $\mathrm{He}$ & $\begin{array}{l}\text { Her: 20/10/1999. Di Giácomo, A. } 429 \\
\text { (CTES) }\end{array}$ & Di Giacomo, A., 2005 \\
\hline $\begin{array}{l}\text { Portulaca aff. } \\
\text { cryptopetala Speg. }\end{array}$ & $\mathrm{Ar}$ & $\mathrm{He}$ & $\begin{array}{l}\text { Her: 03/10/1998. Di Giácomo, A. } 370 \\
\text { (CTES) }\end{array}$ & Di Giacomo, A., 2005 \\
\hline Talinum fruticosum (L.) Juss. & S & $\mathrm{He}$ & $* * *$ & Di Giacomo, A., 2005 \\
\hline \multicolumn{5}{|l|}{ Ranunculaceae } \\
\hline Clematis sp. & $\mathrm{PzH}$ & En & $\begin{array}{l}\text { CP: 06/12/12. Contreras, S. A. et al. } 123 . \\
\text { (CTES) }\end{array}$ & \\
\hline $\begin{array}{l}\text { Clematis bonariensis } \\
\text { Juss. ex DC. }\end{array}$ & S & En & $\begin{array}{l}\text { CP: 25/06/11. Contreras, S. A. et al. } 20 . \\
\text { (CTES) }\end{array}$ & \\
\hline Clematis montevidensis Spreng. & B & En & $* * *$ & Di Giacomo, A., 2005 \\
\hline $\begin{array}{l}\text { Ranunculus bonariensis } \\
\text { Poir. var. bonariensis }\end{array}$ & $\mathrm{PzH}$ & $\mathrm{He}$ & $\begin{array}{l}\text { Her: 11/10/2011. Aliscioni, S. S. } 858 \\
\text { (BAA) }\end{array}$ & Di Giacomo, A., 2005 \\
\hline $\begin{array}{l}\text { Ranunculus bonariensis Poir. } \\
\text { var. Phyteumifolius (A. St.- } \\
\text { Hil.) Hicken ex Lourteig }\end{array}$ & $\mathrm{PzH}$ & $\mathrm{He}$ & $* * *$ & Di Giacomo, A., 2005 \\
\hline \multicolumn{5}{|l|}{ Rhamnaceae } \\
\hline Zizyphus mistol Griseb. & B & A & $* * *$ & $\begin{array}{l}\text { Di Giacomo, A., 2005; } \\
\text { Maturo et al., } 2005\end{array}$ \\
\hline \multicolumn{5}{|l|}{ Rubiaceae } \\
\hline $\begin{array}{l}\text { Borreria densiflora DC. } \\
\text { var. perennis Standl. }\end{array}$ & $* * * *$ & $\mathrm{He}$ & $\begin{array}{l}\text { Her: 07/11/1998. Di Giácomo, A. } 398 \\
\text { (CTES) }\end{array}$ & Di Giacomo, A., 2005 \\
\hline $\begin{array}{l}\text { Borreria eryngioides } \\
\text { Cham. \& Schltdl. }\end{array}$ & $\mathrm{PzH}$ & $\mathrm{He}$ & $\begin{array}{l}\text { Her: 30/09/1998. Di Giácomo, A. } 389 \\
\text { (CTES) }\end{array}$ & Di Giacomo, A., 2005 \\
\hline $\begin{array}{l}\text { Galianthe centranthoides } \\
\text { (Cham. \& Schltdl.) E. L. Cabral }\end{array}$ & PzM & SubArb & $* * *$ & Di Giacomo, A., 2005 \\
\hline $\begin{array}{l}\text { Guettarda uruguensis } \\
\text { Cham. \& Schltdl. }\end{array}$ & $\mathrm{S}$ & A/Arb & $* * *$ & Di Giacomo, A., 2005 \\
\hline $\begin{array}{l}\text { Mitracarpus megapotamicus } \\
\text { (Spreng.) Standl. }\end{array}$ & $\mathrm{Ar}$ & $\mathrm{He}$ & $\begin{array}{l}\text { Her: 15/05/1999. Di Giácomo, A. } 418 \\
\text { (CTES) }\end{array}$ & Di Giacomo, A., 2005 \\
\hline Randia armata (Sw.) DC. & $S$ & A/Arb & $\begin{array}{l}\text { CP: } 18 / 06 / 11 \text {. Contreras, S. A. et al. } 31 \text {. } \\
\text { (CTES) }\end{array}$ & Di Giacomo, A., 2005 \\
\hline
\end{tabular}




\begin{tabular}{|c|c|c|c|c|}
\hline Especies & $\begin{array}{l}\text { Unidad } \\
\text { Vegetal }\end{array}$ & Hábito & coleccionista y $\mathbf{N}^{\circ}$ & Bibliografía \\
\hline Richardia brasiliensis Gomes & $* * * *$ & $\mathrm{He}$ & $\begin{array}{l}\text { Her: 15/10/1999. Di Giácomo, A. } 445 \\
\text { (CTES) }\end{array}$ & Di Giacomo, A., 2005 \\
\hline \multicolumn{5}{|l|}{ Rutaceae } \\
\hline $\begin{array}{l}\text { Fagara hyemalis (S. } \\
\text { St. Hil.) Engl. }\end{array}$ & $\mathrm{S}$ & A/Arb & $\begin{array}{l}\text { Her: 22/09/2000. Di Giácomo, A. } 470 \\
\text { (CTES) }\end{array}$ & Di Giacomo, A., 2005 \\
\hline Fagara naranjillo (Griseb.) Engl. & $\mathrm{S}$ & A & $* * *$ & Di Giacomo, A., 2005 \\
\hline Fagara pterota L. & B & Arb & $\begin{array}{l}\text { Her: 27/10/2002. Di Giácomo, A. } 583 \\
\text { (CTES) }\end{array}$ & Di Giacomo, A., 2005 \\
\hline Fagara rhoifolia (Lam.) Engl. & $\mathrm{S}$ & A & $* * *$ & Di Giacomo, A., 2005 \\
\hline Zanthoxylum fagara (L.) Sarg. & S & A & $\begin{array}{l}\text { CP: 20/12/11. Contreras, S. A. et al. } 90 . \\
\text { (CTES) }\end{array}$ & \\
\hline \multicolumn{5}{|l|}{ Salicaceae } \\
\hline Prockia crucis P. Browne ex L. & S & Arb & $* * *$ & Di Giacomo, A., 2005 \\
\hline Xylosma venosa N. E. Br. & $\mathrm{PzH}$ & A/Arb & $* * *$ & Di Giacomo, A., 2005 \\
\hline \multicolumn{5}{|l|}{ Santalaceae } \\
\hline Acanthosyris sp. & $\mathrm{S}$ & A & $\begin{array}{l}\text { CP: } 20 / 12 / 11 \text {. Contreras, S. A. et al. } 86 . \\
\text { (CTES) }\end{array}$ & \\
\hline Acanthosyris falcata Griseb. & $\mathrm{S}$ & A/Arb & $\begin{array}{l}\text { Her: 10/12/2001. Di Giácomo, A. } 547 \\
\text { (CTES) }\end{array}$ & Di Giacomo, A., 2005 \\
\hline \multicolumn{5}{|l|}{ Sapindaceae } \\
\hline $\begin{array}{l}\text { Allophylus edulis (A. St.- } \\
\text { Hil., A. Juss. \& Cambess.) } \\
\text { Hieron. ex Niederl. }\end{array}$ & $\mathrm{S}$ & A & $\begin{array}{l}\text { Her, CP: 10/10/2001. Di Giácomo, A. } \\
530 \text { (CTES); 18/06/11. Contreras, S. A. } \\
\text { et al. 30. (CTES) }\end{array}$ & $\begin{array}{l}\text { Di Giacomo, A., 2005; } \\
\text { Maturo et al., } 2005\end{array}$ \\
\hline $\begin{array}{l}\text { Cardiospermum } \\
\text { glandiflorum Sw. }\end{array}$ & $\mathrm{S}$ & En & $* * *$ & Di Giacomo, A., 2005 \\
\hline $\begin{array}{l}\text { Cardiospermum halicacabum L. } \\
\text { var. microcarpum (Kunth) Blume }\end{array}$ & $\mathrm{S}$ & En & $\begin{array}{l}\text { Her: 15/11/1998. Di Giácomo, A. } 381 \\
\text { (CTES) }\end{array}$ & Di Giacomo, A., 2005 \\
\hline Diplokeleba floribunda N.E. Br. & $\mathrm{S}$ & A & $\begin{array}{l}\text { Her: 20/12/2001. Di Giácomo, A. } 543 \\
\text { (CTES) }\end{array}$ & $\begin{array}{l}\text { Di Giacomo, A., } 2005 \text {; } \\
\text { Maturo et al., } 2005\end{array}$ \\
\hline Paullinia elegans Cambess. & S & En & $\begin{array}{l}\text { CP: } 20 / 12 / 11 \text {. Contreras, S. A. et al. } 63 . \\
\text { (CTES) }\end{array}$ & \\
\hline Paullinia pinnata L. & $\mathrm{S}$ & En & *** & Di Giacomo, A., 2005 \\
\hline Serjania fuscifolia Radlk. & S & En & $\begin{array}{l}\text { Her: 27/07/2007. Meza Torres, E. I. } 668 . \\
\text { (CTES) }\end{array}$ & \\
\hline Serjania perulacea Radlk. & S & En & $* * *$ & Di Giacomo, A., 2005 \\
\hline \multicolumn{5}{|l|}{ Sapotaceae } \\
\hline $\begin{array}{l}\text { Chrysophyllum gonocarpum } \\
\text { (Mart. et Eichler) Engl. }\end{array}$ & $\mathrm{S}$ & A & $\begin{array}{l}\text { Her: 10/12/2001. Di Giácomo, A. } 550 \\
\text { (CTES) }\end{array}$ & $\begin{array}{l}\text { Di Giacomo, A., } 2005 \text {; } \\
\text { Maturo et al., } 2005\end{array}$ \\
\hline Pouteria glomerata (Miq.) Radlk. & S & A & $\begin{array}{l}\text { Her: 20/11/2004. Maturo, H. } 149 \text { (SI- } \\
\text { 073824; SI-073827) }\end{array}$ & \\
\hline $\begin{array}{l}\text { Sideroxylon obtusifolium } \\
\text { (Roem. \& Schult.) T.D. Penn. }\end{array}$ & $\mathrm{S}$ & A & $\begin{array}{l}\text { Her: 20/09/2001. Di Giácomo, A. } 522 \\
\text { (CTES) }\end{array}$ & Di Giacomo, A., 2005 \\
\hline \multicolumn{5}{|l|}{ Scrophulariaceae } \\
\hline Angelonia gardneri Hook. & $\mathrm{PzH}$ & $\mathrm{He}$ & $* * *$ & Di Giacomo, A., 2005 \\
\hline Angelonia integerrima Spreng. & $\mathrm{PzM}$ & $\mathrm{He}$ & $* * *$ & Di Giacomo, A., 2005 \\
\hline Buchnera ternifolia Kunth & PzM & $\mathrm{He}$ & $* * *$ & Di Giacomo, A., 2005 \\
\hline
\end{tabular}




\begin{tabular}{|c|c|c|c|c|}
\hline Especies & $\begin{array}{l}\text { Unidad } \\
\text { Vegetal }\end{array}$ & Hábito & coleccionista y $\mathbf{N}^{\circ}$ & Bibliografía \\
\hline $\begin{array}{l}\text { Buddleja brasiliensis } \\
\text { Jacq. Ex Spreng. }\end{array}$ & S & Arb & $* * *$ & Di Giacomo, A., 2005 \\
\hline Buddleja tubiflora Benth & PzM & $\mathrm{He}$ & $* * *$ & $\begin{array}{l}\text { Di Giacomo, A., 2005; } \\
\text { Maturo et al., } 2006\end{array}$ \\
\hline $\begin{array}{l}\text { Scoparia montevidensis } \\
\text { (Spreng.) R. E. Fr. }\end{array}$ & $* * * *$ & $\mathrm{He}$ & *** & Di Giacomo, A., 2005 \\
\hline Stemodia palustris A. St.-Hil. & PzM & $\mathrm{He}$ & *** & Di Giacomo, A., 2005 \\
\hline \multicolumn{5}{|l|}{ Simaroubaceae } \\
\hline Castela coccinea Griseb. & $\mathrm{Ar}$ & Arb & $* * *$ & $\begin{array}{l}\text { Di Giacomo, A., 2005; } \\
\text { Maturo et al., } 2005\end{array}$ \\
\hline \multicolumn{5}{|l|}{ Solanaceae } \\
\hline $\begin{array}{l}\text { Bouchetia anomala } \\
\text { (Miers) Britton \& Rusby }\end{array}$ & PzM & $\mathrm{He}$ & $* * *$ & Di Giacomo, A., 2005 \\
\hline Brunfelsia australis Benth. & S & Arb & $\begin{array}{l}\text { Her: 10/10/2001. Di Giácomo, A. } 531 \\
\text { (CTES) }\end{array}$ & $\begin{array}{l}\text { Di Giacomo, A., } 2005 ; \\
\text { Maturo et al., } 2005\end{array}$ \\
\hline Capsicum cfr. chacoense Hunz. & $B, S$ & Arb & $\begin{array}{l}\text { Her, CP: 05/04/2003. Di Giácomo, A. } \\
607 \text { (CTES); 20/12/11. Contreras, S. A. } \\
\text { et al. 81. (CTES) }\end{array}$ & Di Giacomo, A., 2005 \\
\hline Cestrum sp. & S & Arb & $\begin{array}{l}\text { CP: 20/12/11. Contreras, S. A. et al. } 69 . \\
\text { (CTES) }\end{array}$ & \\
\hline Cestrum corymbosum Schlecht. & S & Arb & $\begin{array}{l}\text { CP: } 20 / 12 / 11 \text {. Contreras, S. A. et al. } 71 . \\
\text { (CTES) }\end{array}$ & \\
\hline Cestrum parquii L Hér. & S & Arb & $* * *$ & Di Giacomo, A., 2005 \\
\hline Cestrum strigillatum Ruiz \& Pav. & S & Arb & *** & $\begin{array}{l}\text { Di Giacomo, A., 2005; } \\
\text { Maturo et al., } 2005\end{array}$ \\
\hline Jaborosa integrifolia Lam. & $* * * *$ & $\mathrm{He}$ & $\begin{array}{l}\text { Her: 15/09/1998. Di Giácomo, A. } 403 \\
\text { (CTES) }\end{array}$ & Di Giacomo, A., 2005 \\
\hline Lycium americanum Jacq. & B & Arb & $* * *$ & Di Giacomo, A., 2005 \\
\hline Lycium morongii Britton & $\mathrm{Ar}$ & Arb & *** & $\begin{array}{l}\text { Di Giacomo, A., 2005; } \\
\text { Maturo et al., } 2005\end{array}$ \\
\hline Nicotiana longiflora Cav. & $* * \star *$ & $\mathrm{He}$ & $* * *$ & Di Giacomo, A., 2005 \\
\hline Petunia cfr. pygmaea R. E. Fr. & $\mathrm{Ar}$ & $\mathrm{He}$ & $* * *$ & Di Giacomo, A., 2005 \\
\hline Physalis angulata L. & $* * * *$ & $\mathrm{He}$ & $\begin{array}{l}\text { Her: 14/01/1980. Guaglianone, E. R. } 715 \\
\text { (SI-029662; CORD-CORD00028440) }\end{array}$ & \\
\hline Physalis pubescens L. & PzM & $\mathrm{He}$ & $\begin{array}{l}\text { Her: 30/11/1998. Di Giácomo, A. } 372 \\
\text { (CTES) }\end{array}$ & Di Giacomo, A., 2005 \\
\hline Physalis viscosa L. & S & $\mathrm{He}$ & $\begin{array}{l}\text { Her: 10/03/1979. Piccinini, B. } 3436 \\
\text { (CORD-CORD00028977; BAB) }\end{array}$ & $\begin{array}{l}\text { Di Giacomo, A., 2005; } \\
\text { Maturo et al., } 2005\end{array}$ \\
\hline $\begin{array}{l}\text { Salpichroa origanifolia } \\
\text { (Lam.) Baill. }\end{array}$ & S & $\begin{array}{c}\mathrm{He} / \\
\text { SubArb }\end{array}$ & $\begin{array}{l}\text { Her: 00/2002. Di Giácomo, A. } 570 \\
\text { (CTES) }\end{array}$ & \\
\hline Solanum angustifidum Bitter & S & Arb & $* * *$ & Di Giacomo, A., 2005 \\
\hline $\begin{array}{l}\text { Solanum atropurpureum } \\
\text { Schrank }\end{array}$ & S & $\begin{array}{c}\mathrm{He} / \\
\text { SubArb }\end{array}$ & $\begin{array}{l}\text { Her: 27/01/1970. Hunziker, A. T. } 20241 \\
\text { (CORD-CORD00023536) }\end{array}$ & Di Giacomo, A., 2005 \\
\hline Solanum chacoense Bitter & $S$ & $\mathrm{He}$ & $* * *$ & Di Giacomo, A., 2005 \\
\hline
\end{tabular}




\begin{tabular}{|c|c|c|c|c|}
\hline Especies & $\begin{array}{l}\text { Unidad } \\
\text { Vegetal }\end{array}$ & Hábito & coleccionista y $\mathbf{N}^{\circ}$ & Bibliografía \\
\hline $\begin{array}{l}\text { Solanum chroniotrichum } \\
\text { (Bitter) C. V. Morton }\end{array}$ & S & Arb & $* * *$ & Di Giacomo, A., 2005 \\
\hline Solanum claviceps Griseb. & $* * * *$ & Arb & $* * *$ & Di Giacomo, A., 2005 \\
\hline Solanum conditum C. V. Morton & $* * * *$ & $\mathrm{He}$ & $\begin{array}{l}\text { Her: 20/12/1998. Di Giácomo, A. } 378 \\
\text { (CTES) }\end{array}$ & Di Giacomo, A., 2005 \\
\hline Solanum diflorum Vell. & B & Arb & $* * *$ & Di Giacomo, A., 2005 \\
\hline $\begin{array}{l}\text { Solanum granulosum- } \\
\text { leprosum Dunal }\end{array}$ & $S$ & Arb & $* * *$ & Di Giacomo, A., 2005 \\
\hline Solanum glaucophyllum Desf. & $\mathrm{PzH}$ & Arb & $* * *$ & Di Giacomo, A., 2005 \\
\hline $\begin{array}{l}\text { Solanum megalocarpon } \\
\text { C. V. Morton }\end{array}$ & B & Arb & $* * *$ & Di Giacomo, A., 2005 \\
\hline Solanum nigrum L. & $\mathrm{PzH}$ & $\mathrm{He}$ & $\begin{array}{l}\text { CP: 06/12/12. Contreras, S. A. et al. } 94 \\
\text { (CTES) }\end{array}$ & \\
\hline Solanum pilcomayense Morong & $S$ & $\mathrm{He}$ & $\begin{array}{l}\text { CP: 25/06/11. Contreras, S. A. et al. } \\
\text { 27. (CTES) }\end{array}$ & Di Giacomo, A., 2005 \\
\hline Solanum pseudocapsicum L. & S & Arb & $\begin{array}{l}\text { CP: 08/09. Contreras, S. A. et al. } 6 . \\
\text { (CTES) }\end{array}$ & \\
\hline Solanum robustum $\mathrm{H}$. Wendl. & S & Arb & $* * *$ & Di Giacomo, A., 2005 \\
\hline Solanum sisymbriifolium Lam. & PL & $\mathrm{He}$ & $\begin{array}{l}\text { Her, CP: 02/02/2007. Paula-Souza, } \\
\text { J. 8156(SI-075467; ESA); 06/12/12. } \\
\text { Contreras, S. A. et al. 112. (CTES) }\end{array}$ & Di Giacomo, A., 2005 \\
\hline Solanum symetricum Rusby & $S$ & Arb & $\begin{array}{l}\text { Her: 20/11/1999. Di Giácomo, A. } 451 \\
\text { (CTES) }\end{array}$ & Di Giacomo, A., 2005 \\
\hline $\begin{array}{l}\text { Vassobia breviflora } \\
\text { (Send.) A.T. Hunz. }\end{array}$ & S & Arb & $\begin{array}{l}\text { Her: 20/03/2003. Di Giácomo, A. } 605 \\
\text { (CTES) }\end{array}$ & Di Giacomo, A., 2005 \\
\hline \multicolumn{5}{|l|}{ Ulmaceae } \\
\hline $\begin{array}{l}\text { Phyllostylon rhamnoides } \\
\text { (J. Poiss.) Taub }\end{array}$ & S & A & $* * *$ & $\begin{array}{l}\text { Di Giacomo, A., 2005; } \\
\text { Maturo et al., } 2005\end{array}$ \\
\hline \multicolumn{5}{|l|}{ Urticaceae } \\
\hline Parietaria debilis G. Forst. & $* * * *$ & $\mathrm{He}$ & $* * *$ & Di Giacomo, A., 2005 \\
\hline Pilea microphylla (L.) Liebm. & $* * * *$ & $\mathrm{He}$ & $\begin{array}{l}\text { Her: 25/05/2002. Di Giácomo, A. } 572 \\
\text { (CTES) }\end{array}$ & Di Giacomo, A., 2005 \\
\hline Urera aurantiaca Wedd. & S & Arb & $\begin{array}{l}\text { Her: 27/04/1999. Di Giácomo, A. } 373 \\
\text { (CTES) }\end{array}$ & $\begin{array}{l}\text { Di Giacomo, A., } 2005 ; \\
\text { Maturo et al., } 2005\end{array}$ \\
\hline Urera baccifera(L.) Gaudich. & $S$ & A/Arb & $* * *$ & $\begin{array}{l}\text { Di Giacomo, A., 2005; } \\
\text { Maturo et al., } 2005\end{array}$ \\
\hline Urera spatulata Sm. & $* * * *$ & $\mathrm{He}$ & $* * *$ & Di Giacomo, A., 2005 \\
\hline \multicolumn{5}{|l|}{ Verbenaceae } \\
\hline $\begin{array}{l}\text { Aloysia gratissima (Gillies } \\
\text { \& Hook.) Tronc. }\end{array}$ & S & Arb & $* * *$ & Di Giacomo, A., 2005 \\
\hline $\begin{array}{l}\text { Aloysia virgata (Ruiz \& } \\
\text { Pav.) Juss. Var. platyphylla } \\
\text { (Briq.) Moldenke }\end{array}$ & $\mathrm{S}$ & Arb & $* * *$ & Di Giacomo, A., 2005 \\
\hline $\begin{array}{l}\text { Glandularia af. Incisa } \\
\text { (Hook.) Tronc. }\end{array}$ & $* * * *$ & $\mathrm{He}$ & $* * *$ & Di Giacomo, A., 2005 \\
\hline Glandularia peruviana (L.) Small & $\mathrm{S}, \mathrm{PL}$ & $\mathrm{He}$ & $\begin{array}{l}\text { CP: 06/12/12. Contreras, S. A. et al. } 110 . \\
\text { (CTES) }\end{array}$ & \\
\hline
\end{tabular}


Bol. Soc. Argent. Bot. 50 (4) 2015

\begin{tabular}{|c|c|c|c|c|}
\hline Especies & $\begin{array}{l}\text { Unidad } \\
\text { Vegetal }\end{array}$ & Hábito & coleccionista y $\mathbf{N}^{\circ}$ & Bibliografía \\
\hline $\begin{array}{l}\text { Glandularia pulchella } \\
\text { (Sweet) Tronc. }\end{array}$ & $* * * *$ & $\mathrm{He}$ & $* * *$ & Di Giacomo, A., 2005 \\
\hline $\begin{array}{l}\text { Glandularia sessilis } \\
\text { (Cham.) Tronc. }\end{array}$ & $E / L$ & $\mathrm{He}$ & $\begin{array}{l}\text { Her: 22/09/1967. Krapovickas, A. } 13184 . \\
\text { (SI) }\end{array}$ & Di Giacomo, A., 2005 \\
\hline Glandularia subicana Tronc. & PL & $\mathrm{He}$ & $\begin{array}{l}\text { CP: 06/12/12. Contreras, S. A. et al. } 111 . \\
\text { (CTES) }\end{array}$ & \\
\hline Lantana sp. & S & Arb & $\begin{array}{l}\text { CP: } 20 / 12 / 11 \text {. Contreras, S. A. et al. } 78 . \\
\text { (CTES) }\end{array}$ & \\
\hline $\begin{array}{l}\text { Lantana megapotamica } \\
\text { (Spreng.) Tronc. }\end{array}$ & $\mathrm{S}$ & Arb & $\begin{array}{l}\text { CP: 20/10/11. Contreras, S. A. et al. } 44 \text {. } \\
\text { (CTES) }\end{array}$ & Di Giacomo, A., 2005 \\
\hline Lippia asperrima Cham. & $\begin{array}{l}\mathrm{PzH} \\
\mathrm{PzM}\end{array}$ & $\mathrm{He}$ & $\begin{array}{l}\text { Her, CP: 02/10/1998. Di Giácomo, A. } \\
396 \text { (CTES); 06/12/12. Contreras, S. A. } \\
\text { et al. 124. (CTES) }\end{array}$ & Di Giacomo, A., 2005 \\
\hline Verbena bonariensis L. & PzM & $\mathrm{He}$ & $* * *$ & Di Giacomo, A., 2005 \\
\hline verbena gracilescens Cham & $\mathrm{PzH}$ & $\mathrm{He}$ & $\begin{array}{l}\text { CP: 06/12/12. Contreras, S. A. et al. } \\
\text { 122. (CTES) }\end{array}$ & \\
\hline Verbena rigida Spreng. & $\mathrm{PzH}$ & $\mathrm{He}$ & $\begin{array}{l}\text { Her: 20/11/1999. Di Giácomo, A. } 448 \\
\text { (CTES) }\end{array}$ & Di Giacomo, A., 2005 \\
\hline \multicolumn{5}{|l|}{ Violaceae } \\
\hline $\begin{array}{l}\text { Hybanthus parviflorus } \\
\text { (Mutis ex L. f.) Baill. }\end{array}$ & B & SubArb & $\begin{array}{l}\text { Her: 30/09/2001. Di Giácomo, A. } 527 \\
\text { (CTES) }\end{array}$ & Di Giacomo, A., 2005 \\
\hline \multicolumn{5}{|l|}{ Viscaceae } \\
\hline Phoradendron argentinum Urb. & B & Par & $\begin{array}{l}\text { Her: 18/02/2000. Di Giácomo, A. } 453 \\
\text { (CTES) }\end{array}$ & \\
\hline Phoradendron balansae Trel. & S & Par & $\begin{array}{l}\text { Her: 01/12/2000. Di Giácomo, A. } 474 \\
\text { (CTES) }\end{array}$ & Di Giacomo, A., 2005 \\
\hline Phoradendron pruinosum Urb. & B & Par & $\begin{array}{l}\text { Her: 01/12/2000. Di Giácomo, A. } 475 \\
\text { (CTES) }\end{array}$ & Di Giacomo, A., 2005 \\
\hline \multicolumn{5}{|l|}{ Vitaceae } \\
\hline Cissus palmata Poir. & $S$ & En & $* * *$ & Di Giacomo, A., 2005 \\
\hline $\begin{array}{l}\text { Cissus verticillata (L.) } \\
\text { Nicholson \& Jarvis }\end{array}$ & $\mathrm{S}$ & En & $\begin{array}{l}\text { Her: 15/02/2003. Di Giácomo, A. } 588 \\
\text { (CTES) }\end{array}$ & Di Giacomo, A., 2005 \\
\hline
\end{tabular}

